\title{
Geomechanical Characterization of Newberry Tuff
}

2

\section{5}

\author{
Jihoon Wang, Woodong Jung, Yawei Li, Ahmad Ghassemi*
}

Mewbourne School of Petroleum and Geological Engineering, The University of Oklahoma, Norman, Oklahoma, USA

\begin{abstract}
In this paper we present the results of a petrophysical and geomechanical characterization program focusing on the rock mechanical properties of welded tuffs from Newberry volcano, Oregon. The rock samples are from drill cores obtained from three wells in the vicinity of the Newberry EGS namely, GEO $\mathrm{N}-2$, GEO N-1, and OXY 72-3. As part of the rock characterization process, petrographic thin sections were prepared and used to describe rock texture and mineralogy. High resolution X-ray CT scanner was also used to provide 3D images of the rock pore structure. Rock porosity and permeability were measured using the gas expansion method and a pulse permeameter, respectively. Triaxial compression tests were performed on the specimens extracted from whole core to determine their Young's modulus, Poisson's ratio, and failure envelopes. In particular, multistage triaxial compression tests were carried out to determine deformation and failure properties, and to establish relationships between petrophysical and mechanical/failure properties. In addition, multistage triaxial shear tests were performed to determine the mechanical properties and shear strengths of the fractures developed in triaxial compression tests. Joint roughness coefficient (JRC) and Joint Wall Compressive Strength (JCS) were obtained through analysis of the shear tests. Joint normal stiffness and shear stiffness were also estimated and it was observed that a higher confining pressure results in higher joint shear stiffness. These studies provide insight into the effects of mineralogy and texture and structure on the strength and deformation properties of the tuff samples tested. Mineral composition and the presence of phenocrysts, argillitic materials, and natural fracture were noted to impact rock mechanical properties. Natural fracture and vein mineralogy also influence fracture development in the samples as well as frictional and shear strength properties of the joints tested. Rock samples with higher clay mineral content were found to be relatively more ductile with minimal increase, or even decrease, in permeability under failure in compression tests. The data set obtained in this study is very useful for stimulation design and interpretation of observed micro-seismicity in relation to permeability enhancement.
\end{abstract}

Keywords: Reservoir geomechanics, natural fractures, Newberry EGS, rock strength, seismicity, stimulation, welded tuff 
$41 \quad$ Nomenclature

$i \quad$ the average asperities (teeth) inclination angle from the mean joint plane (effective roughness)

JRC joint roughness coefficient

JCS joint wall compressive strength

$K_{n} \quad$ joint normal stiffness

$K_{s} \quad$ joint shear stiffness

$\beta \quad$ the inclination angle of failure plane from $\sigma_{3}$

$\tau \quad$ shear stress

$\sigma_{n} \quad$ normal stress

$\sigma_{3} \quad$ minimum principal stress

$\sigma_{d} \quad$ deviatoric stress, $\left(\sigma_{1}-\sigma_{3}\right)$, during a triaxial test

$\theta \quad$ the joint inclination angle from $\sigma_{1}$ direction

$\phi \quad$ the internal friction angle of intact rock

$\phi_{b} \quad$ the basic friction angle of a joint surface

$\phi_{r} \quad$ the residual friction angle of a joint (when normal stress is larger than a critical value)

UCS uniaxial/unconfined compressive strength 
An Enhanced Geothermal System is created by stimulation, a process which involves fracture initiation and/or activation of discontinuities such as joints by pore pressure and stress perturbations. Intact rock and fracture mechanical properties affect failure and permeability change in response to water injection and thus, are of critical relevance to EGS. Also, redistribution of local and global reservoir stress states is a key mechanism driving seismicity which accompanies stimulation. Deformation around natural and induced fractures is produced by several distinct processes such as tensile fracturing, shear deformation and slip, or a combination of both, all of which are influenced by pore pressure increases and rock cooling. Depending on rock mechanical properties, hydraulically stimulated fractures undergo slip and self-prop due to fracture surface roughness so that the natural fracture deformation and failure properties are important to permeability enhancement. Stimulation design and identification of causal mechanisms of induced seismicity can significantly benefit from geomechanics reservoir characterization, and rock and fracture mechanical properties are an integral part of such an effort. The objective of this study was to develop such data for the Newberry EGS project.

In this paper, we describe the petrophysical properties of the Newberry Tuff samples and then present the results of a rock mechanics study based on single and multistage triaxial tests on intact and fractured rock. The specimens were cored in two directions, vertically and horizontally, to analyze the effect of anisotropy. Moreover, the permeability was measured before and after each triaxial test to study the effect of rock failure on permeability enhancement for each rock type encountered in drill core.

The multistage triaxial test is a rather novel approach to overcome limited sample availability. In conventional triaxial tests, multiple samples are used under different confining pressures to determine the mechanical properties and the failure envelope. For each confining pressure, the Young's modulus and Poisson's ratio are calculated from the linear portion of the stress-strain curves or at a particular deviatoric stress level. However, performing the tests on different specimens poses significant uncertainty as intact rock properties vary among the samples, particularly when there is significant heterogeneity in the rock formation as is the case for Newberry EGS. In the multistage triaxial test, a single specimen is used under different confining pressures to determine the elastic properties of rock as well as its failure envelope, which can eliminate the uncertainty from heterogeneity. Although the approach of testing a single specimen can resolve the heterogeneity effect, several issues arise regarding the test procedures and data analysis which were resolved in this work. To our knowledge, the multi-stage test has not been applied to tuffs as described in this work. In what follows we present data and analyses on rock samples from 3 wells namely, GEO N-1, GEO N-2, and OXY 72-3 all located on the western flank of Newberry Volcano. As expected, mineral composition and rock texture and fabric have major impact on rock mechanical response. Phenocrysts and tiny vesicles, and mineralized fractures result in heterogeneous strength and deformation properties. The data show the Newberry rock system to consist of a diverse set of rock sequences with distinct petrophysical and geomechanical properties. In each well, rocks of highly brittle and ductile nature are encountered. The geomechanical characterization program is ongoing and only a part is presented in this paper.

\section{2. Geological Setting}

The Newberry volcano has been studied by many investigators. Williams (1935) mapped the flanks of the volcano in a reconnaissance mode and studied the caldera in more detail. According to a recent study by 
volcanic vents that extend northwestward across much of the south east quarter of Oregon. The flanks of Newberry volcano are mantled by more than 400 cinder cones and fissure vents, several rhyolitic domes, as well as basaltic to basaltic andesite flows and pyroclastic deposits, all of Quaternary age (Macleod and Sherrod, 1988).

Based on geophysical studies (summarized in Fitterman et al. 1988)), the interior of Newberry volcano is composed of three distinct zones (Figure 1). The upper zone (Newberry/Deschutes) consists of predominantly younger unaltered silicic to mafic lava flows and tuffs along with their feeder pipes and dikes. The intermediate zone (John Day) contains older, hydrothermally altered silicic to mafic lava flows and tuffs, abundant dikes, and some small intrusive pod like bodies. The lowermost zone (Intruded John Day) may contain numerous sills, dikes, and small pods that are mostly solidified. Newberry shield volcano is at the intersection of three distinct structural zones in the Cascade Range: the Cascades Graben, the Brother's Fault zone, and the Basin and Range (AltaRock Inc. 2015). According to Cladouhos et al. (2011) recently acquired topographic data in the study area reveals N-S trending normal fault scarps in modern alluvial sediments with only minor variation in strike west of the NWG 55-29 and N-S trending alignments of fissures/vents to the east; both sets of structures indicate E-W extension in the immediate area. These structures reflect the geologically recent direction of the least compressive principal stress near the Newberry EGS site.

\section{Rock Types Studied}

The rock samples used in this study are from drill core obtained from three wells namely, GEO N-1, GEO N-2, and OXY 72-3 (Figures 2-4) all located on the western flank of Newberry volcano. The $6.35 \mathrm{~cm}$ (2.5 inches) by $30.48 \mathrm{~cm}$ (1 foot) cores were obtained from five different depth intervals in wells GEO N-1, GEO N-2, and OXY 72-3. GEO N-1 samples were from 4013-4014 feet and 4348-4349 feet, GEO N-2 samples were from 4219.5-4221 feet, and 4281-4282.5 ft, and OXY 72-3 (labeled as Santa Fe NC 72-03 in Figure 1) samples from 4394.5-4396 feet. The location of these wells with respect to the Newberry volcano is shown in Figure 1. The GEO N-1 core hole is located about $4.9 \mathrm{~km}$ south of the southern rim of Newberry caldera near the vent of a Holocene basalt flow(Swanberg et al., 1988). All whole cores were obtained from the University of Utah Core Library. Horizontal and vertical plugs were extracted from each core some of which are shown in Figure 5.

\subsection{GEO $\mathrm{N}-1$ cores}

The GEO N-1 core is from the southern rim of Newberry caldera near the vent of a Holocene basalt flow (Macleod and Sherrod, 1988). Based on geological studies (Fitterman et al., 1988), cores N-1-4013-4014 and N-1-4348-4349 may predominantly consist of younger unaltered silicic to mafic lava flows and tuffs along with their feeder dikes and pipes. Bargar and Keith (1999) reported that the GEO N-1 core consists mostly of lava flows, associated flow breccia, and ash-flow material occurring between lava flows. To conduct petrophysical and mechanical tests, plugs were extracted from GEO-N-1cores and thin sections prepared.

Petrographic images from core plugs N-1-4013-1H, and N-1-4013-1V are shown in Figure 6. As can be seen the rock contains recognizable mineral crystals (phenocrysts) embedded in glass matrix. The rock has very fine crystals and aphanitic texture. The samples with visible crystals have phaneritic or pegmatitic texture. The images of $\mathrm{N}-1-4013-1 \mathrm{H}$ and $1 \mathrm{~V}$ show two distinctive crystal sizes (phenocrysts) within an aphanitic matrix. There is a large contrast between the strength and other mechanical properties of the phenocrysts and the fine-grained matrix. Similar to Lutz et al. (2010), a point count technique was 
used in the petrographic images of core plugs $\mathrm{N}-1-4013-1 \mathrm{H}$ and $1 \mathrm{~V}$ to quantify the images. Plugs from GEO N-1-4348 contains smectite/clay minerals suggesting it might have undergone significant hydrothermal alterations (see thin section in Figure 6). The matrix consists of both glassy and argillitic materials. Both petrographic images contain a few recognizable mineral crystals (phenocrysts) embedded in an argillitic matrix. The images show a very heterogeneous rock containing different grains and various minerals of plagioclase, quartz, calcite, smectite-illite, pyrite, and iron-oxide. The large grains contain micro-cracks within them and at their boundaries. These micro-cracks do not appear to be connected.

Abundant tiny vesicles like meringue are observed on the surface of the core and in CT images (Figure 7 and 8). The plug was scanned and 1000 slices perpendicular to its axis were imaged. Three of these slices are shown in Figure 7. Note a crack appears in the central region of the sample (2V) but it mostly terminates after slice 457. The images in Figure 8 show the presence of large and micro-pores in different zones of the core. These are poorly connected, so that the rock is not very permeable. Overall, the pore space is dominated by tiny vesicles and occasional cracks in the matrix and within some large embedded grains.

\subsection{GEO N-2 cores}

The GEO N-2 well is located about $2.8 \mathrm{~km}$ outside the west flank of the Newberry caldera and approximately $1 \mathrm{~km}$ from the injection well NWG 55-29. Cores from 4219.5-4221 feet and 4281-4282.5 feet depth were recovered from GEO N-2 whole core. Cladouhos et al. (2011) suggest that three significant geologic processes affected GEO N-2 rocks; hydrofracturing, hydrothermal alteration, and fluid inclusion. They reported GEO N-2 cores to consist of basaltic to rhyolitic silicic lava flows with intervening flow breccia, lithic tuff, and volcanic sandstone. Basaltic dike intruded a vesicular mafic lava flow at 1,186 m depth. Flow banding, fractures, spherical or elliptical vesicles are also reported in the core samples. To perform petrophysical characterization and to conduct mechanical tests, $2.54 \mathrm{~cm}$ diameter, $5.08 \mathrm{~cm}$ long plugs were extracted from the whole core.

Based on the petrographic images (Figure 6) from thin sections of plugs GEO N-2-4219.5-2H and GEO $\mathrm{N}-2-4281-1 \mathrm{~V}$ and N-2-4281-1H, the rock has an aphanitic texture. The matrix consists mostly of very fine-grained silicic particles. The rock could be a rhyolite or welded tuff. It is medium to dark gray in color with pre-dominantly rhyolite composition with glassy light gray matrix. This tuff contains mostly micro-porphyritic plagioclase, feldspar, and quartz and appears hard and brittle. Microprobe or X-ray diffraction (XRD) analyses that were conducted (not reported in this paper) showed the presence of a few argillitic materials containing small montmorillonite (or authigenic smectite) or kaolinite around some of the plagioclase feldspars formed by devitrification of the original volcanic ash. There are significant fractures completely filled by white hydrothermal alteration minerals. Fluid inclusions appear to have formed along these healed fractures. XRD analysis showed the filling mineral in the fractures and vesicles to be calcite, dolomite, and/or quartz. One distinctive vertical fracture was observed in GEO N-2-4219.5$2 \mathrm{H}$ core plug. The fracture is completely fllled with secondary minerals identified as calcite, dolomite, and/or quartz (based on XRD analysis). These minerals have healed the fracture such that the core plugs from GEO N-2-4219.5-2H were completely intact before rock mechanical tests.

Core GEO N-2-4281-4282.5 (Figure 6) contains breccia fragments, a few white fractures, and spherical to elliptical vesicles completely filled by hydrothermal alteration minerals. Groundmass is dominated by 
fine-grained aphanitic silicic or porphyritic texture with breccia fragments that are slightly hard and brittle. Many tiny vesicles are observed on the surface of the core which are produced from the vapor bubble in many of the fluid inclusions.

Core GEO N-2-4219.5-4221 is a grey rock with white fractures and spherical to elliptical vesicles completely filled by hydrothermal alteration minerals. The ground mass of this rock also has a finegrained aphanitic silicic texture with hard and brittle fragments. Sparesly distributed small, and at times large pores, are present in the matrix of GEO N-2-4281-3V but they are mostly not connected. CT images of GEO N-2-4219-2V (after testing) and GEO N-2-4281-3V (before testing) are shown in Figures 9 and 10. In addition, images of plug GEO N-2-4281-1H and GEO N-2-4281-1V and their CT images are shown in Figures 11, 12, respectively. The images of sample 2V do not show significant porosity in the matrix. Note that the sample failed mostly along pre-existing healed fractures. Sample $3 \mathrm{~V}$ does have some relatively large lenticular open vesicles that run from top to the bottom of the sample (sub-parallel to plug axis) in a tapered manner (as indicted by the change in size of the opening in different CT slices along the plug). These larege openings are isolated and do not contribute to effective porosity and permeability.

\subsection{OXY 72-3 cores}

Four vertical plugs were retrieved from whole core OXY 72-3 (4394.5-4396). Petrographic thin section images (e.g., OXY $72-3-5 \mathrm{~V}$ and $4 \mathrm{~V}$ ) show the rock has an aphanitic fine-grained texture and can be classified as mafic igneous basalt. It consists of dominantly plagioclase (light-colored) minerals, and dark gray iron-oxide minerals with minor amounts of hematite. The rock is dense with very little visible porosity; it has fine-grained crystals and few vesicles, and appears to be very hard and brittle. X-ray computerized tomography (CT) images of some plugs (Figure 13) indicate it to be relatively homogeneous. However, heterogeneous zones can be seen in other plugs. The plugs contain different types of grains and various minerals, and pre-existing flaws and very low aperture mostly healed fractures many of which are filled with calcite and quartz.

Additional petrophysical and geomechanical characterization work has been carried out on these cores and will be reported in the future.

\section{Experimental Procedures}

\subsection{Core preparation $\&$ analysis}

The primary objective was to obtain as many specimens as possible in good condition for triaxial testing. The plugs were drilled parallel $(\mathrm{H})$ and perpendicular $(\mathrm{V})$ to the core axis to analyze anisotropy. The extraction and smoothening processes were performed according to the requirement of ISRM (1978).

\subsection{Porosity, permeability measurement}

Effective porosity was measured using either core plugs or rock pieces using a porosimeter. Permeability was measured on plugs using the pressure pulse method before and, if available, after triaxial testing. The permeability of each specimen was measured to analyze the variation of permeability with rock failure. 
The permeability testing conditions were the same for all plugs namely, 4.83-6.2 MPa of effective confining pressure and room temperature. Argon gas was used as the fluid.

\subsection{Triaxial compression and shear testing}

Drained multistage triaxial compression tests were performed using TerraTek Model FX-S-33090 load frame. Multistage testing protocols available in the literature (e.g., Kovari et al., 1983, Kim and Ko, 1979) were adopted to best fit the rock types in this study. Four to five different stages were used to determine rock failure envelops and to estimate the compressive strength, cohesion, and friction angle. The highest confining pressures used (see stress-strain curves) were equal to the horizontal stress that could be encountered in Newberry EGS as reported by AltaRock Inc. (Cladouhos et al., 2011). It is now known (AltaRock, 2015) that the horizontal stresses are higher than initially expected. However, these higher stresses would not have substantial impact on the analysis of test results. Other rock properties such as Young's modulus and Poisson's ratio were also determined from triaxial stress-strain curves.

Prior to testing, each specimen was saturated with tap water using a vacuum chamber for 2-3days. All samples were jacketed with Teflon to isolate the samples from the confining oil. Axial stress was then applied using a strain control mode at a rate of $7 \times 10^{-6}$ strain/sec. Before increasing the load, three strain readings, 1 vertical and 2 radial, were nulled at $0.345 \mathrm{MPa}$ (50 psi) of deviatoric stress. Strains were measured using TerraTek axial, and cantilever radial extensometers (Figure 14). During the first four loading stages, the axial load was stopped and released when the volumetric strain began to decrease (tangent of $\mathrm{d} \sigma / \mathrm{d} \varepsilon \mathrm{v}=0$ ) i.e., at the onset of dilatant deformation. This criterion was modified as needed to best fit the rock type encountered based on mineralogy and experience. For specimens that did not show dilatancy, the loading was stopped when the tangent modulus decreased $2 \%$ compared to that of the elastic region. During the last stage of testing, the rock was loaded to failure to measure the compressive strength of the rock at the prescribed confining pressure. The failure envelope for each sample was then determined assuming that the best fit tangent line of non-failure Mohr circles have the same slope as the failure envelope for the last stage (Tran et al., 2010; Kovari et al., 1983, Kim and Ko, 1979).

\section{Geomechanical properties}

Thirteen plugs from the four whole cores were used in this part of the work (Table 1). Four of the samples are shown after testing in Figure 14. Note the distinct texture and fabric of each sample. These samples were used in multistage triaxial compression tests. Four plugs were tested using the conventional triaxial test (i.e., single stage). The overall test results are shown in Tables 2 and 3 while some individual stressstrain curves and resulting failure envelops are shown in Figures 15-26.

The stress-strain plots for most plugs display a brittle response characterized by a rapid drop in load carrying capacity after peak stress and at a relatively small strain, $1.21 \%$ and $1.00 \%$ for GEO N-1-4013$1 \mathrm{H}$ and $1 \mathrm{~V}$ plugs, respectively (e.g., Figure 15, 16, 17). But four plugs from GEO N-1-4348 (N-1-4348$2 \mathrm{H}, 2 \mathrm{~V}, 3 \mathrm{~V}$ and $4 \mathrm{~V}$ ) display a relatively ductile response (Figures 18, 19, 20) with some post-peak hardening. This appears to be caused by the presence of smectite and other clay minerals. The variations of compressive strength and elastic modulus of GEO N-1-4013-1V and 1H with confining pressure are shown in Figures 21 and 22 and will be discussed later in this section. 
The stress-strain plots for GEO N-2-4281-3V shows a relatively linear elastic response with a sudden failure at about $220 \mathrm{MPa}$ peak load. It is interesting that despite a relatively brittle response, there is no apparent volumetric strain before failure. This could be because extensive micro-cracking did not precede sample failure (shear failure dominating the process). It is also possible that local heterogeneity affected the cantilever extensometer as indicated by the unexpected volumetric response after failure.

The stress-strain plots for OXY 72-3-4394.5-4396 display a relatively brittle behavior and show a clear softening response indicative of micro-cracking and strain localization on a major fault in the sample (Figures 23, 24, 25, 26). Different post-peak zones represent possible slip on induced and pre-existing healed fractures (see also Figure 14, the right most sample). It is suggested that the sample failed by activation and coalescence of healed fractures through additional micro-cracking.

The Young's modulus of each sample was calculated from the linear portion of the stress-strain response. The moduli of the more ductile rock samples, N-1-4348, are relatively lower (13.76-15.16 GPa at 31.02 $\mathrm{MPa}$ confining pressure), while those of OXY 72-3-4394.5 are much higher (46.36-57.42 GPa at 31.02 MPa confining pressure). The average Poisson's ratio was determined by fitting straight lines to the axial and radial strain curves for the same stress range used for average Young's modulus. The Poisson's ratio values are relatively higher for the core GEO N-1-4013 and OXY 72-3-4394.5. A summary of all data is shown in Table 2. A high elastic modulus and low Poisson's ration is characteristic of a more brittle response. It can be correlated with mineral composition and textural properties of the rocks. Higher pressure and temperature generally enhance ductility.

The Mohr circles and the failure envelope are drawn from the multistage tests and are shown in Figures 15-26; single stage triaxial tests, Figures 19, 24, 26, do not yield sufficient information to build the envelope. A summary of the failure criterion parameters is presented in Table 3 . The dashed Mohr circles were obtained from data corresponding to the stress state at the onset of dilatancy, while the solid circles were calculated from the best tangent line using the peak stress from the last (i.e., failure) stage.

The compressive strength values of the samples for a given stage were calculated using the failure envelope from the estimated Mohr circles. The uniaxial compressive strength of the specimen was determined from the y-intercept of the best fitted line for the compressive strength of all stages using the overall failure criterion obtained from all multistage data. As expected, the compressive strength values increase with confining pressure and are relatively higher for GEO N-1-4013 and GEO N-2-4281 and OXY 72-3-4394.5. Data in Table 3 show that not only the cohesive strength but also the internal friction angle varies among plugs from the same whole core. The cohesion values are in the range of 24.72-32.47 $\mathrm{MPa}$ except for GEO N-1-4348-2V (15.24 MPa), GEO N-2-4281-3V (61.34 MPa) and OXY 72-34394.51V (65.83 MPa).

The mechanical properties of GEO N-1-4013-4014-1V and 1H show some anisotropy at high confining pressures (Figure 21a). The uniaxial compressive strengths (strength at zero confining pressure) show a very small difference of $0.31 \mathrm{MPa}(45 \mathrm{psi})$. However, the strength increment with confining pressure for sample $1 \mathrm{H}$ is almost twice that of $1 \mathrm{~V}(6.07 \mathrm{MPa}$ vs. $3.54 \mathrm{MPa})$. This means that in this interval, the increase in rock strength with confining pressure is anisotropic. The Poisson's ratio values do not show anisotropy. The Young's modulus values seem isotropic (Figure 21b). The Young's moduli for both H and $\mathrm{V}$ plug orientations are relatively low at $3.45 \mathrm{MPa}$ of confining pressure. The calculated values of cohesion and internal friction angle are different for each plug. The cohesion of plug $1 \mathrm{~V}$ is about 7.60 $\mathrm{MPa}$ higher than that of $1 \mathrm{H}$, while $1 \mathrm{H}$ has the larger friction angle of $45.83^{\circ}$ than $1 \mathrm{~V}\left(34.01^{\circ}\right)$. The multistage triaxial compression test on GEO N-1-4348-2H resulted in an inclined fracture with an angle 
of $58^{\circ}$ to $\sigma_{3}$ direction (horizontal). After the test, a flat pre-existing weakness plane was also observed to have split the GEO N-1-4348-2V sample.

The mechanical properties of plugs from GEO N-1-4348-4349 are not uniform and vary from sample to sample. For example, samples $2 \mathrm{H}$ and $4 \mathrm{~V}$ have high strength while sample $2 \mathrm{~V}$ has low strength (119.6125.0 MPa- and 96.0 MPa at 24 MPa of confining pressure, respectively). Although there is heterogeneity in uniaxial compressive strength (UCS), the variation of strength with confining pressure has a narrow range of 1.74 to $2.35 \mathrm{MPa}$. The high UCS sample group, $2 \mathrm{H}$ and $4 \mathrm{~V}$, has a larger Young's modulus. The plug $2 \mathrm{H}$ has a higher Young's modulus (16.4 GPa- at $24 \mathrm{MPa}$ of confining pressure) compared to the others (13.4-14.3 GPa at $24 \mathrm{MPa}$ of confining pressure). The results from $4 \mathrm{~V}$ are similar to that of $2 \mathrm{~V}$ and $3 \mathrm{~V}$. The Poisson's ratios are in the range from 0.22 to 0.37 with high heterogeneity among the four plugs. The cohesion values of the high UCS group plugs, $2 \mathrm{H}$ and $4 \mathrm{~V}$, are only a little different (25.44 vs 29.5 $\mathrm{MPa}$ ) and are larger than that of $1 \mathrm{~V}(14.24 \mathrm{MPa})$. However, the internal friction angle values of this group show an opposite trend, they are the highest for plug $2 \mathrm{~V}$ and are the lowest for plug $4 \mathrm{~V}$. In addition, the failure angles of $2 \mathrm{H}$ and $2 \mathrm{~V}$ do not vary much $\left(21.38^{\circ}\right.$ and $\left.23.72^{\circ}\right)$, while that of $4 \mathrm{~V}$ has a much lower value $\left(12.60^{\circ}\right)$.

For OXY 72-3 plugs from 4394.5-4396 feet, the variations of compressive strength and elastic modulus with stress and plug direction display features similar to those in other cores tested. The calculated uniaxial strengths from the multistage triaxial tests have a large variation. Although the results from two multistage tests do not show a significant difference at $10.34 \mathrm{MPa}$ confining pressure, the difference increases as the confining pressure increases. This is because the Young's modulus of $1 \mathrm{~V}$ is stable over 13.8 $\mathrm{MPa}$ of confining pressure, while that of $5 \mathrm{~V}$ decreases as higher confining pressures are applied (softening). The Poisson's ratios from $1 \mathrm{~V}, 4 \mathrm{~V}$ and $6 \mathrm{~V}$ differ by only $5 \%$, while their cohesion and internal friction angles show large difference (samples $1 \mathrm{~V}$ and $5 \mathrm{~V}$ ). These trends are caused by the variation in composition and texture along the core.

\subsection{Multistage triaxial shear tests}

Multi-stage joint shear tests were carried out to determine the natural fracture properties of the lithofacies encountered in the cores. Joint stiffness and Barton joint model parameters were determined from the experimental results. The joint tests were done on samples that were fractured under triaxial compression with the failure plane cutting through the sample without intersecting the samples' ends so that only a few specimens could be tested.

Four multi-stage shear tests were performed on the four compression-induced jointed rock samples. A multi-stage triaxial shear test usually consist of 6-9 stages, each stage corresponds to deviatoric loading under a constant confining pressure. The experimental procedure can be found in Goodman (1989) and Jaeger (1971). For the four tested samples (Figure 14), the confining pressures applied are listed in Table 4. The shear tests were carried out on samples with some residual moisture level (without oven drying or further saturation). To better illustrate the gradual transition from the initial slope to the final slope of the shear strength envelope of a joint, usually 3 confining pressures in the range of 0-6.89 MPa were used. But more stages would provide a clearer transition.

The shear strength of the jointed specimen is determined by constructing Mohr circles for each stage of the test in the normal stress vs. shear stress space. The failure inclination angle for a joint, $\theta$, is predetermined and is used to calculate the stresses on the failure plane for each stage. Using the strength data 
of a multi-stage triaxial shear tests, the shear strength envelopes of a jointed sample were determined, as shown in Figures 27-29.

With the shear strength envelope, Barton's shear strength model is used to back calculate its parameters. Barton's shear strength model takes the surface roughness, dilation, and asperity strength into account, it has the following form $\tau=\sigma_{n} \tan \left[J R C * \log \left(J C S / \sigma_{n}\right)+\phi_{b}\right]$. The model contains two empirical parameters namely, JRC (joint roughness coefficient), and JCS (joint asperity compressive strength). The JRC is a dimensionless number that reflects the amount of surface undulations and asperities present in the discontinuity surface and it ranges from 0 to 20. The value of JCS is the normal stress at which the dilatancy contribution is reduced to zero, and is taken equal to the uniaxial compressive strength of intact rock (it could be lower for weathered, and fatigued surfaces). $\phi_{b}$ is the joint's basic angle of friction and usually equals $\phi_{r}$, i.e., the angle of shearing resistance mobilized at high normal stress levels at which all dilatancy effects are suppressed and all the asperities are sheared off forming a smooth shearing plane.

Using a least-square curve fitting method, JRC, JCS, and $\phi_{b}$ were determined. The friction angle at any stress level can be obtained from the inverse tangent $\left(\tan ^{-1}\right)$ of Barton's curve slope, as shown in Figure 30. Similarly, the shear strength envelopes from other samples were processed and the results are summarized in Table 5. As it can be seen in Table 5, the residual friction angles $\phi_{r}$ are smaller than the internal friction angles (of intact rock), because the asperities were sheared off after repetitive shear tests; the fracture surfaces became smoother than the newly formed fracture surfaces at failure under triaxial compression. The high JRC value of N-1-4348 can be explained by mineral composition heterogeneity and small cracks in the sample. Heterogeneity and cracks make the fracture surface more undulating and meandering. The sample's small JCS value is consistent with its small UCS value and its high clay content. The silica and calcite minerals inside the small fractures of N-2-4020-2H lubricate the surface making the JRC value small. Generally the JCS values show the same trend as the UCS values.

The procedure proposed by Rosso (1976) is used for determining the joint stiffness using the multistage triaxial shear test results. The joint stiffness values are shown in Figure 31-34 and summarized in Table 6. The fracture deformation was calculated by subtracting the intact rock deformation from total deformation of the sample. By measuring strains in two orthogonal directions, the slippage of fracture was detected by observing the quick increase of strain in one lateral direction. The difference between the two lateral strains can cause the measured fracture deformation to begin from a negative value.

The JRC values obtained from back-analysis are much smaller than the values from visual comparison with Barton's standard JRC (Figure $35 \mathrm{a}, \mathrm{b}$ ). This could be caused by the presence of water causing the JRC values to be smaller. Repetitive shearing of one fractured sample crushes the asperities and makes the fracture surface smoother, thus the friction angle is reduced. The JCS values turned out to be larger than the uniaxial compressive strength which might be attributed to size effect and/or to the strong inclusions and gouge minerals present near the joint surface.

\subsection{Permeability variation with intact rock failure}

Permeability was measured using a pulse permeameter before and, if possible, after the triaxial compressive tests. The overall permeability values of each plug are shown in Table 7. The permeability values of the Newberry tuff are generally very low (less than $0.1 \mathrm{md}$ ). Analysis of the data for GEO N-14013-1H, 1V, GEO N-1-4348-2H, 3V, 4V, and OXY 72-3-4394.5-6V, shows that the rock samples permeability was enhanced by rock failure and induced cracks. The relatively ductile plugs such as GEO 
$\mathrm{N}-1-4348$ showed a lowering of permeability due to compaction and deformation without the formation of new micro and macro cracks. Implications of these differing mechanical behaviors for reservoir stimulation are discussed below.

\section{Discussion on petrological and geomechanical properties and their roles in stimulation}

Mineralogical and textural characteristics have strong effects on rock mechanical properties. Natural fracture and vein mineralogy also affect rock deformation and failure and impact the evolution of reservoir permeability. Our experimental results underscore these trends.

For GEO N-1 cores, whether the matrix texture is dominated by glassy or argillitic material results in significant contrast in rock strength. Whereas the matrix of core GEO N-1-4013-4014 consists mostly of very fine-grained glassy particles, the matrix of core GEO N-1-4348-4349 is dominated by argillitic materials. The uniaxial compressive strength of GEO N-1-4013-4014 ranged from 121.9-122.2 MPa (17,676-17,721 psi) for the glassy texture and 48-74.5 MPa (6,956.28-10,811 psi) for the argillitic matrix. The cohesion and friction angle of GEO N-1-4013-4014 ranged from 24.72 to $32.47 \mathrm{MPa}(3,585.86$ psi to $4,709.82 \mathrm{psi})$, and from $34.01^{\circ}$ to $45.83^{\circ}$ for the glassy texture, and from 17.04 to $23.30 \mathrm{MPs}(2,471.29$ psi to $3,376 \mathrm{psi}$ ) and from $19.3^{\circ}$ to $21.4^{\circ}$ for the argillitic matrix, respectively. In addition, the inclination angle of intact rock failure plane $(\beta)$ in glassy texture rock is higher than that in the rock with argillitic matrix, ranging from $62.01^{\circ}$ to $67.92^{\circ}$, and from $54.6^{\circ}$ to $55.7^{\circ}$, respectively.

The strongest rock in the GEO N-1 core plugs appears to be the GEO N-1-4013-1V. It contains the most glassy content in its matrix with the highest amounts of recognizable mineral crystals (phenocrysts) embedded in the glass matrix. The weakest rock appears to be the GEO N-1-4348-2V; it contains the most argillitic material in its matrix with the lowest value of recognizable mineral crystals (phenocrysts) embedded in argillitic matrix.

The presence of phenocrysts in the plugs tested can have a weakening or a strengthening effect depending on the matrix composition, bonding, and the strength of the phenocrysts themselves. For example, phenocrysts in clay rich GEO N-1-4348 tend to strengthen the rock while weak phenocrysts in glass matrix (e.g., GEO N-1-4013 and OXY 72-3) tend to weaken the rock.

Using a point count technique, the GEO N-1-4348 plugs containing higher values of recognizable phenocrysts show higher strength. For example, the point count result shows that the GEO N-1-4013-1H has $18 \%$ phenocrysts, and the GEO N-1-4013-1V has $24 \%$ phenocrysts within the similar glassy matrix. The cohesion and friction angle of GEO N-1-4013-1H is $24.72 \mathrm{MPa}(3,585.86 \mathrm{psi})$ and $45.83^{\circ}$ (18\% phenocrysts), and that of GEO N-1-4013-1V is $32.47 \mathrm{MPa}\left(4,709.82 \mathrm{psi}\right.$ ) and $34.01^{\circ}$ (24\% phenocrysts). Both samples contained healed or partially healed cracks. In GEO N-1-4013-1H plug the crack was subvertical so that the sample failed along a newly formed shear plane. The crack in GEO N-1-4013-1V plug was sub-horizontal and the shear plane at failure was dominated by its presence.

The plugs from core GEO N-2-4219.5 containing mineral-filled or open micro-hydraulic fractures and natural fractures show low strength. The uniaxial compressive strength of plug GEO N-2-4219.5-2H is 47.02 $\mathrm{MPa}(6,818 \mathrm{psi})$ and it has a cohesion and friction angle of $15.25 \mathrm{MPa}(2,211 \mathrm{psi})$ and $33.7^{\circ}$, respectively. Although GEO N-2-4281-3V contains two or three major vesicles inside the core plug, it has a higher value of uniaxial compressive strength $(179.47 \mathrm{MPa}=26,023 \mathrm{psi})$ compared to GEO N-2-4281-2H and $2 \mathrm{~V}$ (UCS of $4.18 \mathrm{MPa}=605 \mathrm{psi}$ and $27.18 \mathrm{MPa}=3,941 \mathrm{psi}$, respectively) containing large breccia 
fragments. This is because the latter is from a part of the core that contains many more vesicles and micro-cracks and partially healed cracks (see Figure 3).

The mechanical properties of OXY 72-3 which is a relatively less heterogeneous core are largely affected by the existence of micro-cracks and healed fractures. The plugs without micro-cracks such as OXY 72-31V (see Figure 6) show higher Young's modulus and lower Poisson's ratio than the others. Moreover, the cohesion of the $1 \mathrm{~V}$ plug is $65.84 \mathrm{MPa}$, which is much higher than that of $5 \mathrm{~V}$ which had a visible crack across the plug.

In general, mechanical properties of tuffs tested correlate well with their mineralogical and textural characteristics. Samples with higher clay minerals content show lower strength; fine-grained siliceous samples (e.g., OXY 72-3-5V, GEO N-2-4281-3V) are stronger than the coarser-grained samples. Brittle behavior with high dilatancy has been observed in the more basaltic samples. The clay-rich intervals (e.g., GEO N-1-4348-4349) display a strongly ductile deformation. Overall, rock mechanical and failure properties (Mohr-Coulomb parameters) of the tuffs tested are very heterogeneous and vary from sample to sample and core to core.

Results show samples having higher Young's modulus display a relatively more brittle response with dilation due to micro-cracking and failure at low strain levels. However, a clear correlation with Poisson's ratio was not observed for the rocks tested.

The permeability values of brittle plugs are enhanced with the rock failure, while the permeability of ductile plugs is not increased or is deteriorated. Pre-existing healed fractures are prevalent in the basaltic samples and at times they are intersected by the compression induced shear and tensile fractures that form during the failure process, resulting in enhanced permeability of the brittle basaltic samples. Compression test results of these rocks shows the pre-existing fractures either have very large shear strength or are not critically oriented in the specimen, causing the formation of a new failure plane.

The joint strengths and frictional properties also show a dependence on mineral content of these discontinuities. The joint roughness (JRC) is increased by heterogeneities and small cracks that enhance the joint surface undulations. The residual friction angles obtained from joint tests are smaller than the internal friction angles of the intact rocks. This is because the asperities were sheared off and crushed after repetitive shearing making the fracture surfaces smoother than the newly formed fracture surfaces. Also, crushed calcite minerals inside the fractures tend to lubricate the surface.

\subsection{Implications for reservoir stimulation}

The geological investigations of the Newberry EGS have shown the presence of a variety of rock units in the subsurface. The composition and textural properties within these units are also heterogeneous reflecting different compaction, deformation, and hydrothermal processes. Although, core from the reservoir depth was not available, the core samples from deepest wells in the vicinity clearly reflect this heterogeneity. The results of the geomechanical testing program carried out clearly show zones of ductile and brittle lithology. The brittle rocks show improvement in permeability upon failure, however, these rocks tend to have higher strength requiring high shear stresses for new fracture development. The more ductile rocks showed no permeability enhancement with deformation and failure, suggesting that such zones ought to be avoided in stimulation design. 
460 In relation to stimulation by slip on natural fractures, pre-existing closed fractures were prevalent in the 461 basaltic samples and often they were intersected by new induced fractures at or near failure point of the 462 samples. Failure of pre-existing fractures did occur but at very large stress levels indicating high shear 463 strength and/or uncritical orientation in the specimens. The implication is that higher than expected 464 injection pressures might be needed to reactivate these healed fractures.

465 Additionally, it is suggested that the relatively small number of MEQ's observed in Newberry EGS 466 stimulation (around 400) could partially be caused by the distribution of the ductile zones in the vicinity 467 of the injection well. It is likely that the observed MEQs are caused by failure mechanisms observed in 468 the brittle lithologies (such as the basalts encountered in OXY 72-3 core), involving failure of healed or 469 partially cemented fractures. Additional studies involving acoustic emission (AE) monitoring and 470 permeability measurement during rock deformation/failure are underway to further investigate these 471 questions.

\section{Acknowledgements}

473 This work was supported by the U.S. Department of Energy Office of Energy Efficiency and Renewable 474 Energy under Award Number DE- EE0002757. This support does not constitute an endorsement by the 475 U.S. Department of Energy of the views expressed in this publication. We would like to acknowledge the 476 support of AltaRock, Inc. for supporting this research. We also thank Drs. Joe Moore and Pete Rose who 477 facilitated access to core from the Utah Core Library. Finally, we appreciate the critical comments and 478 suggestions by two reviewers and Dr. Sabodh Garg that have improved the paper. 


\section{References}

AltaRock Inc. 2015, Newberry EGS Phase II Stage Gate Report, Seattle, WA, 138 pp.

481

482

483

484

485

486

487

488

489

490

491

492

493

494

495

496

497

498

499

500

501

502

503

504

505

506

507

508

509

510

Banthia, B. S., King, M.S., and Fatt, I. (1965). Ultrasonic shear-wave velocities in rocks subjected to simulated overburden pressure and internal pore pressure. Geophysics, 30(1): 117121.

Bargar, K. E., and Keith, T. E. C. (1999). Hydrothermal mineralogy of core from geothermal drill holes at Newberry volcano, Oregon. USGS Professional Paper 1578, 101 pp.

Barton, N. (1972). A model study of rock-joint deformation. International Journal of Rock Mechanics \& Mining Sciences and Geomechanics Abstracts, 9, 579-602.

Barton, N. (1973). Review of a new shear strength criterion for rock joints. Engineering Geology, 7, 287-332.

Callahan, O. (2011). Map of Newberry volcano showing locations of geothermal exploration drill holes. In: AltaRock Inc. Newberry EGS Phase I Stage Gate Report, Seattle, WA, 290 pp.

Cladouhos, T.T., Clyne, M., Nichols, M., Petty, S., Osborn, W.L., Nofziger, L. (2011). Newbery Volcano EGS Demonstration Simulation Modeling. GRC Transactions, v. 35, 6 pp.

Crawford, A., M., and Wylie, D.A. (1987). A Modified Multiple Failure State Triaxial Testing Method. 28th U.S. Symposium on Rock Mechanics, Tucsan, AZ, A. A. Balkema, Rotterdam, 8 pp.

Davatzes, N. C. and Hickman, S.H. (2011). Preliminary analysis of stress in the Newberry EGS Well NWG 55-29, GRC Transactions, v. 35, 10 pp.

Fetterman, J.A. and Davatzes, N.C. (2011). Fracture generated porosity evolution in the Newberry volcano Geothermal System, OR: Feedback between deformation and alteration. GRC Transactions, v. 35, 8 pp.

Fitterman, D. V., Stanley, W.D., and Bisdorf, R.J. (1988). Electrical structure of Newberry volcano, Oregon. Journal of Geophysical Research-Solid Earth and Planets 93(B9): 1011910134.

Goodman, R.E. (1989). Introduction to Rock Mechanics. 2nd Ed. Wiley and Sons, 576 pp.

Hoek, E, Bray, J.W. (1981). Rock slope engineering, 3rd ed. London: Institute of Mining and Metallurgy. 368 pp.

ISRM (1978). Suggested methods for determining the strength of rock materials in triaxial compression. International Journal of Rock Mechanics and Mining Sciences \& Geomechanics Abstracts, 15(2), 47-51. 
Jaeger, J.C. (1971). Friction of rocks and stability of rock slopes. Geotechnique, 21 (2), 97-134.

512 Kim, M. M., and Ko, H.,Y. (1979). Multistage triaxial testing of Rocks. Geotechnical Testing 2, 513 98-105.

514 Kovári, K. and Tisa, A. (1975). Multiple failure state and strain controlled triaxial tests. Rock 515 Mechanics and Rock Engineering, 7(1), 17-33.

516 Kovari, K., Tisa, A., Einstein, H., and Franklin, J.A. (1983). Suggested methods for determining 517 the strength materials in triaxial compression. International Journal of Rock Mechanics \& 518 Mining Sciences and Geomechanics Abstracts, 20, 283-290.

519 Macleod, N. S. and Sherrod. D.R. (1988). Geologic evidence for a magma chamber beneath 520 Newberry volcano, Oregon. Journal of Geophysical Research-Solid Earth and Planets 93(B9), 521 10067-10079.

522 Olmstead, D.L., and Wermiel, D.E. (1988). Newberry Crater geothermal resource area. Oregon 523 Department of Geology and Mineral Industries Open-File Report O-88-3. 1 pp.

524 Patton, F. D. (1966). Multiple Modes of Shear Failure in Rock. Proceedings 1st International 525 Congress of the International Society for Rock Mechanics, Colouste Gulbenkian Foundation, 526 Lisbon, v. 1, pp. 509-513.

527 Rosso, R.S. (1976). A comparison of joint stiffness measurements in direct shear, triaxial 528 compression and in situ. International Journal of Rock Mechanics \& Mining Sciences and 529 Geomechanics Abstracts, 13,167-172.

530 Taheri, A. and Tani, K. (2008). Proposal of a New Multiple-step Loading Triaxial Compression 531 Testing Method. ISRM International Symposium - 5th Asian Rock Mechanics Symposium. 532 Tehran, Iran, International Society for Rock Mechanics (ISRM) and Iranian Society for Rock 533 Mechanics (IRSRM), 517-524.

534 Tran, D. T., Pagoulatos, A., Sonderge, C.H., and Canh, N.N. (2010). Quantify Uncertainty of 535 Rock Failure Parameters From Laboratory Triaxial Testings Using Conventional And Multistage 536 Approaches. 44th U.S. Rock Mechanics Symposium, Salt Lake City, Utah.

537 Swanberg, C. A., Walkey, W.C., and Combs, J. (1988). Core Hole drilling and the rain curtain 538 phenomenon at Newberry volcano, Oregon. Journal of Geophysical Research-Solid Earth and 539 Planets 93(B9), 10163-10173.

540 Williams, H. (1935). Newberry volcano of central Oregon. Bulletin of the Geological Society of 541 America 46(1/4), 253-304. 
Table 1. Information on plugs and test type for porosity measurement (bulk volume less than $25 \mathrm{cc}$ indicates the sample used for porosity measurements was not a cylindrical plug). The method used provides effective porosity.

Porosity of whole core could be larger in some cases due to the presence of fractures.

\begin{tabular}{|c|c|c|c|c|c|}
\hline Well & Depth, $\mathrm{ft}$ & Plug ID & Bulk volume, cc & Porosity & Test type \\
\hline \multirow{6}{*}{ GEO N-1 } & \multirow{2}{*}{4013} & $1 \mathrm{H}$ & 15.53 & 1.79 & Multistage test under 5 stages \\
\hline & & $1 \mathrm{~V}$ & 9.31 & 3.24 & Multistage test under 5 stages \\
\hline & \multirow{4}{*}{4348} & $2 \mathrm{H}$ & 13.64 & 12.52 & Multistage test under 5 stages \\
\hline & & $2 \mathrm{~V}$ & 10.76 & 16.71 & Multistage test under 4 stages \\
\hline & & $3 \mathrm{~V}$ & 13.25 & 15.74 & Conventional triaxial test \\
\hline & & $4 \mathrm{~V}$ & 10.84 & 14.54 & Multistage test under 5 stages \\
\hline \multirow{5}{*}{ GEO N-2 } & 4219.5 & $2 \mathrm{H}$ & 10.14 & 5.68 & Multistage test under 4 stages \\
\hline & \multirow{4}{*}{4281} & $1 \mathrm{~V}$ & 12.07 & 5.57 & Conventional triaxial test \\
\hline & & $2 \mathrm{H}$ & 11.88 & 6.44 & Multistage test under 5 stages \\
\hline & & $2 \mathrm{~V}$ & 14.96 & 4.99 & Multistage test under 2 stages \\
\hline & & $3 \mathrm{~V}$ & 25.79 & 5.40 & Multistage test under 5 stages \\
\hline \multirow{4}{*}{ OXY 72-3 } & \multirow{4}{*}{4394.5} & $1 \mathrm{~V}$ & 8.50 & 0.35 & Multistage test under 5 stages \\
\hline & & $4 \mathrm{~V}$ & 3.44 & 1.43 & Conventional triaxial test \\
\hline & & $5 \mathrm{~V}$ & 10.41 & 0.79 & Multistage test under 5 stages \\
\hline & & $6 \mathrm{~V}$ & 10.25 & 2.31 & Conventional triaxial test \\
\hline
\end{tabular}


Table 2. Elastic and strength properties of the plugs.

\begin{tabular}{|c|c|c|c|c|c|c|c|c|c|}
\hline $\begin{array}{c}\mathrm{Pc}, \mathrm{MPa} \\
(\mathrm{psi})\end{array}$ & Well & Depth, ft & Plug & $\begin{array}{c}3.45 \\
(500)\end{array}$ & $\begin{array}{c}10.34 \\
(1500)\end{array}$ & $\begin{array}{l}13.79 \\
(2000)\end{array}$ & $\begin{array}{l}17.24 \\
(2500)\end{array}$ & $\begin{array}{l}24.14 \\
(3500)\end{array}$ & $\begin{array}{l}31.03 \\
(4500)\end{array}$ \\
\hline \multirow{15}{*}{$\begin{array}{l}\text { Estimated } \\
\text { Compressive } \\
\text { Strength, } \\
\mathrm{MPa}\end{array}$} & \multirow{6}{*}{ GEO N-1 } & \multirow{2}{*}{4013} & $1 \mathrm{H}$ & 142.85 & 184.74 & - & 226.63 & 268.53 & 310.42 \\
\hline & & & $1 \mathrm{~V}$ & 134.76 & 158.9 & - & 183.30 & 207.67 & 232.04 \\
\hline & & \multirow{4}{*}{4348} & $2 \mathrm{H}$ & - & 92.61 & 100.70 & 108.79 & 124.97 & 141.15 \\
\hline & & & $2 \mathrm{~V}$ & - & 68.56 & 75.41 & 82.26 & 95.95 & - \\
\hline & & & $3 \mathrm{~V}$ & - & - & - & - & 122.38 & - \\
\hline & & & $4 \mathrm{~V}$ & - & 95.62 & 101.61 & 107.60 & 119.57 & 131.54 \\
\hline & \multirow{5}{*}{ GEO N-2 } & 4219.5 & $2 \mathrm{H}$ & - & 105.35 & 115.38 & 125.42 & - & 165.55 \\
\hline & & \multirow{4}{*}{4281} & $1 \mathrm{~V}$ & 120.69 & - & - & - & - & - \\
\hline & & & $2 \mathrm{H}$ & $\begin{array}{c}14.40 \\
(\mathrm{Pc}=3.03)\end{array}$ & $\begin{array}{c}21.60 \\
(\mathrm{Pc}=5.17)\end{array}$ & $\begin{array}{c}37.86 \\
(\mathrm{Pc}=10.0) \\
\end{array}$ & $\begin{array}{c}68.05 \\
(\mathrm{Pc}=18.97)\end{array}$ & $\begin{array}{c}78.27 \\
(\mathrm{Pc}=22.0)\end{array}$ & - \\
\hline & & & $2 \mathrm{~V}$ & - & - & - & 80.80 & - & 120.47 \\
\hline & & & $3 \mathrm{~V}$ & - & 201.61 & 208.99 & 216.37 & 231.13 & 245.89 \\
\hline & \multirow{4}{*}{ OXY 72-3 } & \multirow{4}{*}{4394.5} & $1 \mathrm{~V}$ & - & 242.78 & 253.00 & 263.22 & 283.66 & 304.11 \\
\hline & & & $4 \mathrm{~V}$ & - & - & - & - & - & 213.85 \\
\hline & & & $5 \mathrm{~V}$ & - & 170.22 & 186.26 & 202.29 & 234.37 & 266.45 \\
\hline & & & $6 \mathrm{~V}$ & - & - & - & - & 278.03 & - \\
\hline \multirow{15}{*}{$\begin{array}{c}\text { Average } \\
\text { Young's Modulus, GPa }\end{array}$} & \multirow{6}{*}{ GEO N-1 } & \multirow{2}{*}{4013} & $1 \mathrm{H}$ & 25.88 & 27.23 & - & 27.83 & 27.47 & 27.20 \\
\hline & & & $1 \mathrm{~V}$ & 25.71 & 28.34 & - & 28.43 & 28.20 & - \\
\hline & & \multirow{4}{*}{4348} & $2 \mathrm{H}$ & - & 15.18 & 16.34 & 16.22 & 16.40 & 16.56 \\
\hline & & & $2 \mathrm{~V}$ & - & 11.17 & 13.40 & 13.76 & 13.38 & - \\
\hline & & & $3 \mathrm{~V}$ & - & - & - & - & 13.99 & - \\
\hline & & & $4 \mathrm{~V}$ & - & 13.24 & 14.27 & 14.38 & 14.26 & 13.76 \\
\hline & \multirow{5}{*}{ GEO N-2 } & 4219.5 & $2 \mathrm{H}$ & - & 20.90 & 21.60 & 18.85 & - & 20.02 \\
\hline & & \multirow{4}{*}{4281} & $1 \mathrm{~V}$ & 24.45 & - & - & - & - & - \\
\hline & & & $2 \mathrm{H}$ & $\begin{array}{c}2.23 \\
(\mathrm{Pc}=3.03)\end{array}$ & $\begin{array}{c}5.70 \\
(\mathrm{Pc}=5.17)\end{array}$ & $\begin{array}{c}7.80 \\
(\mathrm{Pc}=10.0)\end{array}$ & $\begin{array}{c}9.55 \\
(\mathrm{Pc}=18.97)\end{array}$ & $\begin{array}{c}10.71 \\
(\mathrm{Pc}=22.0)\end{array}$ & - \\
\hline & & & $2 \mathrm{~V}$ & - & - & - & 10.57 & - & 8.04 \\
\hline & & & $3 \mathrm{~V}$ & - & 30.48 & 40.18 & 41.56 & 42.81 & 43.43 \\
\hline & \multirow{4}{*}{ OXY 72-3 } & \multirow{4}{*}{4394.5} & $1 \mathrm{~V}$ & - & 56.94 & 58.12 & 58.15 & 58.75 & 57.41 \\
\hline & & & $4 \mathrm{~V}$ & - & - & - & - & - & 45.73 \\
\hline & & & $5 \mathrm{~V}$ & - & 53.83 & 54.75 & 52.02 & 48.95 & 46.35 \\
\hline & & & $6 \mathrm{~V}$ & - & - & - & - & 39.88 & - \\
\hline & & & $1 \mathrm{H}$ & 0.31 & 0.34 & - & 0.36 & 0.40 & 0.42 \\
\hline & & 4013 & $1 \mathrm{~V}$ & 0.28 & 0.33 & - & 0.36 & 0.39 & - \\
\hline & & & $2 \mathrm{H}$ & - & 0.29 & 0.31 & 0.30 & 0.29 & 0.28 \\
\hline & GEU N-1 & & $2 \mathrm{~V}$ & - & 0.32 & 0.36 & 0.37 & 0.36 & - \\
\hline & & 4348 & $3 \mathrm{~V}$ & - & - & - & - & 0.22 & - \\
\hline & & & $4 \mathrm{~V}$ & - & 0.31 & 0.34 & 0.34 & 0.33 & 0.31 \\
\hline & & 4219.5 & $2 \mathrm{H}$ & - & 0.19 & 0.21 & 0.19 & - & 0.20 \\
\hline Average & & & $1 \mathrm{~V}$ & 0.26 & - & - & - & - & - \\
\hline Poisson's Ratio & GEO N-2 & 4281 & $2 \mathrm{H}$ & $\begin{array}{c}0.46 \\
(\mathrm{Pc}=3.03)\end{array}$ & $\begin{array}{c}0.39 \\
(\mathrm{Pc}=5.17)\end{array}$ & $\begin{array}{c}0.37 \\
(\mathrm{Pc}=10.0)\end{array}$ & $\begin{array}{c}0.36 \\
(\mathrm{Pc}=18.97)\end{array}$ & $\begin{array}{c}0.35 \\
(\mathrm{Pc}=22.0)\end{array}$ & - \\
\hline & & & $2 \mathrm{~V}$ & - & - & - & 0.30 & - & 0.22 \\
\hline & & & $3 \mathrm{~V}$ & - & 0.16 & 0.26 & 0.27 & 0.28 & 0.30 \\
\hline & & & $1 \mathrm{~V}$ & - & 0.21 & 0.27 & 0.26 & 0.32 & 0.37 \\
\hline & OXY 72-3 & 4394.5 & $4 \mathrm{~V}$ & - & - & - & - & - & 0.36 \\
\hline & OXY TL-3 & 4394.5 & $5 \mathrm{~V}$ & - & 0.32 & 0.34 & 0.37 & 0.39 & 0.41 \\
\hline & & & $6 \mathrm{~V}$ & - & - & - & - & 0.33 & - \\
\hline & & 4013 & $1 \mathrm{H}$ & & & & 1.87 & & \\
\hline & & 4013 & $1 \mathrm{~V}$ & & & & 2.33 & & \\
\hline & GEO N-1 & & $2 \mathrm{H}$ & & & & .35 & & \\
\hline & & 4348 & $2 \mathrm{~V}$ & & & & .01 & & \\
\hline $\begin{array}{l}\text { Uniaxial } \\
\text { Compressive }\end{array}$ & & & $4 \mathrm{~V}$ & & & & .67 & & \\
\hline $\begin{array}{l}\text { Compressive } \\
\text { Strength } \mathrm{MPa}\end{array}$ & & 4219.5 & $2 \mathrm{H}$ & & & & 25 & & \\
\hline & GFO N-2 & & $2 \mathrm{H}$ & & & & 18 & & \\
\hline & GEU N-2 & 4281 & $2 \mathrm{~V}$ & & & & .18 & & \\
\hline & & & $3 \mathrm{~V}$ & & & & .47 & & \\
\hline & OXY 72-3 & 4394.5 & $1 \mathrm{~V}$ & & & & 2.11 & & \\
\hline & OXY TL-3 & 4394.5 & $5 \mathrm{~V}$ & & & & 2.10 & & \\
\hline
\end{tabular}


Table 3. Overall Mohr-Coulomb parameters.

\begin{tabular}{|c|c|c|c|c|}
\hline \multirow{11}{*}{ Cohesion, $\mathrm{MPa}$} & \multirow{5}{*}{ GEO N-1 } & \multirow{2}{*}{4013} & $1 \mathrm{H}$ & 24.73 \\
\hline & & & $1 \mathrm{~V}$ & 32.55 \\
\hline & & \multirow{3}{*}{4348} & $2 \mathrm{H}$ & 22.32 \\
\hline & & & $2 \mathrm{~V}$ & 17.04 \\
\hline & & & $4 \mathrm{~V}$ & 29.48 \\
\hline & \multirow{4}{*}{ GEO N-2 } & 4219.5 & $2 \mathrm{H}$ & 22.06 \\
\hline & & \multirow{3}{*}{4281} & $2 \mathrm{H}$ & 1.14 \\
\hline & & & $2 \mathrm{~V}$ & 7.84 \\
\hline & & & $3 \mathrm{~V}$ & 61.35 \\
\hline & \multirow{2}{*}{ OXY 72-3 } & \multirow{2}{*}{4394.5} & $1 \mathrm{~V}$ & 61.61 \\
\hline & & & $5 \mathrm{~V}$ & 20.90 \\
\hline \multirow{11}{*}{ Internal Friction Angle, ${ }^{\circ}$} & \multirow{5}{*}{ GEO N-1 } & \multirow{2}{*}{4013} & $1 \mathrm{H}$ & 45.8 \\
\hline & & & $1 \mathrm{~V}$ & 34.0 \\
\hline & & \multirow{3}{*}{4348} & $2 \mathrm{H}$ & 23.7 \\
\hline & & & $2 \mathrm{~V}$ & 19.3 \\
\hline & & & $4 \mathrm{~V}$ & 15.6 \\
\hline & \multirow{4}{*}{ GEO N-2 } & 4219.5 & $2 \mathrm{H}$ & 29.2 \\
\hline & & \multirow{3}{*}{4281} & $2 \mathrm{H}$ & 32.8 \\
\hline & & & $2 \mathrm{~V}$ & 30.1 \\
\hline & & & $3 \mathrm{~V}$ & 21.3 \\
\hline & \multirow{2}{*}{ OXY 72-3 } & \multirow{2}{*}{4394.5} & $1 \mathrm{~V}$ & 29.7 \\
\hline & & & $5 \mathrm{~V}$ & 40.3 \\
\hline
\end{tabular}

553

554

555

556

557

558

559

Table. 4. Confining pressures used during four multi-stage triaxial shear tests, MPa.

\begin{tabular}{|c|c|c|c|c|}
\hline $\begin{array}{l}\text { Stages } \\
\text { Stage }\end{array}$ & $\begin{array}{c}\text { GEO N-1-4013 } \\
(1 \mathrm{H})\end{array}$ & $\begin{array}{c}\text { GEO N-1-4348 } \\
(2 \mathrm{H})\end{array}$ & $\begin{array}{c}\text { GEO N-2-4019 } \\
(2 \mathrm{H})\end{array}$ & $\begin{array}{c}\text { OXY-4395 } \\
(5 \mathrm{~V})\end{array}$ \\
\hline 1 & 1.378 & 1.378 & 1.378 & 1.378 \\
\hline 2 & 3.45 & 3.45 & 3.45 & 3.45 \\
\hline 3 & 5.03 & 5.03 & 5.03 & 5.03 \\
\hline 4 & 7.03 & 7.03 & 7.03 & 7.03 \\
\hline 5 & 10 & 10 & 10 & 10 \\
\hline 6 & 22.06 & 22.06 & 22.06 & 22.06 \\
\hline 7 & 37.92 & 37.92 & 37.92 & 37.92 \\
\hline
\end{tabular}

Table. 5. Summary of frictional angles and Barton's model parameters.

\begin{tabular}{|c|c|c|c|c|c|c|c|c|}
\hline Sample ID & $\phi$ & $\phi_{b}+i\left(\sigma_{\mathrm{n}}=0\right)$ & $\phi_{b}\left(\phi_{r}\right)$ & $i$ & JRC & $\begin{array}{c}\text { JRC } \\
\text { degree }\end{array}$ & JCS MPa & UCS inferred MPa \\
\hline GEO N-1-4013-1H & $45.1^{\circ}$ & $66.7^{\circ}$ & $38.5^{\circ}$ & $28.3^{\circ}$ & 0.236 & 13.52 & 188.8 & 122.0 \\
\hline GEO N-1-4348-2H & $21.3^{\circ}$ & $60.0^{\circ}$ & $19.2^{\circ}$ & $40.8^{\circ}$ & 0.353 & 20.00 & 170.2 & 74.6 \\
\hline GEO N-2-4019-2H & $33.8^{\circ}$ & $47.6^{\circ}$ & $28.5^{\circ}$ & $19.1^{\circ}$ & 0.127 & 7.28 & 181.3 & 57.0 \\
\hline OXY-4395-5V & $40.7^{\circ}$ & $53.7^{\circ}$ & $32.9^{\circ}$ & $20.8^{\circ}$ & 0.372 & 20.00 & 196.9 & 119.0 \\
\hline
\end{tabular}


Table 6. Summary of stiffness values.

\begin{tabular}{|c|c|c|c|c|c|}
\hline $\mathrm{Pc}, \mathrm{MPa}(\mathrm{psi})$ & $\mathrm{K}_{\mathrm{n}} \& \mathrm{~K}_{\mathrm{s}}(\mathrm{MPa} / \mathrm{mm})$ & GEO N-1-4013-1H & GEO N-1-4348-2H & GEO N-2-4019.5-2H & OXY-4395- 5V \\
\hline \multirow{2}{*}{$3.5(500)$} & $\mathrm{K}_{\mathrm{n}}$ & 81.46 & - & - & - \\
\hline & $\mathrm{K}_{\mathrm{s}}$ & 60.35 & - & - & - \\
\hline \multirow{2}{*}{$10.34(1500)$} & $\mathrm{K}_{\mathrm{n}}$ & 162.71 & 65.41 & 129.49 & 141.18 \\
\hline & $\mathrm{K}_{\mathrm{s}}$ & 125.07 & 32.96 & 59.50 & 88.74 \\
\hline \multirow{2}{*}{$31.0(4500)$} & $\frac{\mathrm{K}_{\mathrm{n}}}{V}$ & - & 114.30 & 218.71 & 217.93 \\
\hline & $\mathrm{K}_{\mathrm{s}}$ & - & 58.86 & 146.57 & 136.56 \\
\hline
\end{tabular}

561

562

563 Table 7. Permeability before and after the rock failure measured at an effective confining pressure of 4.83-6.2 MPa.

\begin{tabular}{|c|c|c|c|c|}
\hline Well & Depth, ft & \multicolumn{2}{|c|}{ Plug ID } & Permeability $(\mu \mathrm{D})$ \\
\hline \multirow{11}{*}{ GEO N-1 } & \multirow{4}{*}{4013} & \multirow{2}{*}{$1 \mathrm{H}$} & Before & 0.168 \\
\hline & & & After & 56300 \\
\hline & & \multirow{2}{*}{$1 \mathrm{~V}$} & Before & 0.6 \\
\hline & & & After & 0.434 \\
\hline & \multirow{7}{*}{4348} & \multirow{2}{*}{$2 \mathrm{H}$} & Before & 44 \\
\hline & & & After & 2.99 \\
\hline & & $2 \mathrm{~V}$ & Before & 47 \\
\hline & & \multirow{2}{*}{$3 \mathrm{~V}$} & Before & 7.98 \\
\hline & & & After & 0.182 \\
\hline & & \multirow{2}{*}{$4 \mathrm{~V}$} & Before & 0.00122 \\
\hline & & & After & 0.832 \\
\hline \multirow{3}{*}{ GEO N-2 } & 4219.5 & $2 \mathrm{H}$ & Before & 0.00296 \\
\hline & \multirow{2}{*}{4281} & $1 \mathrm{~V}$ & & - \\
\hline & & $3 \mathrm{~V}$ & Before & 0.074 \\
\hline \multirow{5}{*}{ OXY 72-3 } & \multirow{5}{*}{4394.5} & $1 \mathrm{~V}$ & Before & 0.00458 \\
\hline & & $4 \mathrm{~V}$ & Before & 0.00697 \\
\hline & & $5 \mathrm{~V}$ & Before & 0.00452 \\
\hline & & \multirow{2}{*}{$6 \mathrm{~V}$} & Before & 0.00312 \\
\hline & & & After & 0.512 \\
\hline
\end{tabular}

564

565 


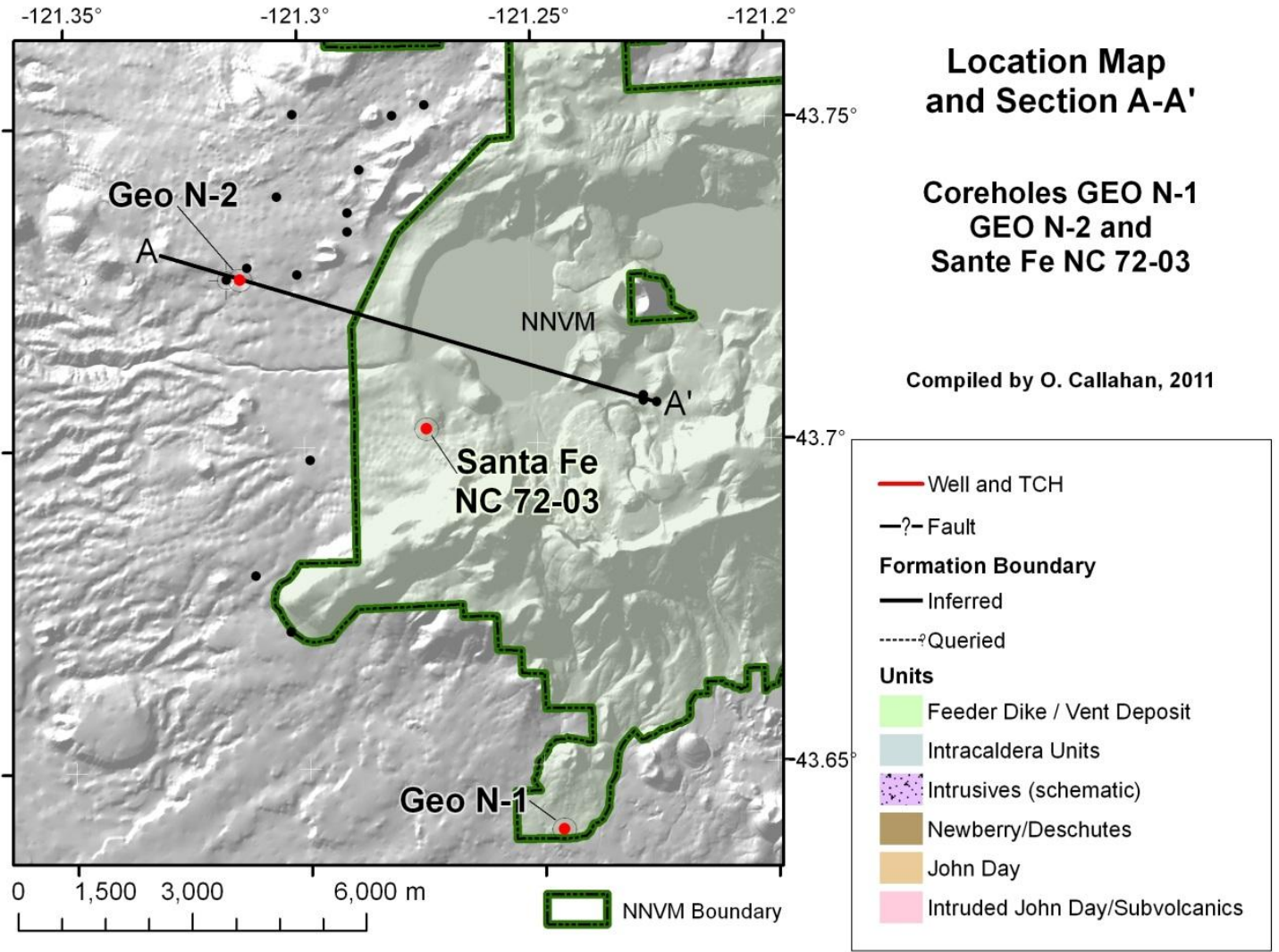

567

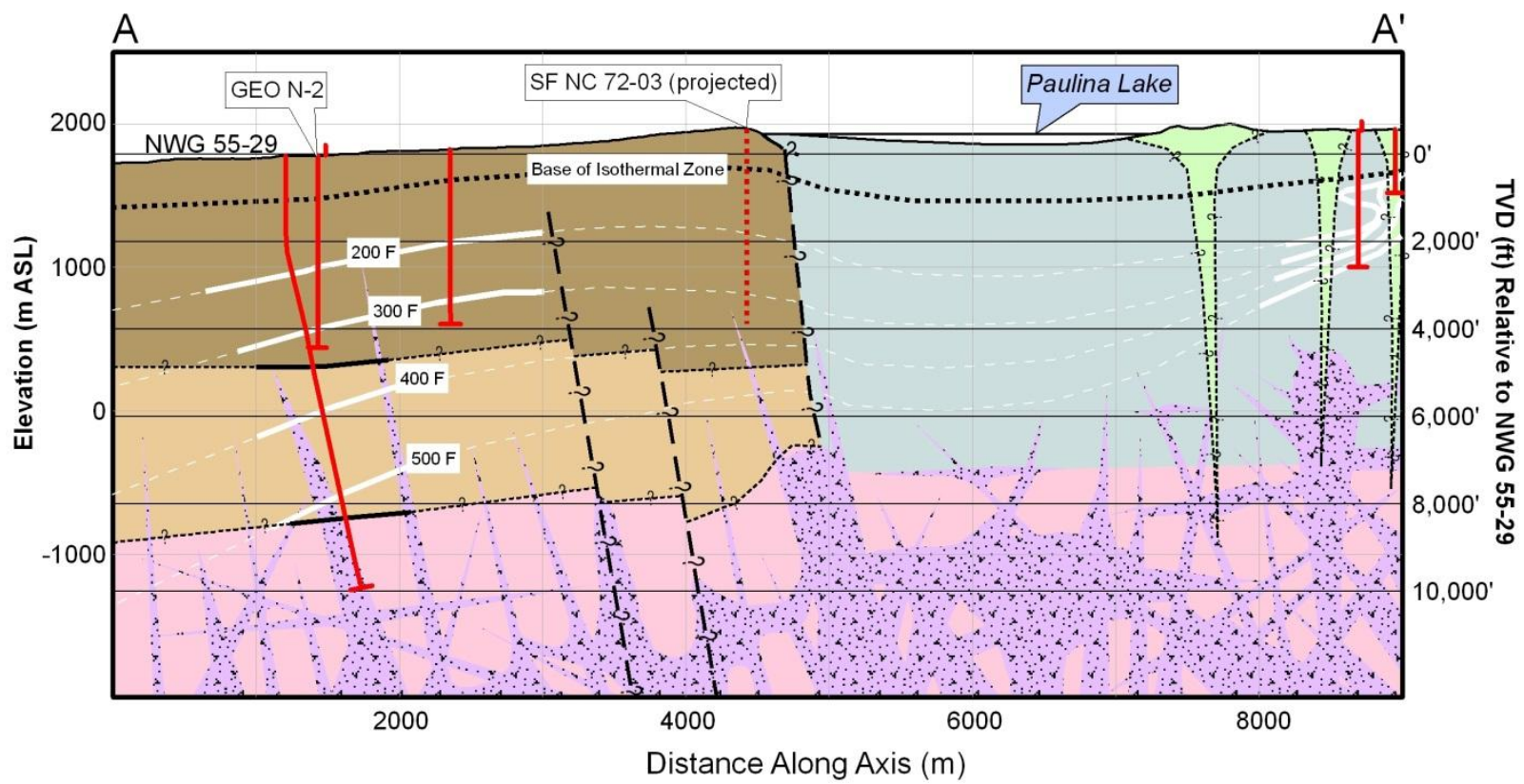

Figure 1. Map showing locations of geothermal exploration drill holes at Newberry volcano (After Callahan, 2011). 
573

574

575
576

577

578
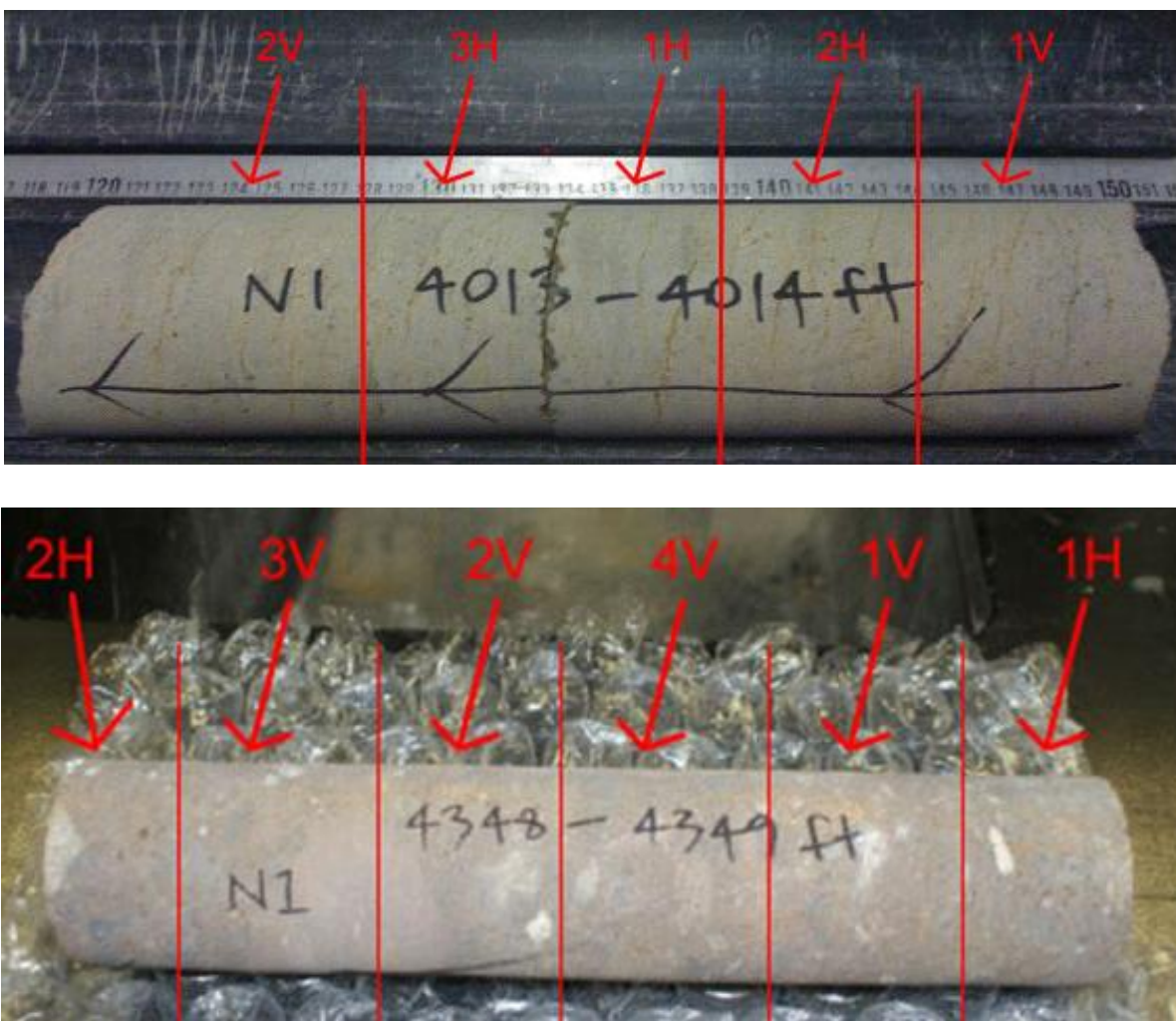

Figure 2. Cored from GEO-N1 showing the location of 1" diameter, 2" long plugs (V: vertical, H: horizontal) used in geomechanical testing.
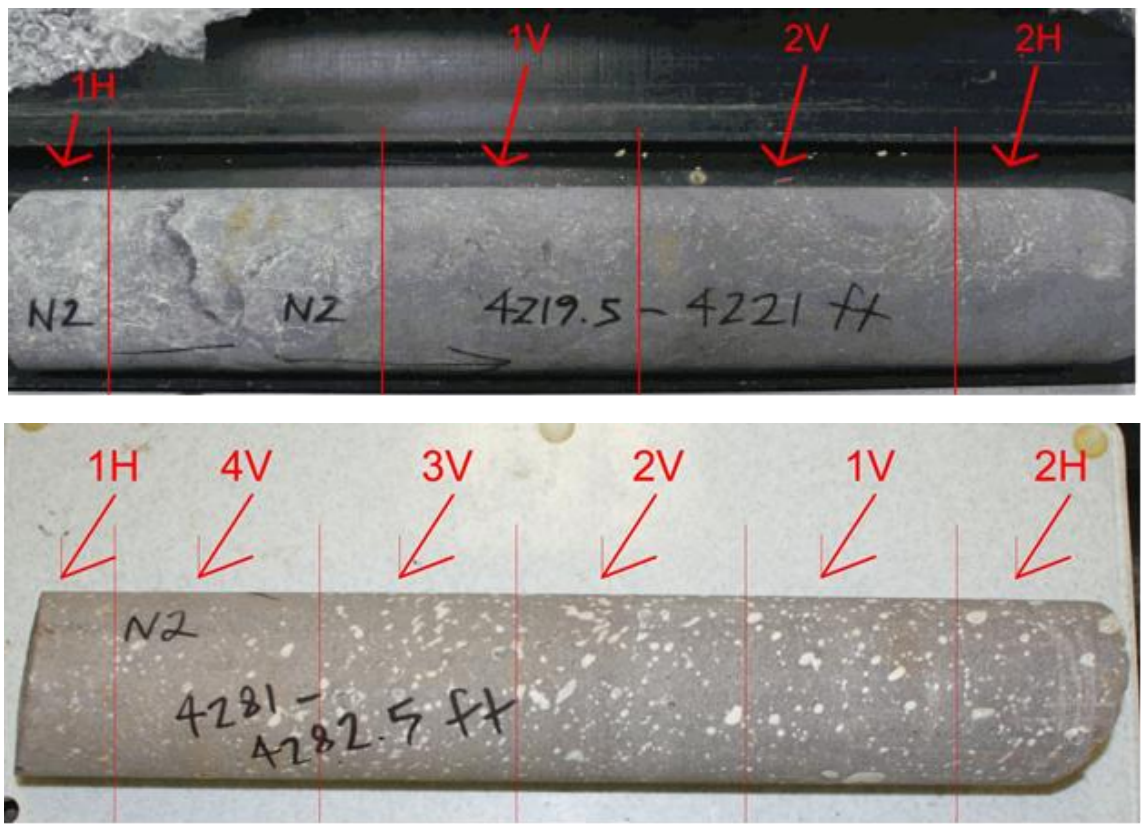

Figure 3. Cored from GEO-N2 showing the location of 1" diameter, 2" long plugs (v: vertical, H: horizontal) used in geomechanical testing. 


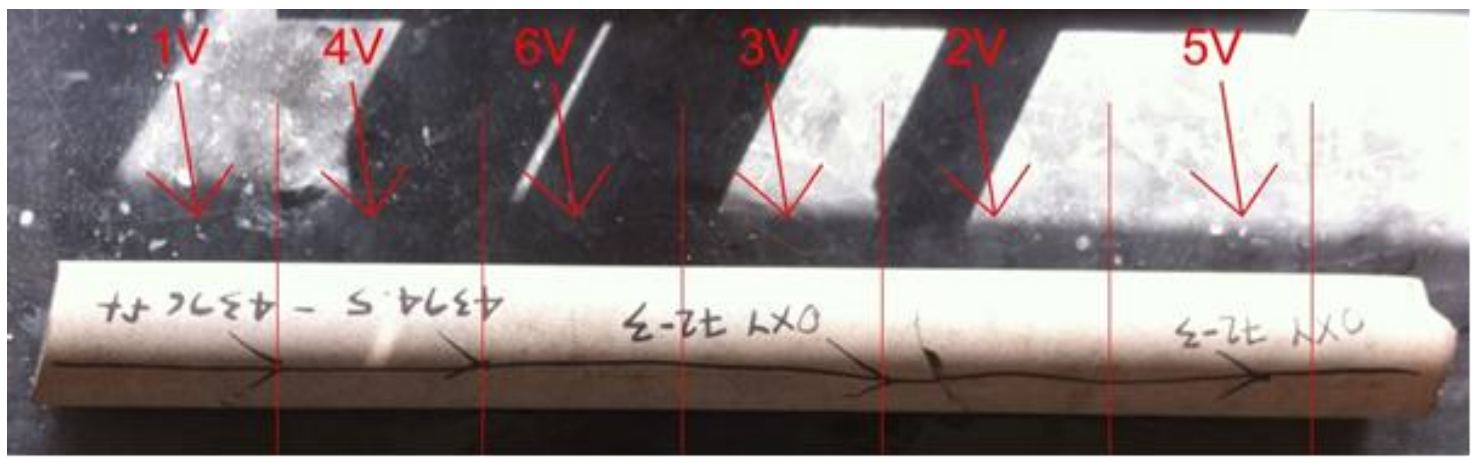

Figure 4. Cored from OXY 72-3showing the location of 1" diameter, 2" long plugs (v: vertical, H: horizontal) used 586 in geomechanical testing.
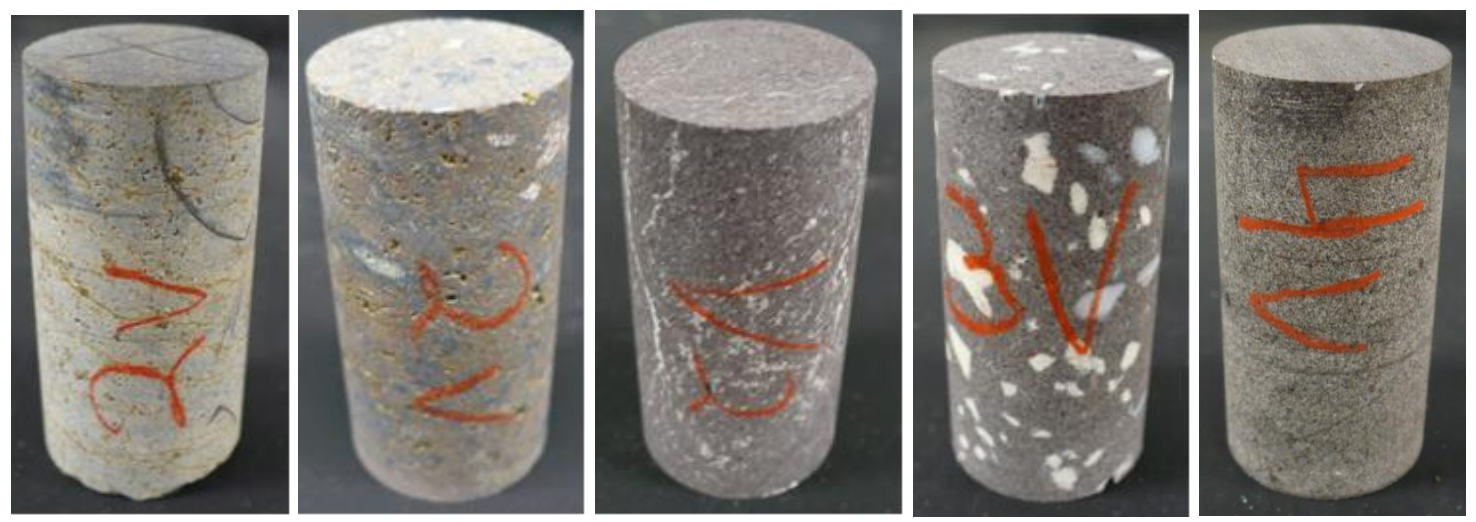

Figure 5. Plugs from GEO-N1 (4013 ft), GEO-N1 (4348) GEO-N2 (4219), GEON2-N2 4281 and OXY (4396) with visible differences in texture. 

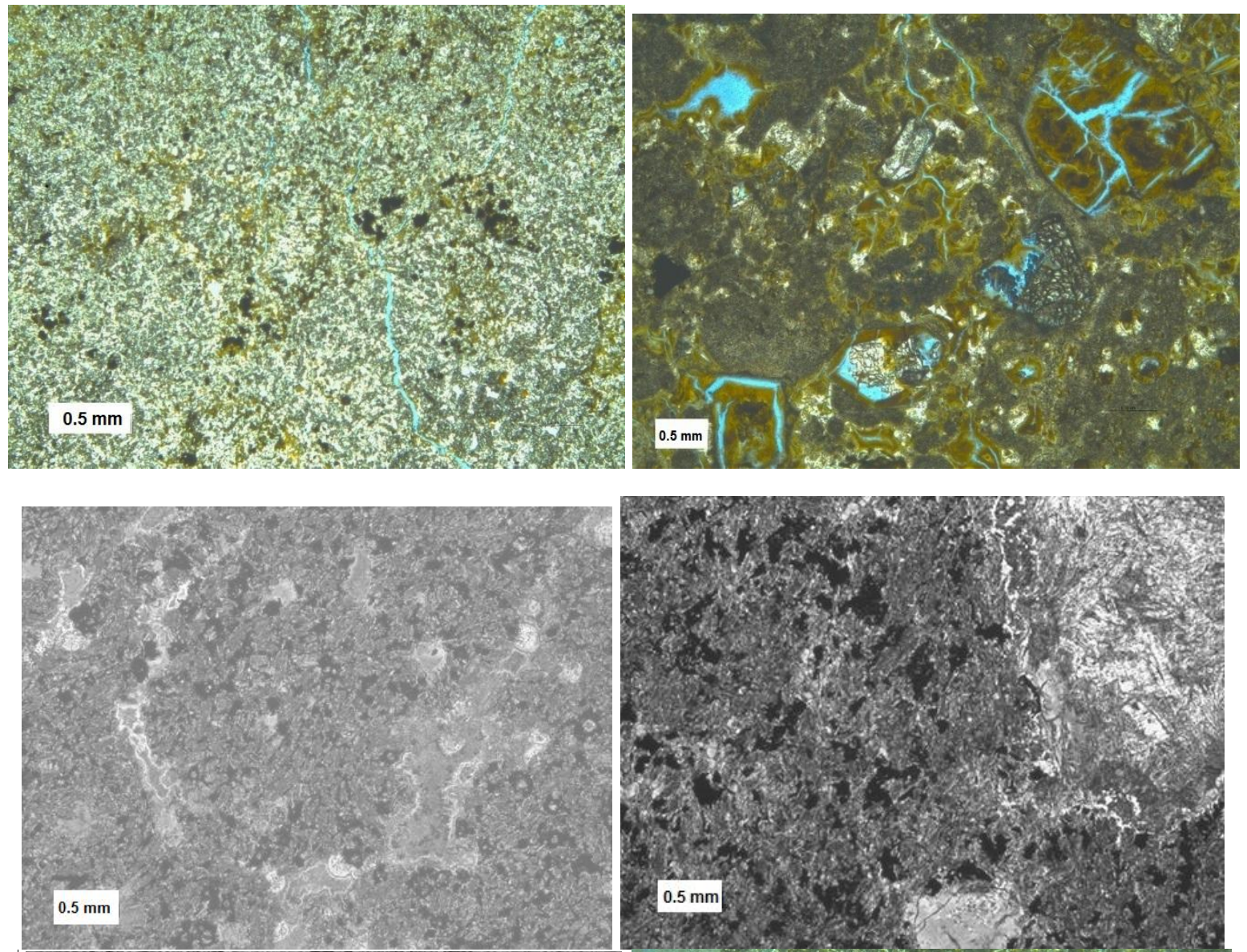

604
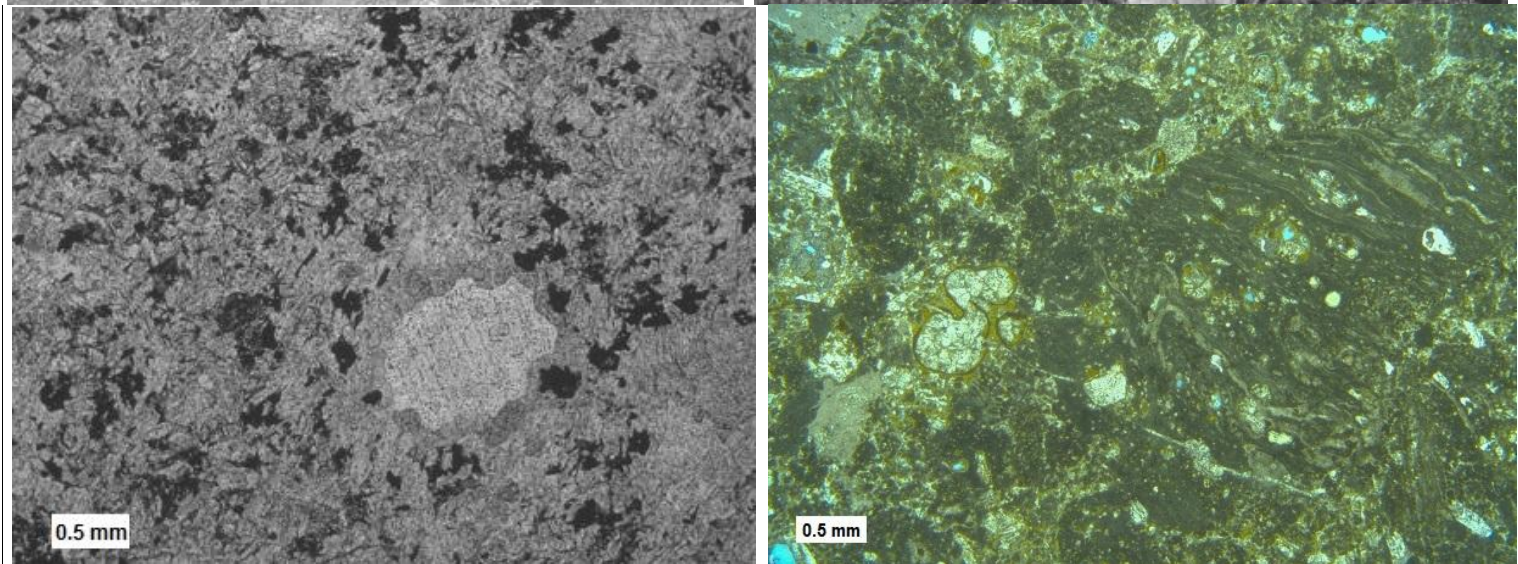

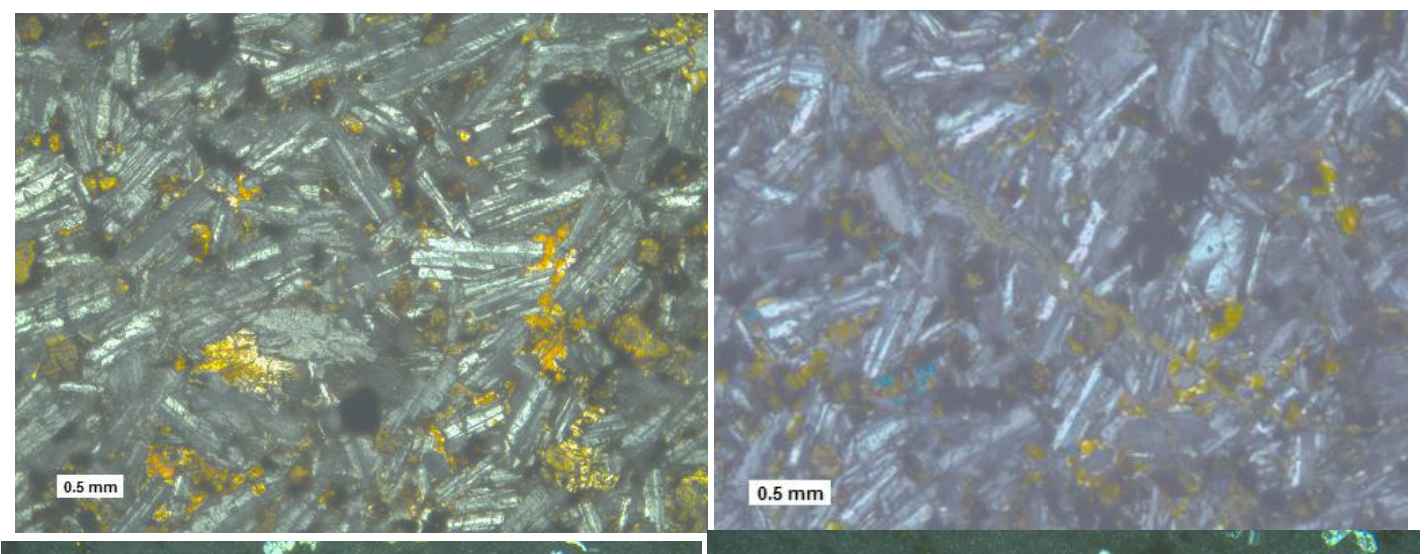

607
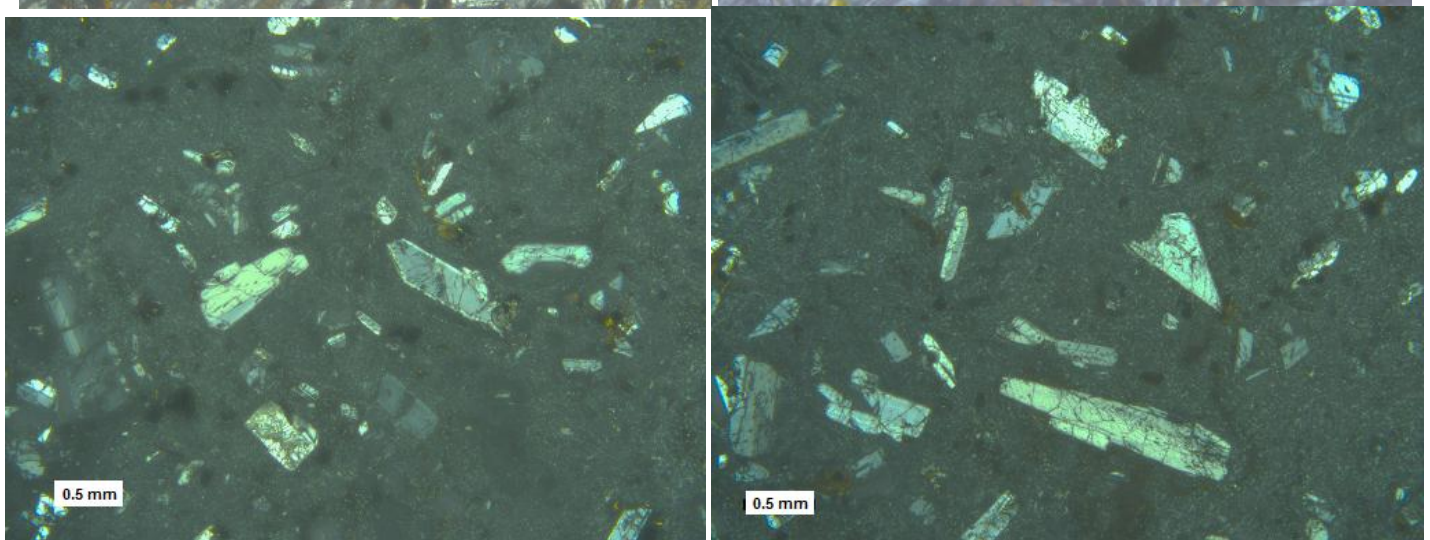

608

Figure 6. Petrographic images of the core plugs: row 1: N1-4348-1H (left), N1-4348-1H (right); row 2: N2-4219.52H ( left), N2-4281-1V (right); row 3: N2-4281-1H (left) N1-4348-2V (right); row 4: Oxy 72-3-4394.5-5V (left) Oxy 72-3-4394.5-4V (right); row 5: N1-4013-1H (left), N1-4013-1V (right).

611 

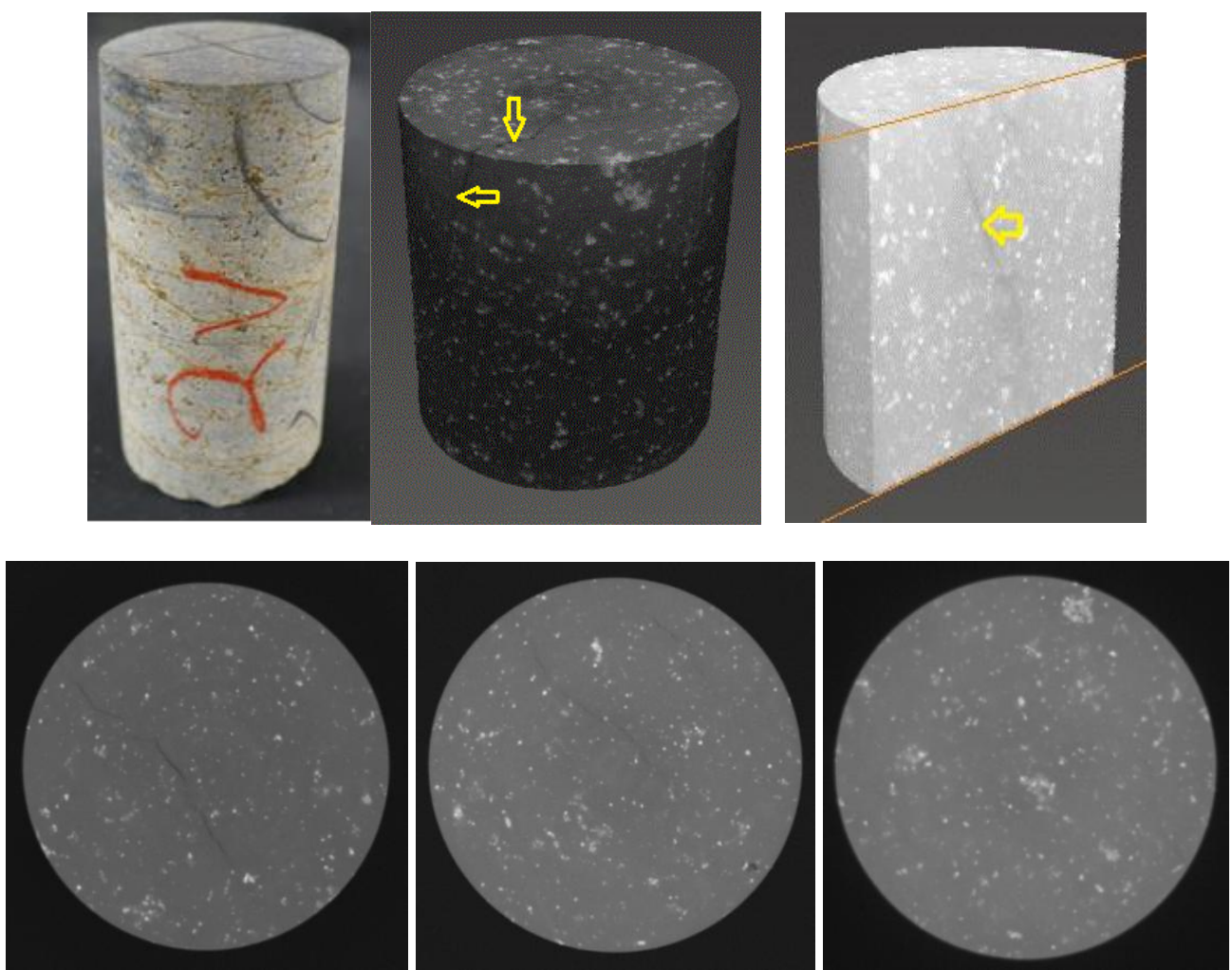

621 Figure 7. Sample plug N1-4013-2V and its 3D CT images before triaxial compression test. A vertical 622 fracture is identified through CT images; it runs through the plug and its trace is visible on the top of the 623 sample. This, and other fracture are completely filled with alteration minerals (plagioclase, quartz, and 624 calcite etc.) The last row shows three CT slices $(292,457,872)$ out of 1000 perpendicular slices from top 625 to the bottom of the plug, perpendicular to its axis. Intermittent pores are present in the matrix (black 626 spots) as is a hairline crack. Rock effective porosity is around $2-4 \%$. 

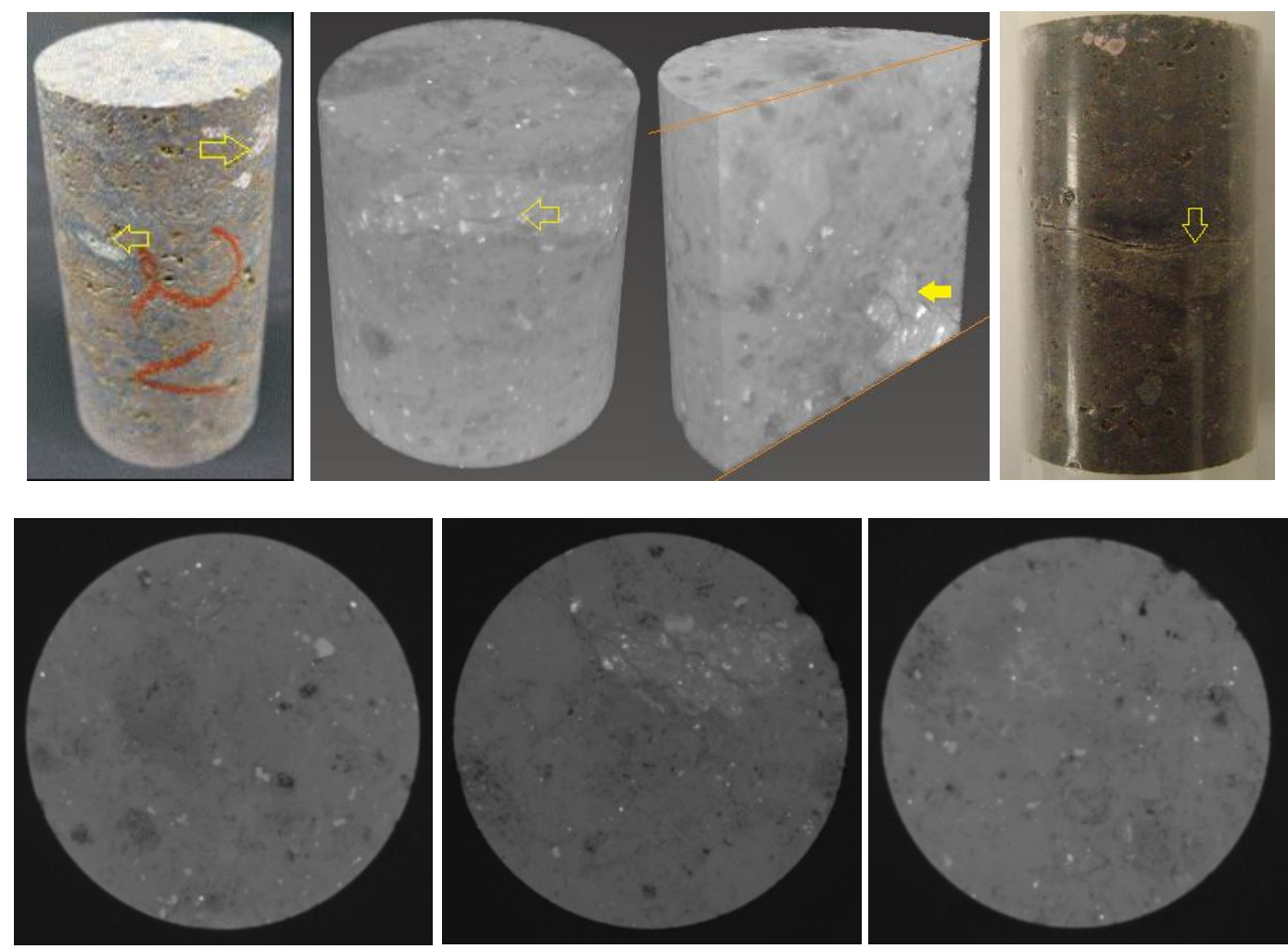

637 Figure 8. Sample plug N1-4348-2V and its 3D CT images before triaxial compression test. As can be 638 seen, the rock is very heterogeneous containing different grains and minerals such as plagioclase, quartz, calcite, smectite-illite, pyrite, and iron-oxide. The CT images show several small pre-existing fractures localized within some of the large mineral grains (yellow arrows) embedded in a matrix of clay minerals.

641 The picture on the right shows the sample after testing with a sub-horizontal failure plane developed in 642 the midsection. CT slices 200, 425, 830 are shown in the bottom row. The micro-cracks within the 643 embedded large grain (bottom row, middle image) are visible. These micro-cracks were also visible in 644 thin section images (Figure 6). Many large pores are also present that are not connected but do impact the 645 mechanical response of the rock. The vesicle diameter is in $1 \mu \mathrm{m}$ to $0.3 \mathrm{~mm}$ range. The pore are dominated by tiny vesicles, however, the images also show micro-pores within the fine-grained matrix. The effective porosity is relatively high, in the range of $12-16 \%$. 

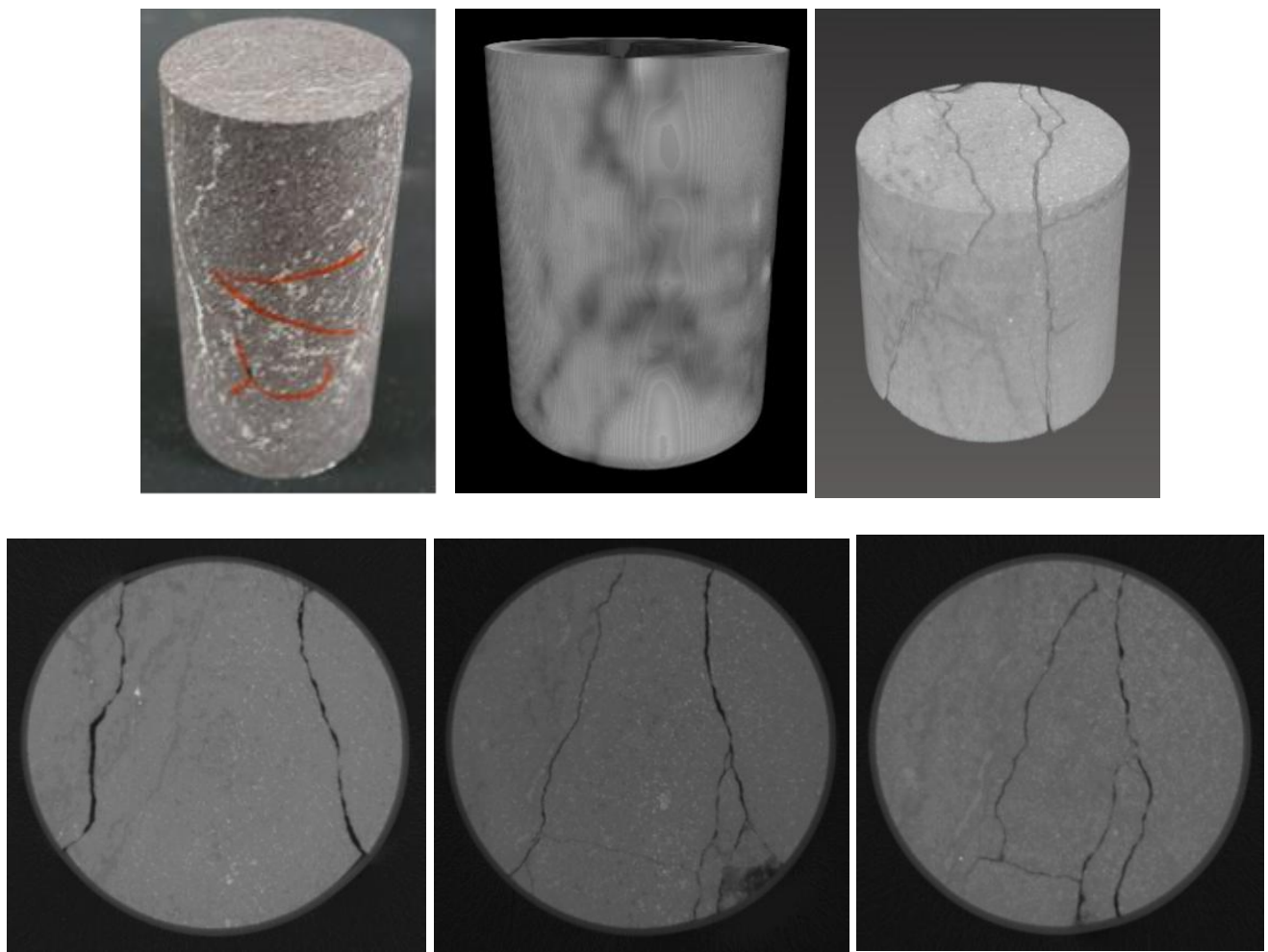

653 Figure 9. Sample plug N2-4219-2V and a 3D CT images of core before (top left) and after triaxial 654 compression test. Multiple vertical and horizonal healed fractures are present in the core plug. Horizontal 655 fractured do not cut through the sample. Fractures are completely fllled with secondary minerals of 656 calcite, dolomite, and quartz (based on XRD analysis) and the core plug is completely intact (one piece) 657 before mechanical tests. CT slices 395, 659, 759 on the plug after triaxial testing is also shown. Failure 658 has developed along pre-exisitng healed crack. Porosity is relatively moderate, around $6 \%$ and is likely 659 due to cracks as the CT images do not show connected pores. 

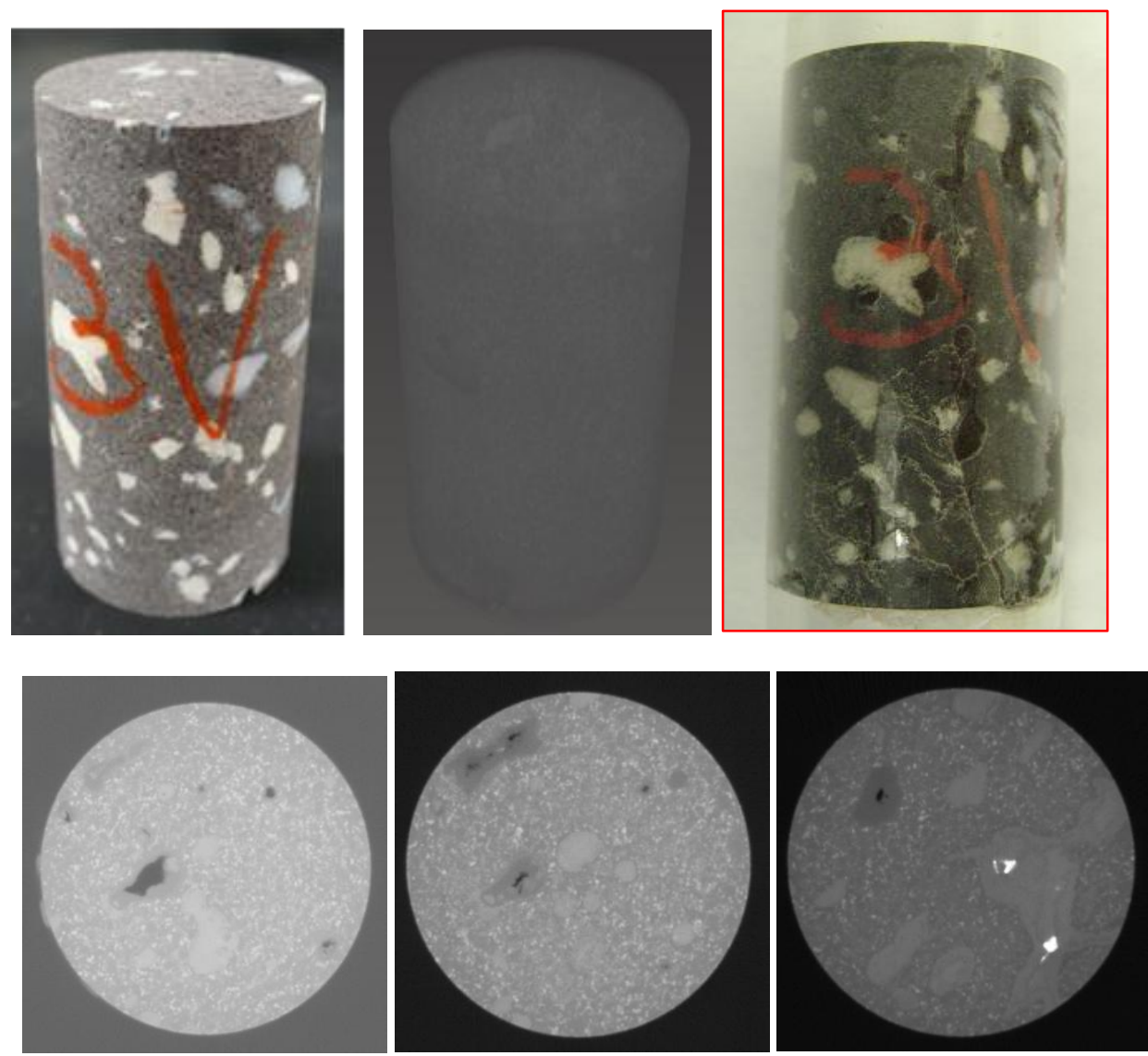

Figure 10. Sample plug N2-4281-3V and its 3D CT image before triaxial compression test. The plug contains breccia fragments (white), a few light-colored (white) fractures, and spherical to elliptical vesicles completely or partillay filled by hydrothermal alteration minerals. The picture on the right shows the plug after triaxial compression test. Fractures developed mostly in the matrix around larger grains but at times they cut through the grains. Slices 163, 175, 744 in the bottom row illustrate the change in vesicle 

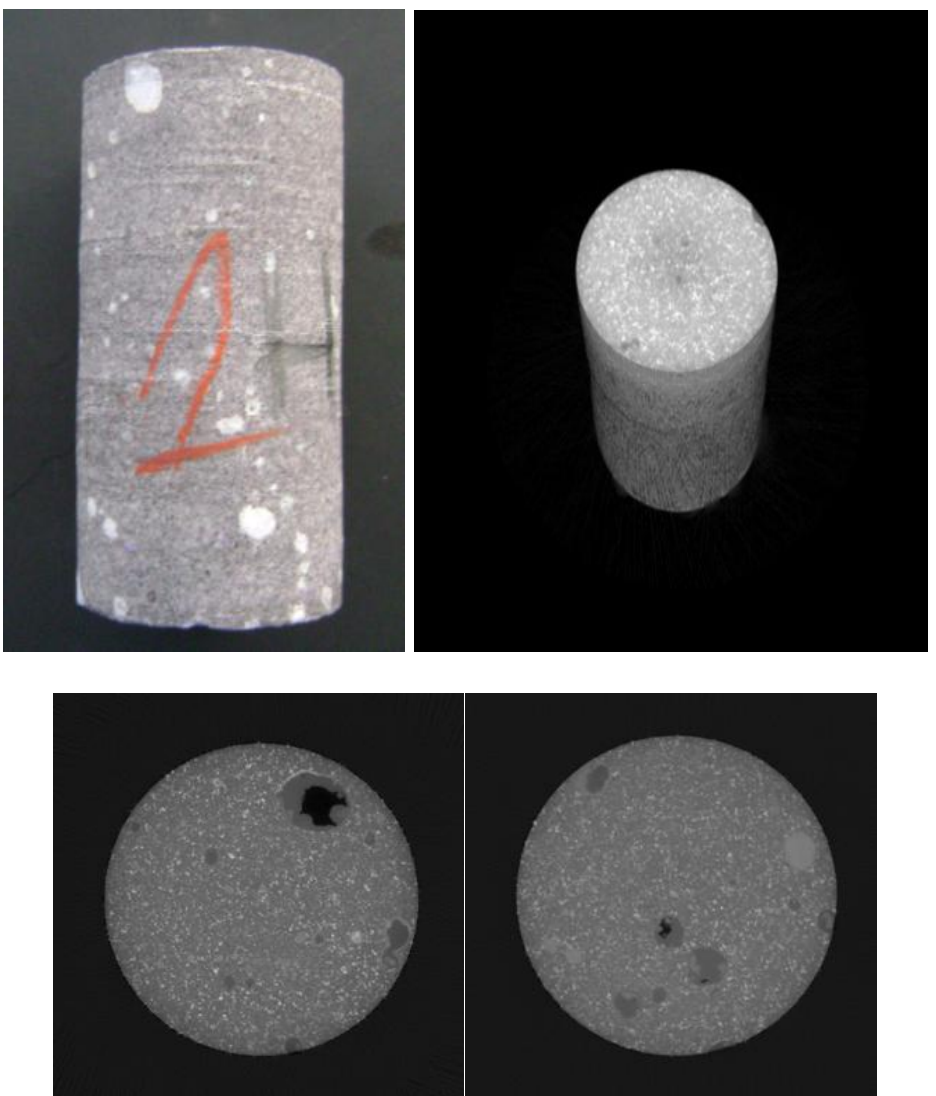

Figure 11. Sample plug N2-4281-1H and its CT images before the triaxial compression test. Two or three major vesicles are shown. There are no naturally developed fractures identified in these CT images. The image shows small size breccia fragments embedded in groundmass. Porosity of $6 \%$.
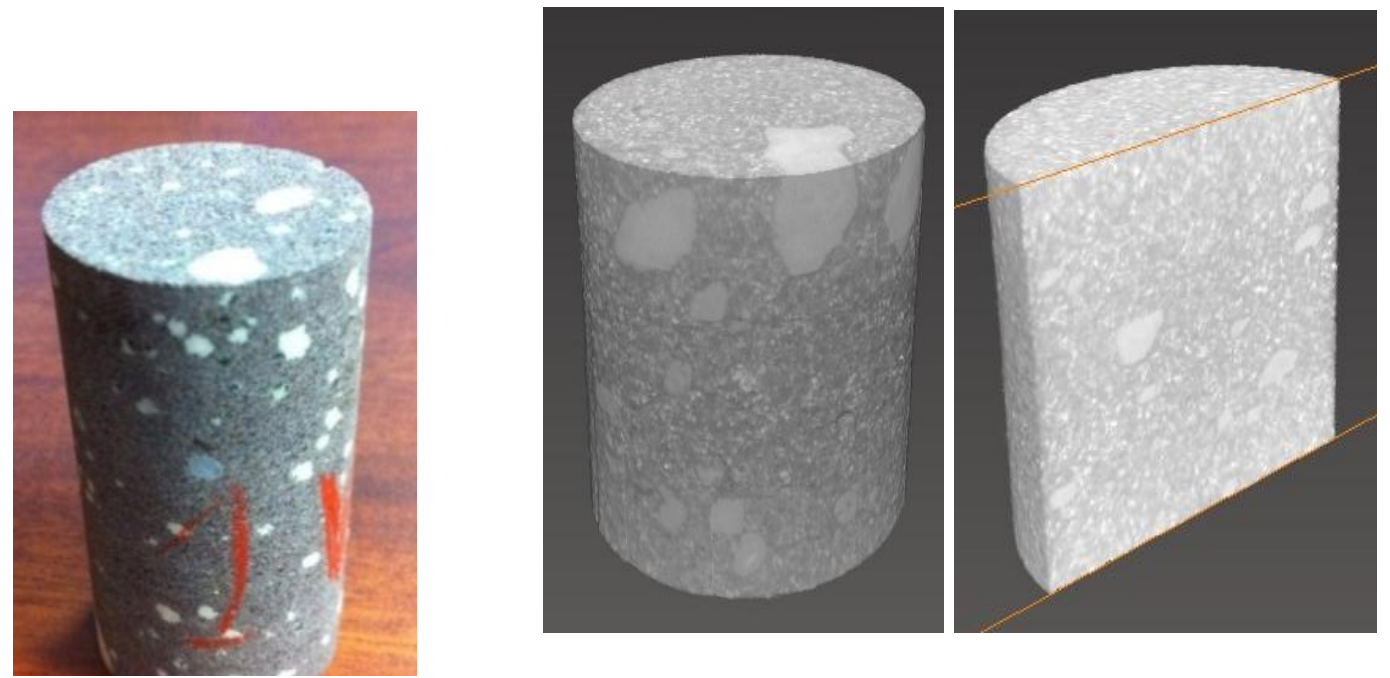

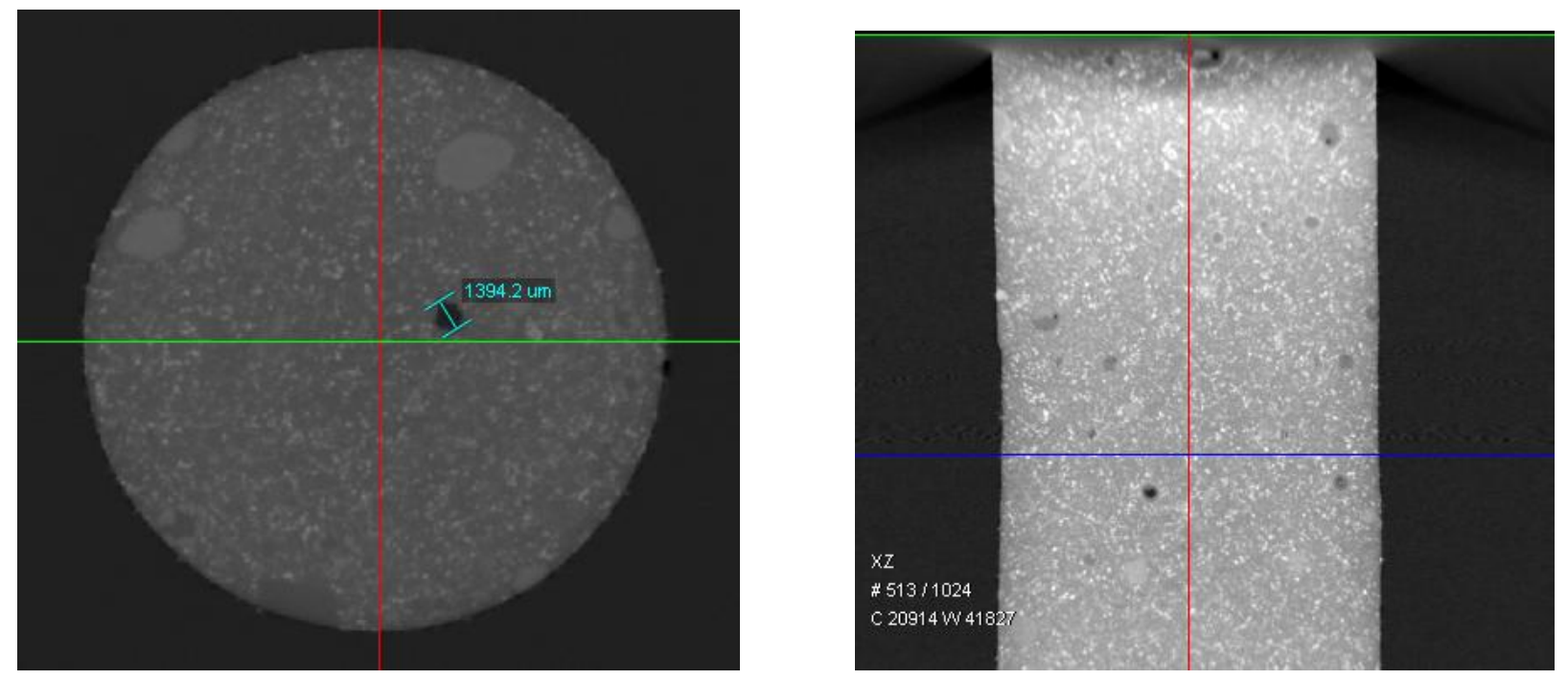

694 Figure 12. Top row: Sample N2-4281-1V and its 3D CT image before triaxial compression test.There are 695 no naturally fractures identified through these CT images. The image shows vescicles and large breccia 696 fragments embayed in groundmass. One of the largest empty vesicles is 1394.2 micrometers in diameter. 697 This is a tight rock with few unconnected vesicles and open pores. Low to moderate effective porosity of $6986 \%$.
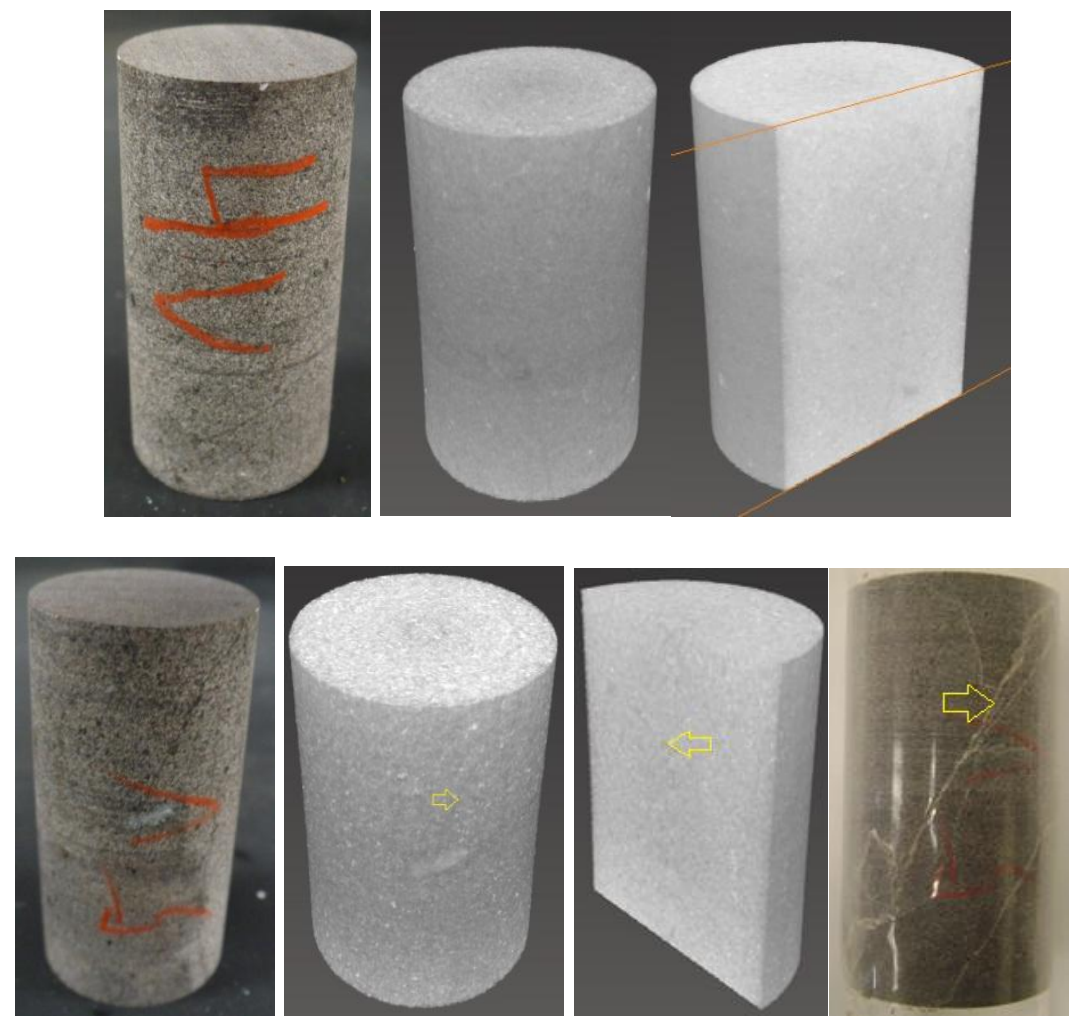
Figure 13. Core plug OXY-4V and its CT image before triaxial compression test. The images show the rock contains different types of grains, and a few pre-existing fractures. The fractures are not identified well through horizontal sectional CT images but are visible through vertical section of the CT image (arrow in yellow). This is a very tight rock with very low effective porosity of $1.4 \%$. The post-failure image is not available but the right side image in the bottom row shows another plug from the same interval $(\mathrm{OXY}-5 \mathrm{~V})$ after failure, indicating activation of multiple (healed) cracks intersecting the major fault developed in the sample.
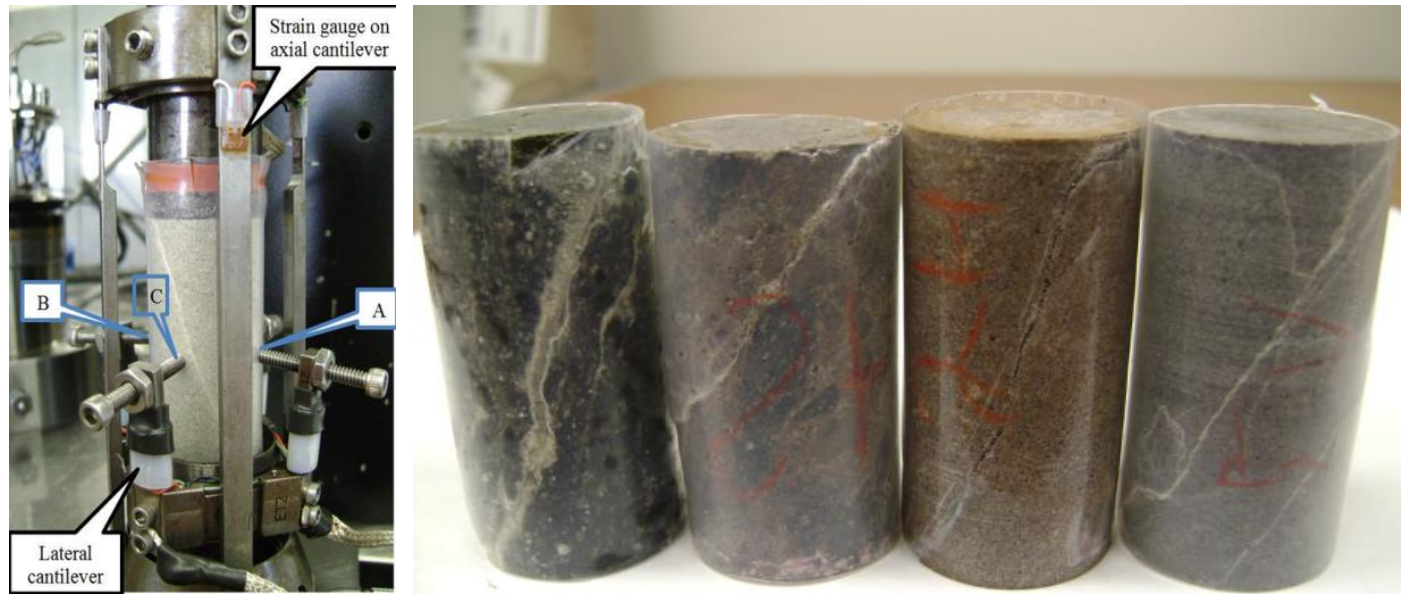

Figure 14. (a) Sample assembly for triaxial testing (left); and (b) four samples after testing (left to right: N1-40131H, N1-4348-2H, N2-4219-2H, Oxy-4394.5-4396-5V). Figure 14(b) shows that texture and fabric of each sample has influenced rock failure. Notre different failure configurations from left to right: fracture along a healed fracture; failure through clay-rich weak zone propagating around a strong inclusion; highly localized shear plane; and failure on multiple healed fractures with predominant motion along a major fracture. 


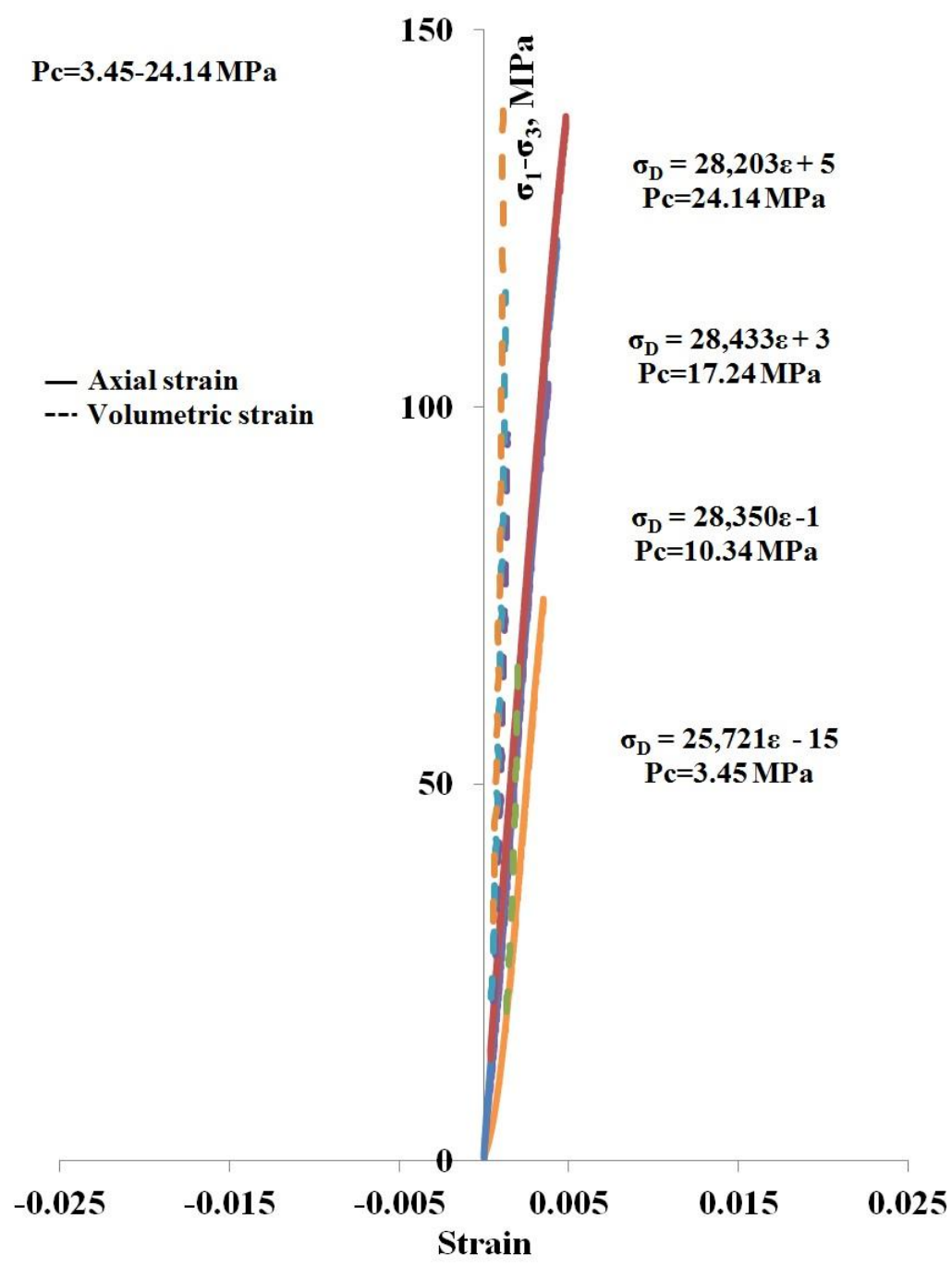

Figure 15a. Stress-strain response at 4 stages of N1-4013-1V.

732

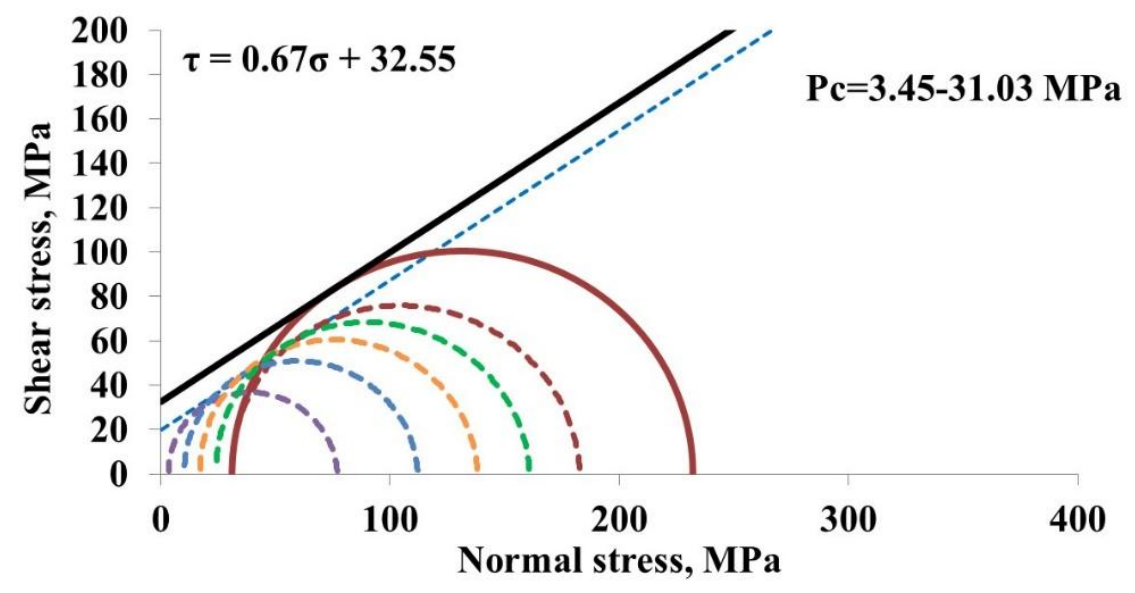

Figure 15b. Mohr circles for the stress state at the onset of dilatancy for 4 stages and the failure envelope for sample 735 N1-4013-1V. 


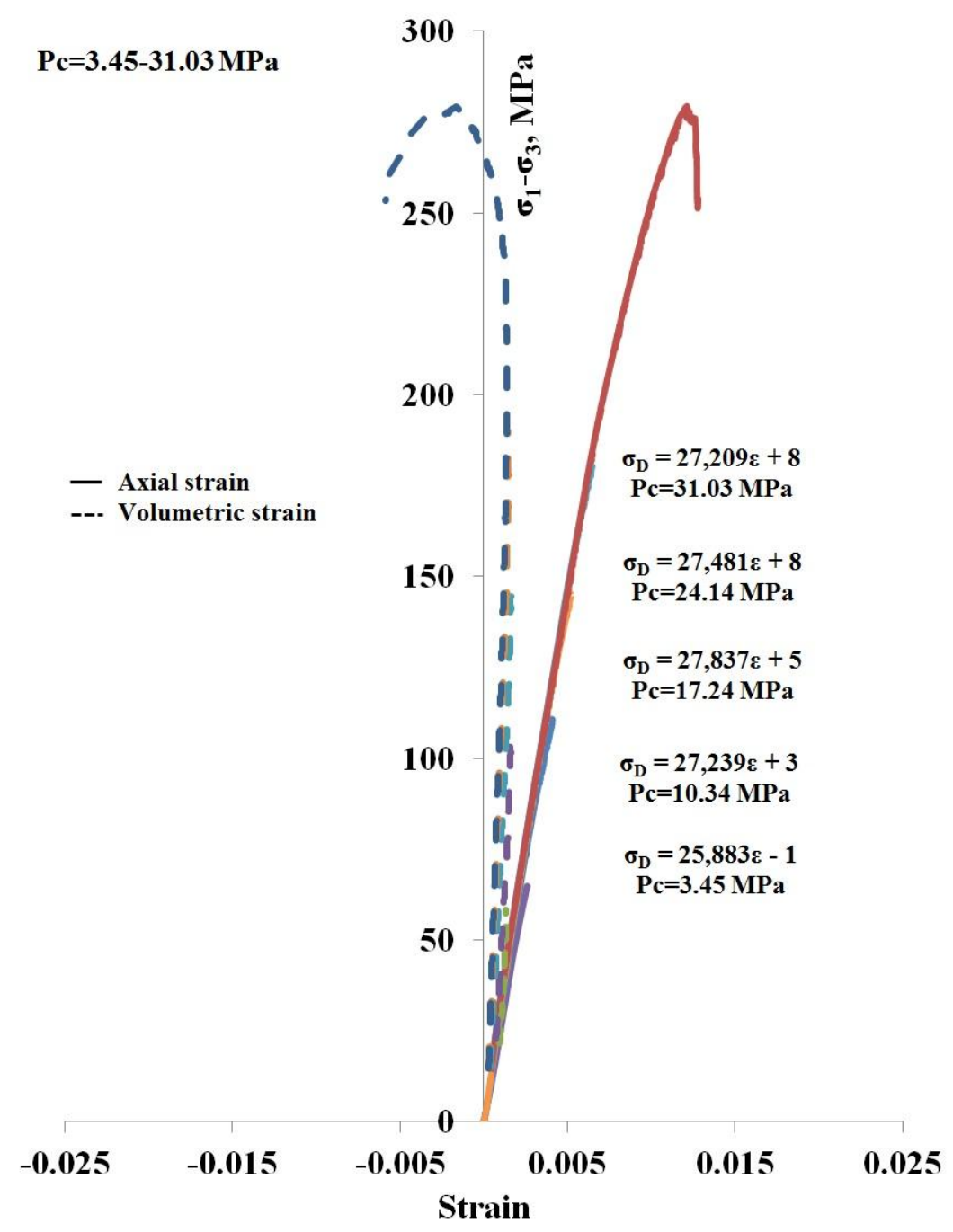

736

Figure 16a. Stress-strain response at 5 stages of N1-4013-1H.

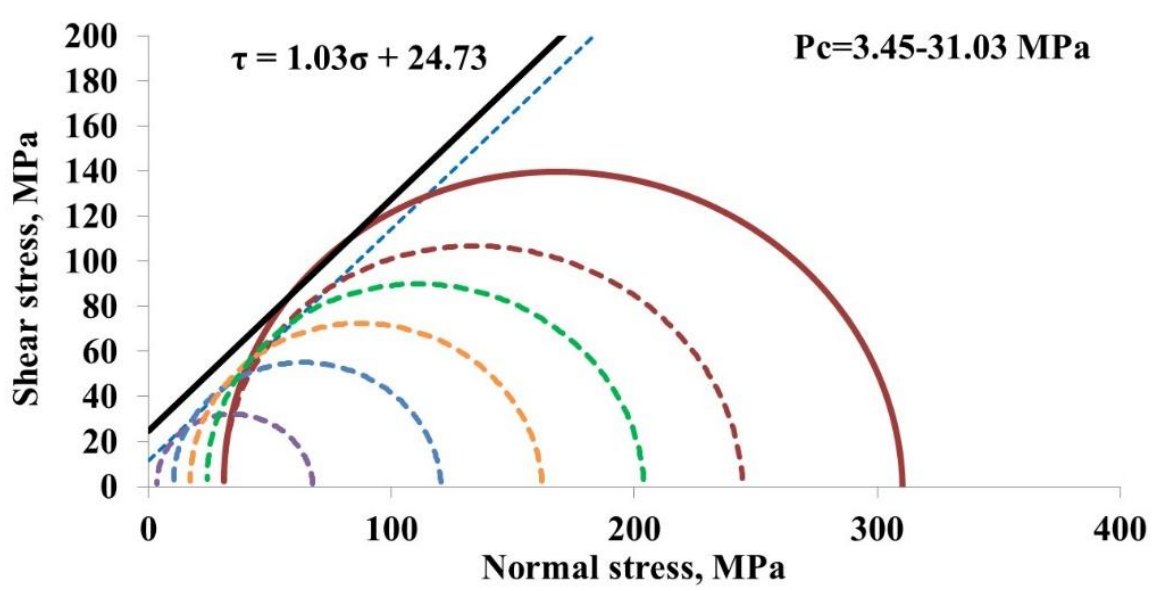

Figure 16b. Mohr circles for the stress state at the onset of dilatancy and the Mohr circles at 5 stages and failure 


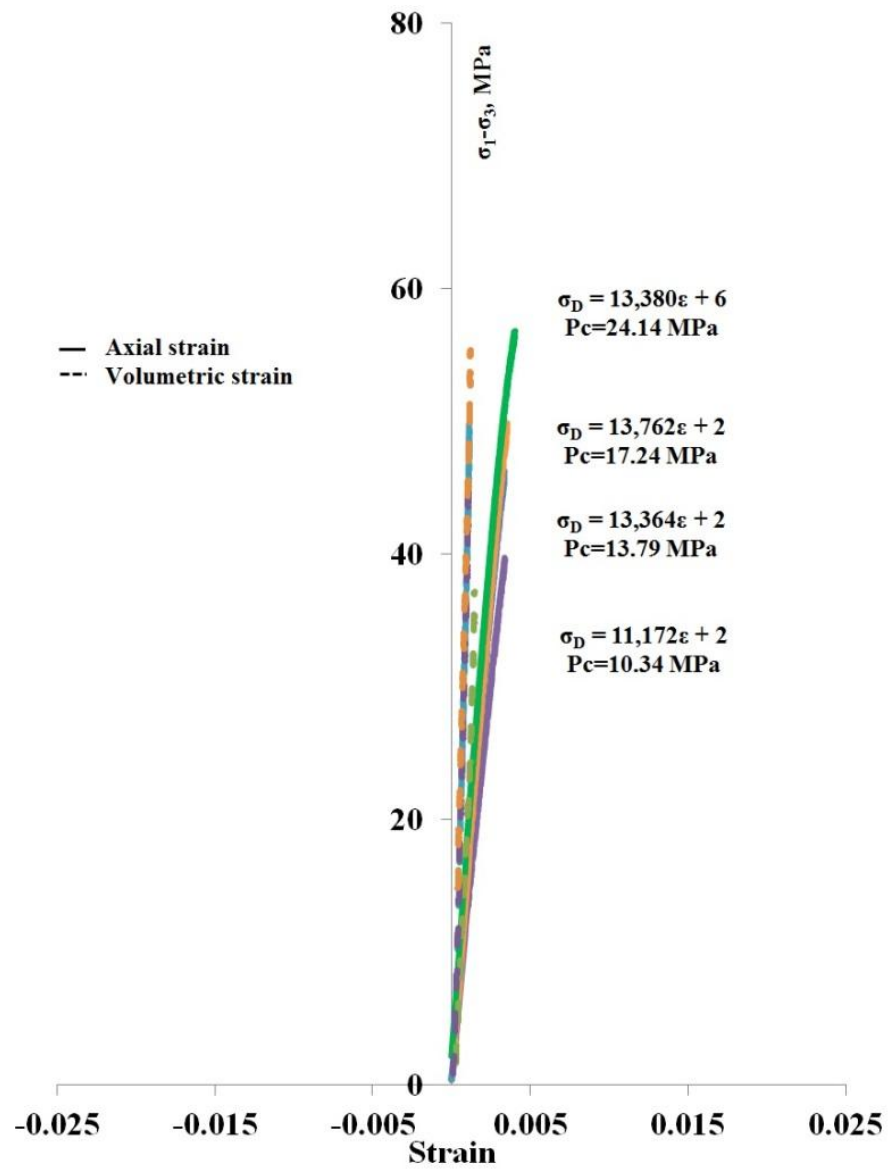

Figure 17a. Stress-strain response at 4 stages of N1-4348-2V.

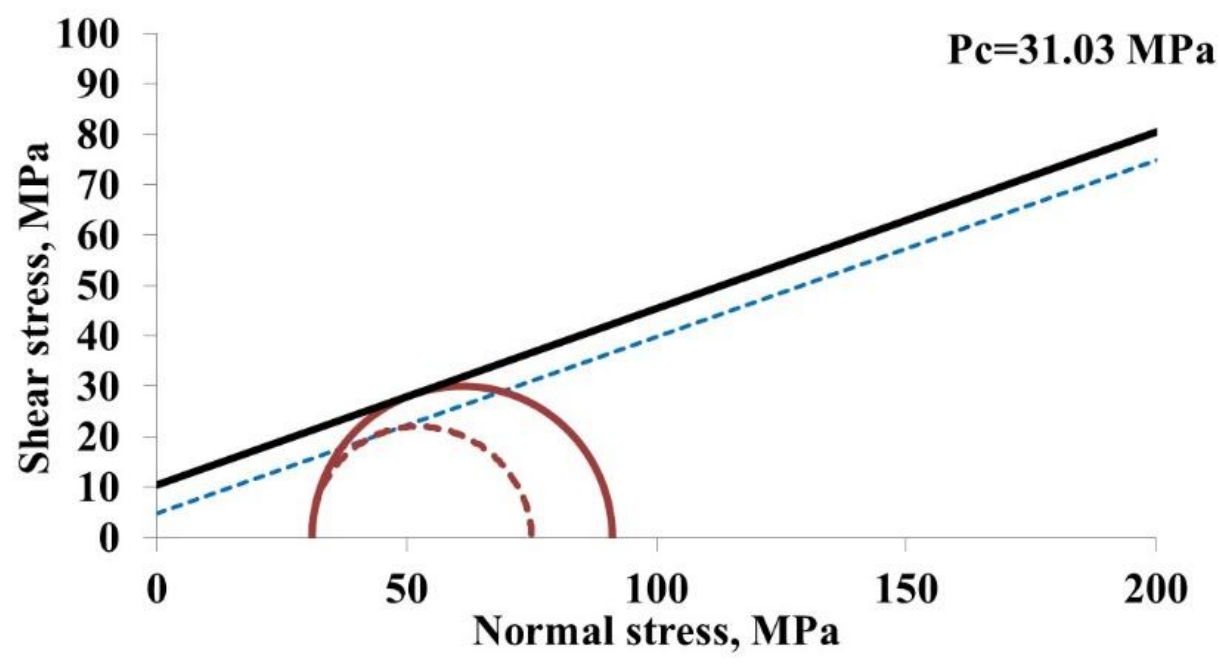

Figure 17b. Difference between the stress states at dilatancy and at failure at the fifth stage of N1-4348-2V. 


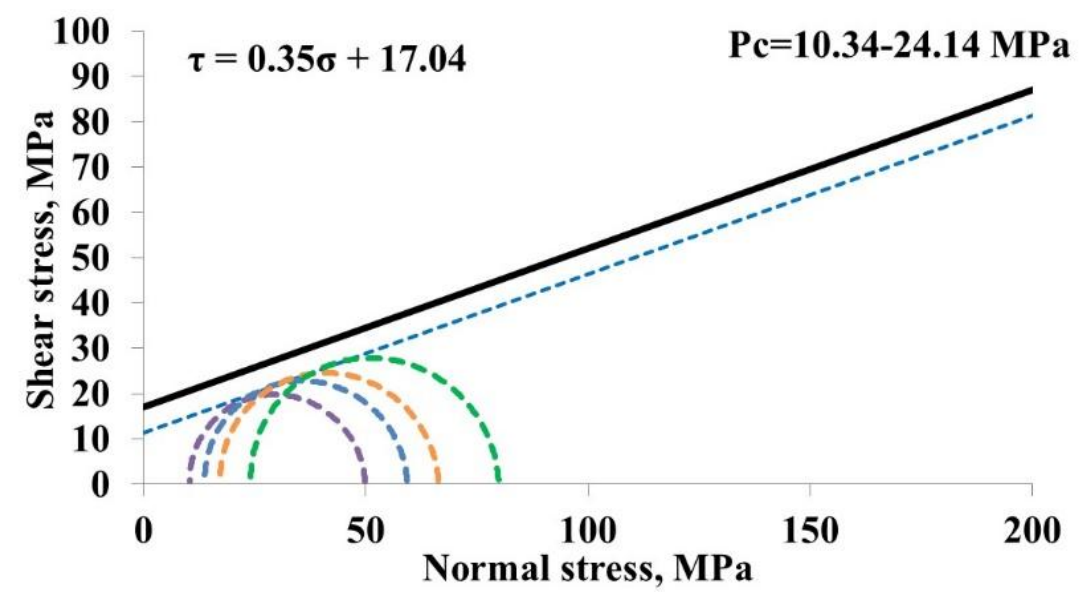

748 Figure 17c. Mohr circles for the stress state at the onset of dilatancy for 4 stages and failure envelope of the sample

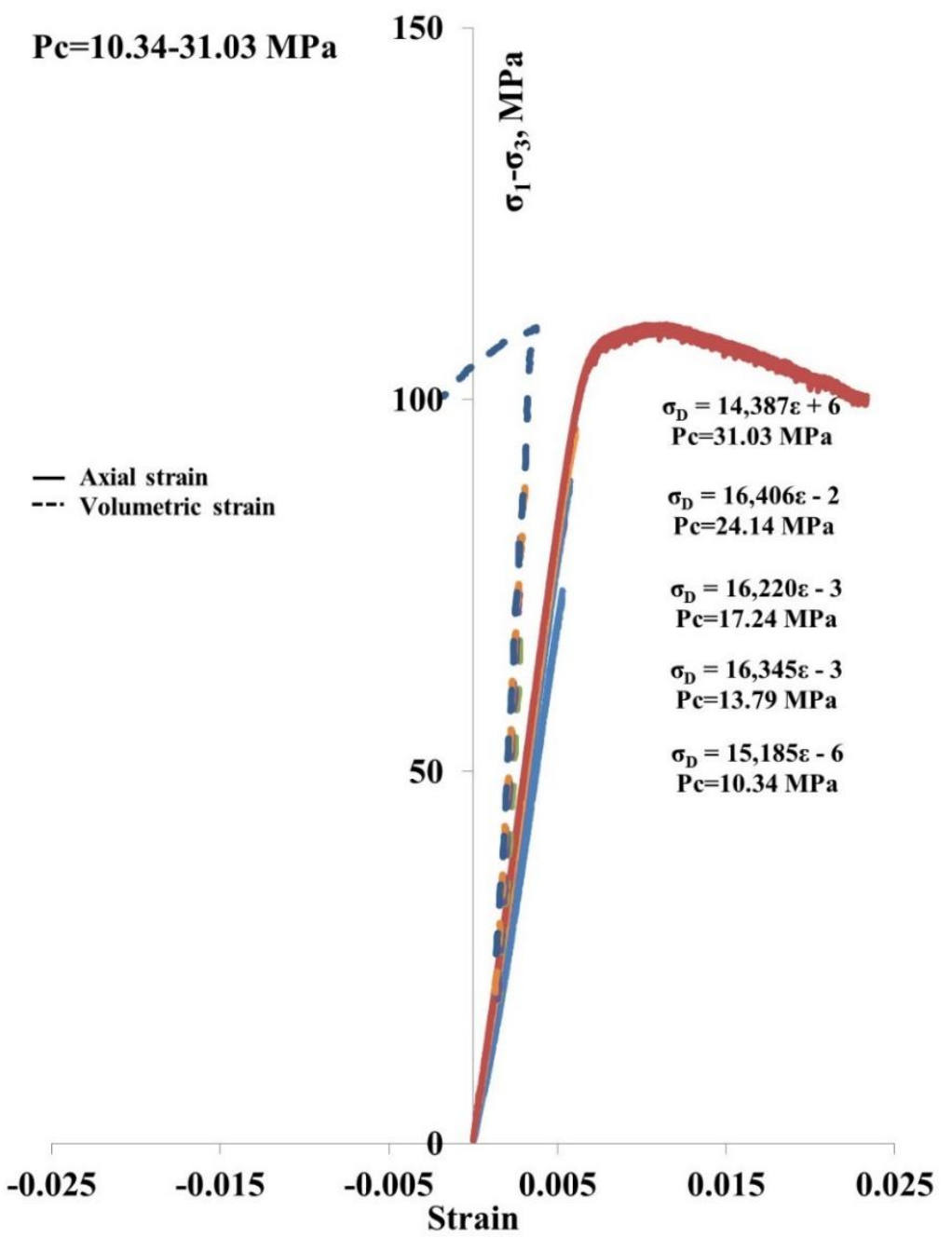

Figure 18a. Stress-strain response at 5 stages of N1-4348-2H. 


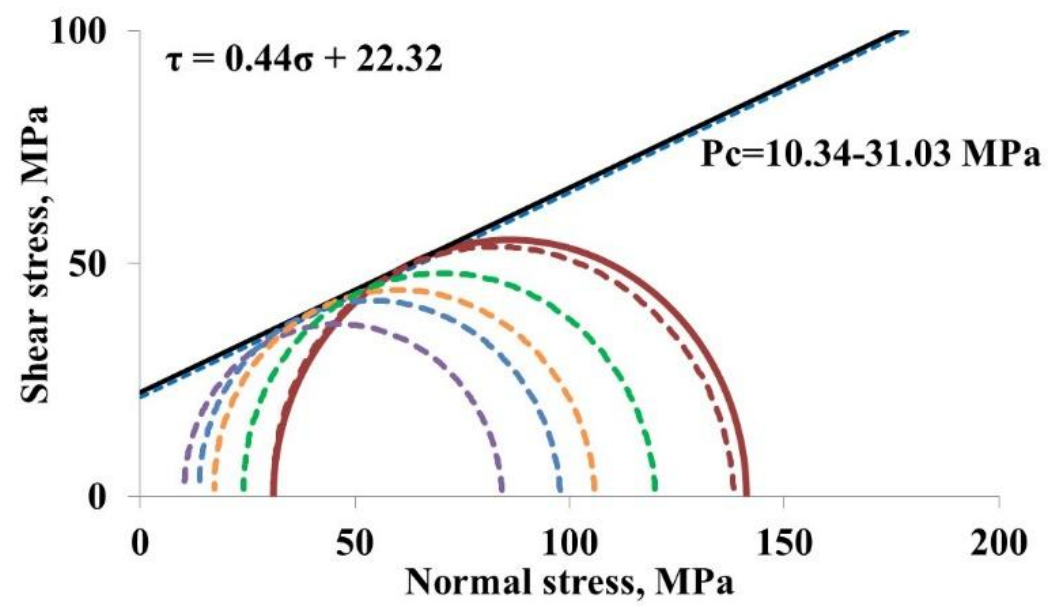

754

Figure 18b. Mohr circles for the stress state at the onset of dilatancy and at failure envelop of sample N1$4348-2 \mathrm{H}$.

757

758

759

760 


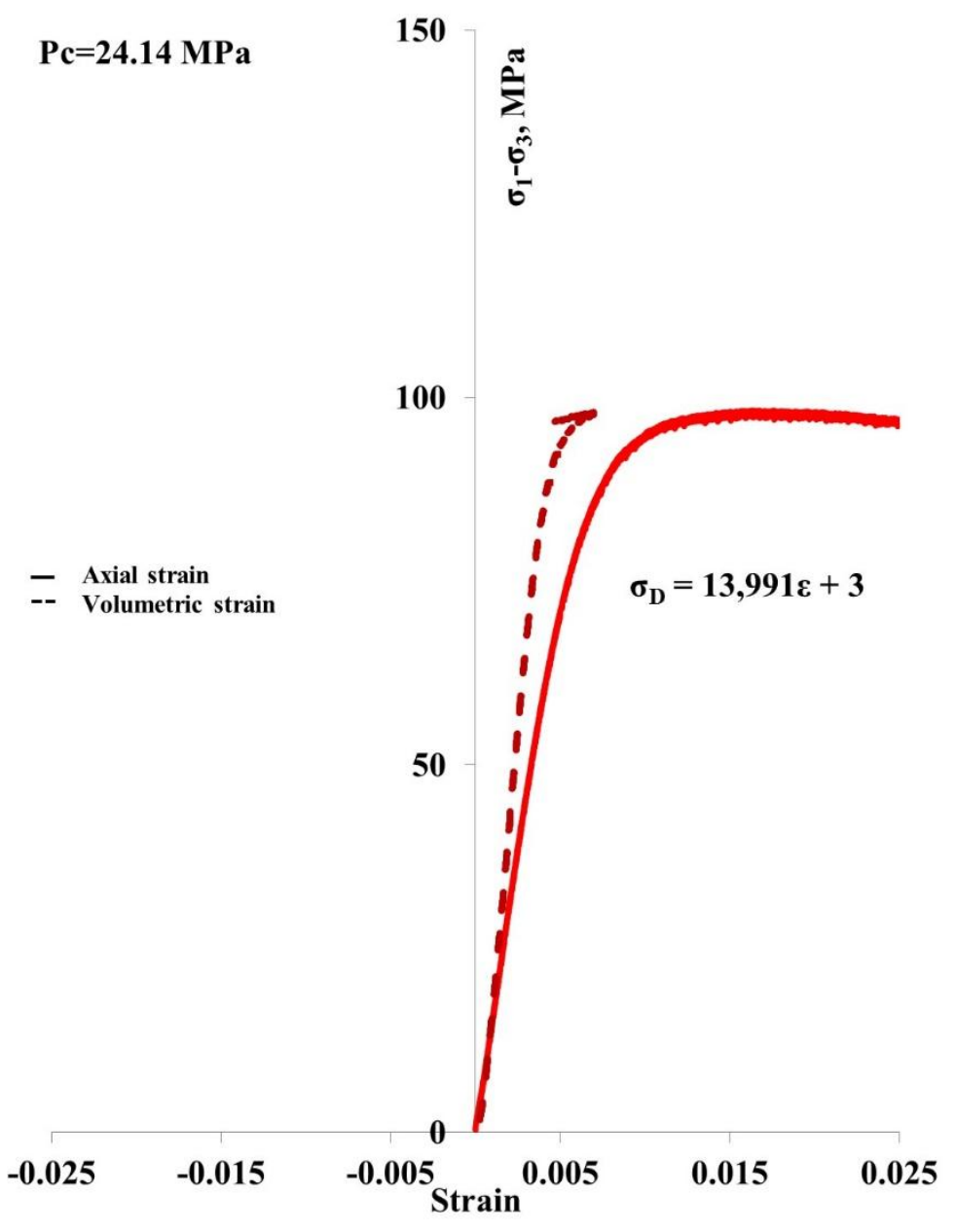

Figure 19. Stress-strain response of N1-4348-3V in a conventional triaxial compression test.

763

764 


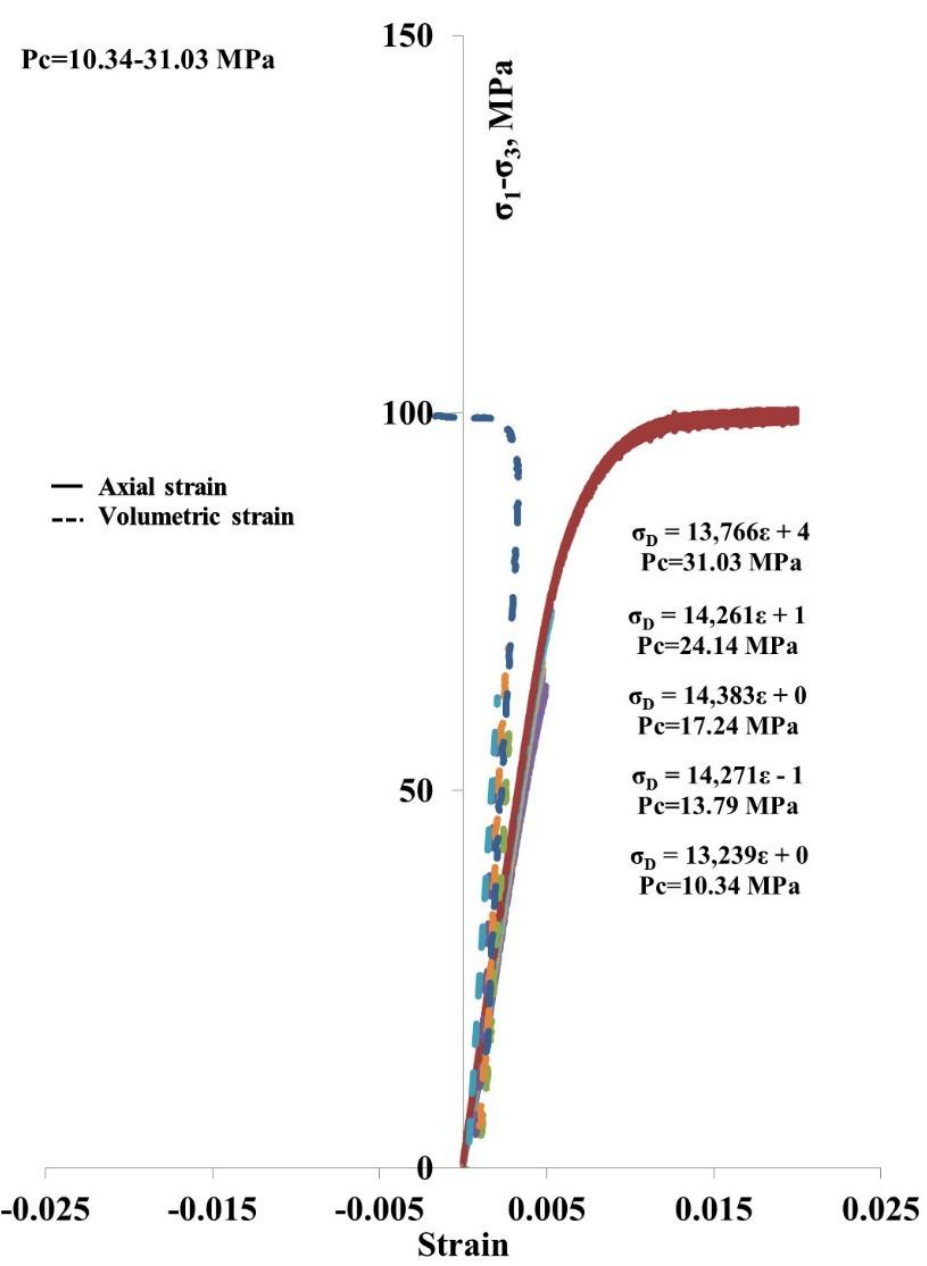

Figure 20a. Stress-strain response at 5 stages of N1-4348-4V.

767

768

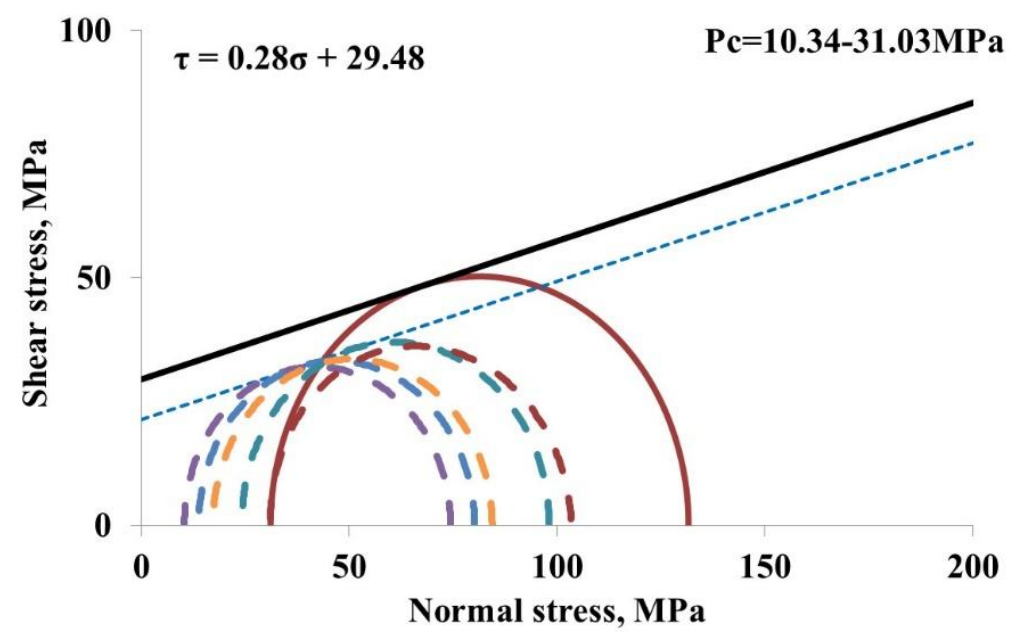

Figure 20b. Mohr circles for the stress state at the onset of dilatancy and the failure envelope of the sample N1- 


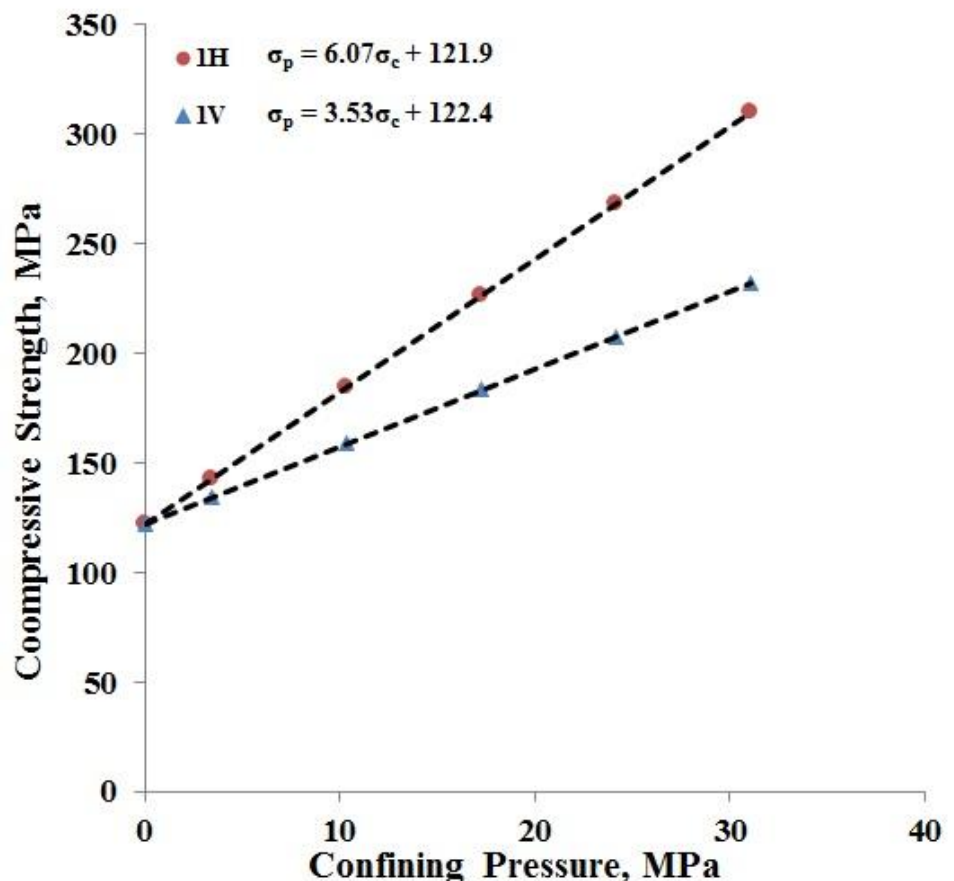

775

Figure 21a. Compressive strength of N1-4013-1V and 1H.

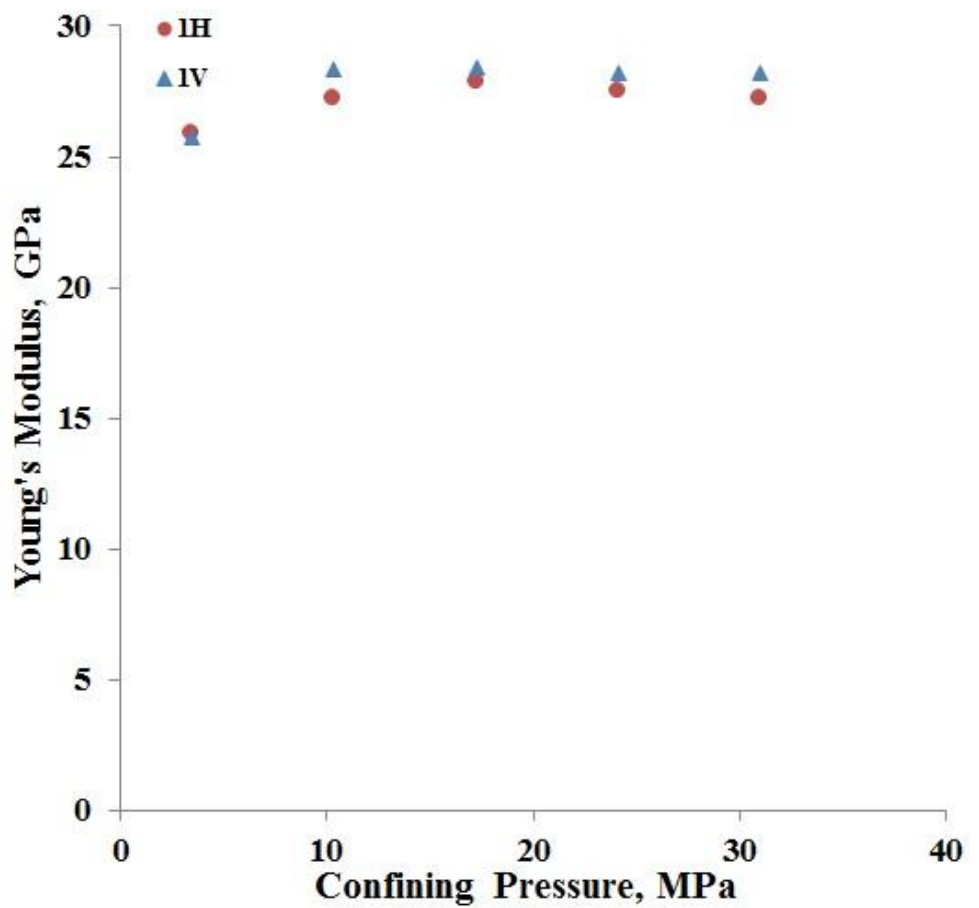

Figure 21b. Young's modulus of N1-4013-1V and 1H. 


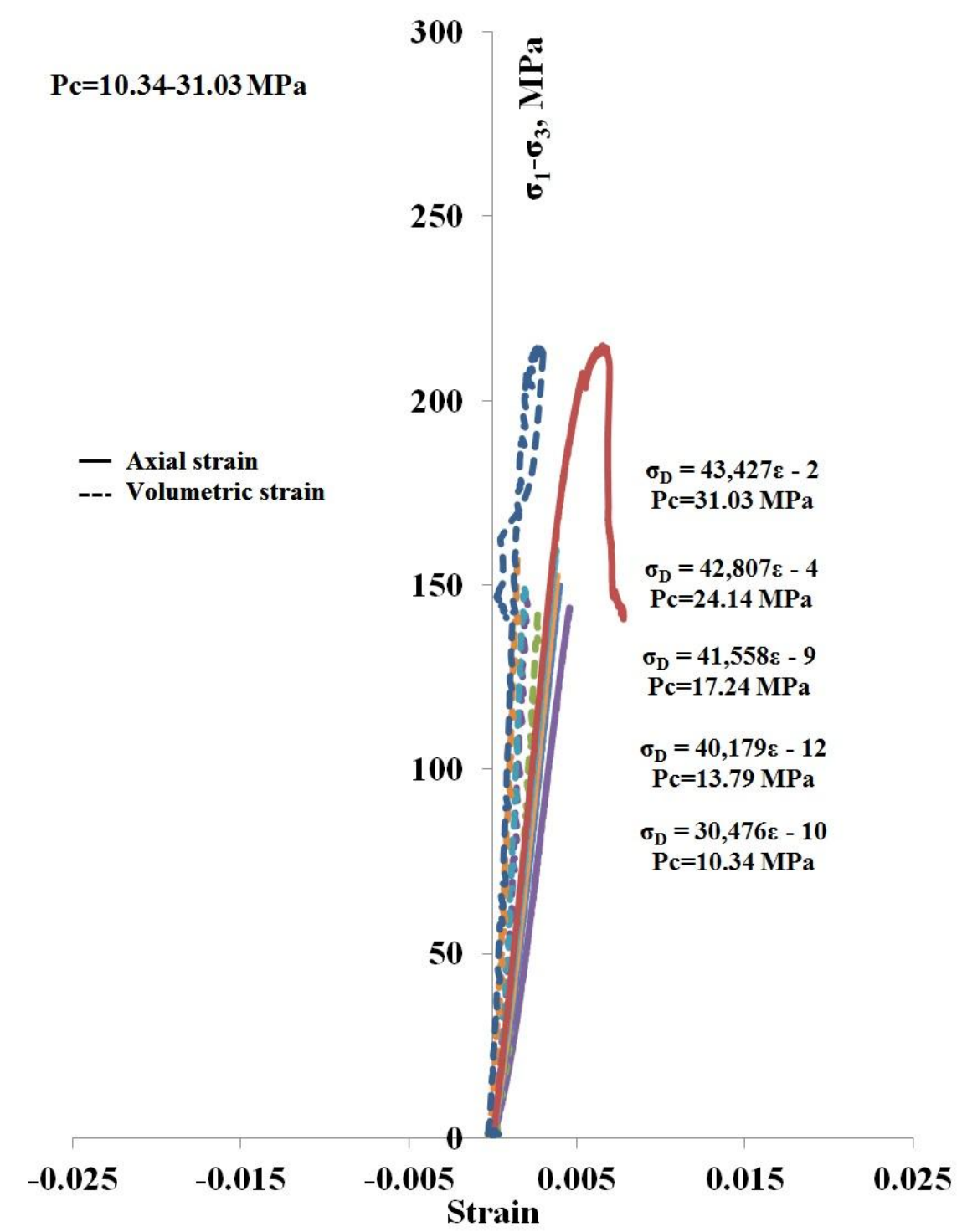

Figure 22a. Stress-strain response at 5 stages of N2-4281-3V.

780

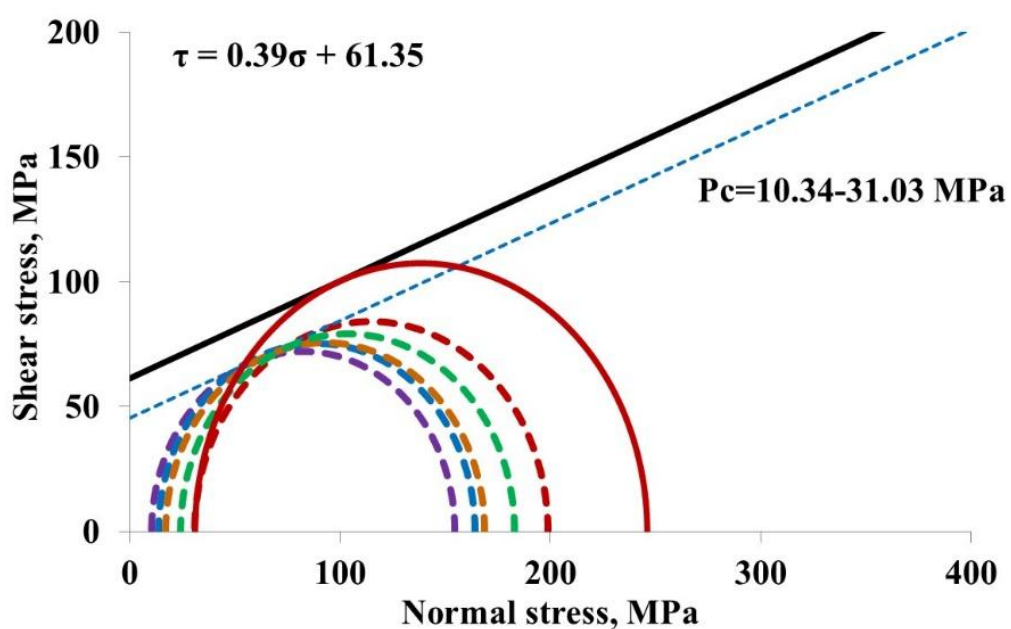


784

Figure 22b. Mohr circles for the stress state at the onset of dilatancy and the Mohr Circles from multistage test of $\mathrm{N} 2-4281-3 \mathrm{~V}$

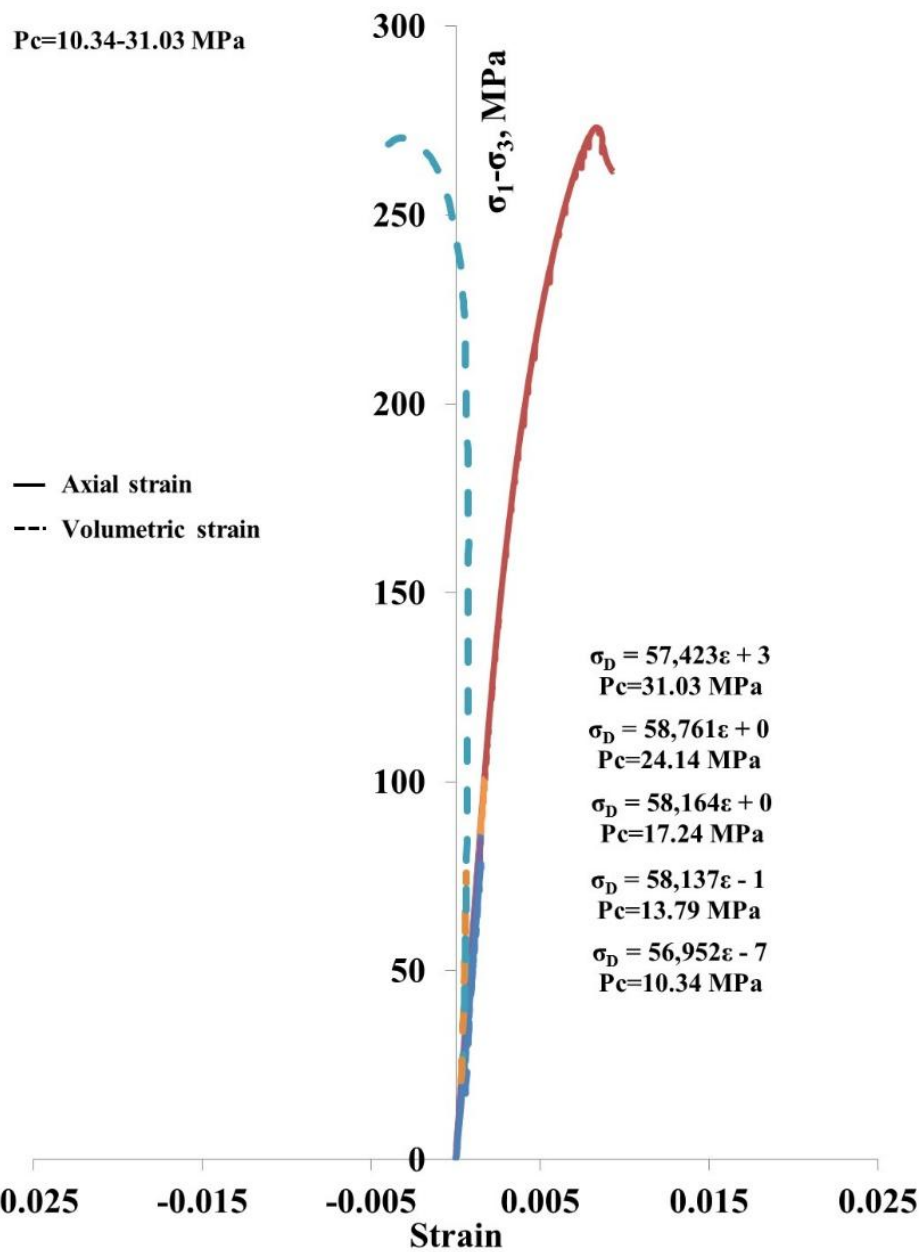

Figure 23a. Stress-strain response at 5 stages of Oxy 72-3 4394.5-1V.

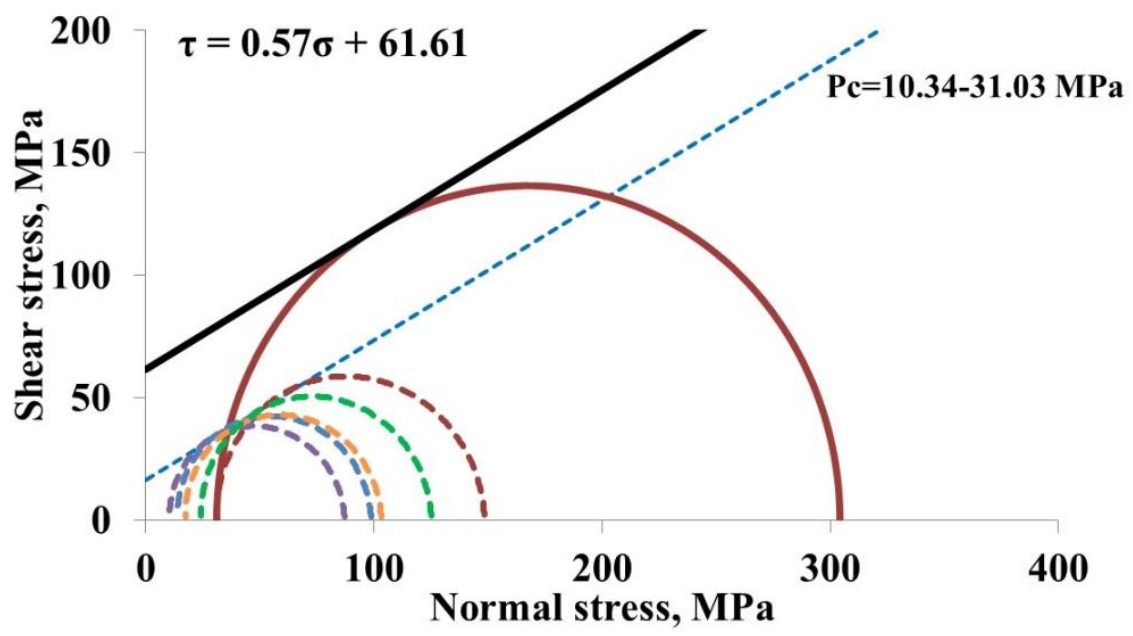

Figure 23b. Mohr circles for at 5 stages and failure envelope of Oxy 72-3 4394.5-1V. 


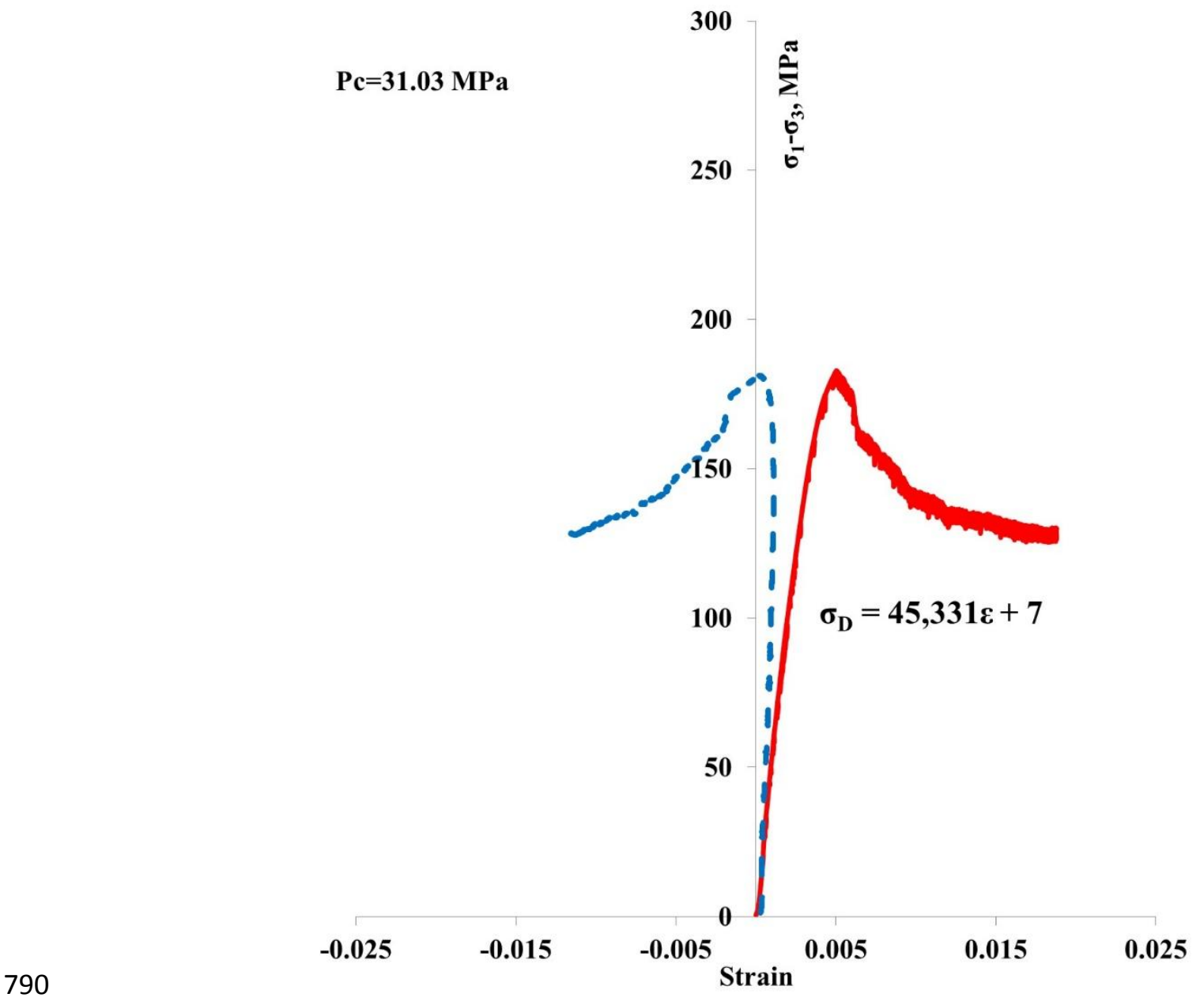

791 Figure 24. Stress-strain response of Oxy 72-3 4394.5-4V during conventional triaxial test at a confining pressure of 792 4500 psi. 


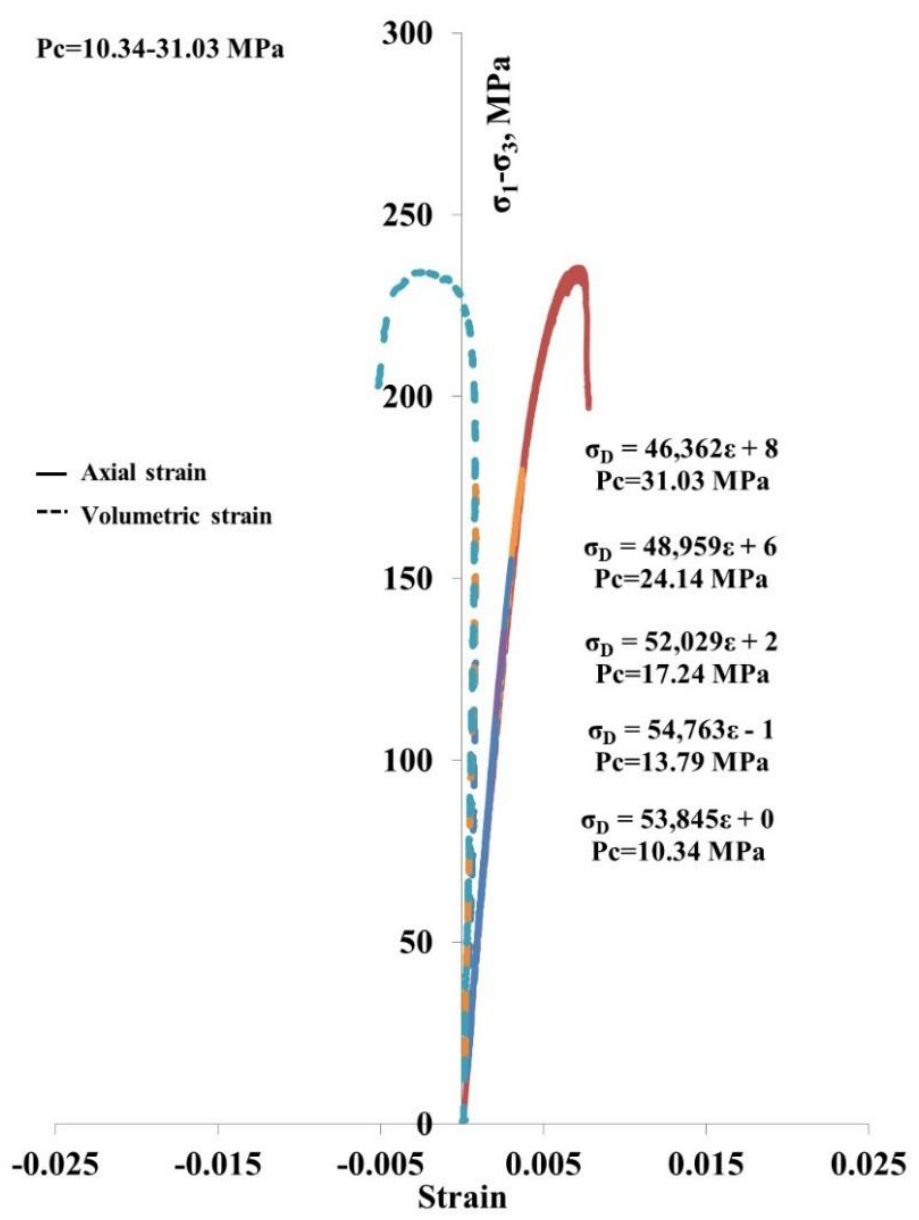

Figure 25a. Stress-strain response at 5 stages of Oxy 72-3 4394.5-5V.

796

797

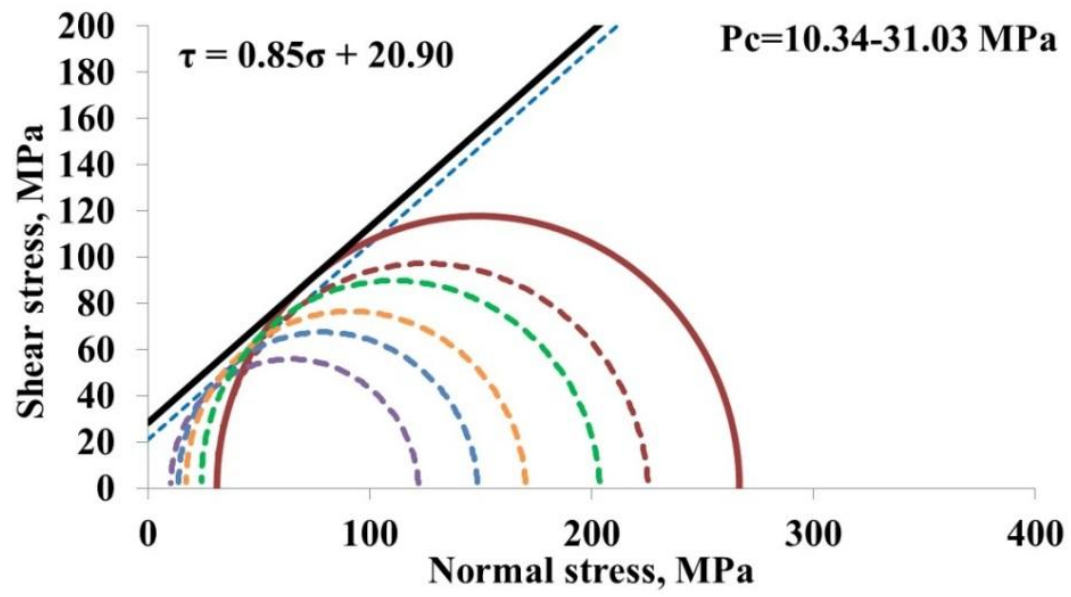

Figure 25b. Mohr circles for dilatancy at 5 stages and failure envelope of Oxy 72-3 4394.5-5V. 


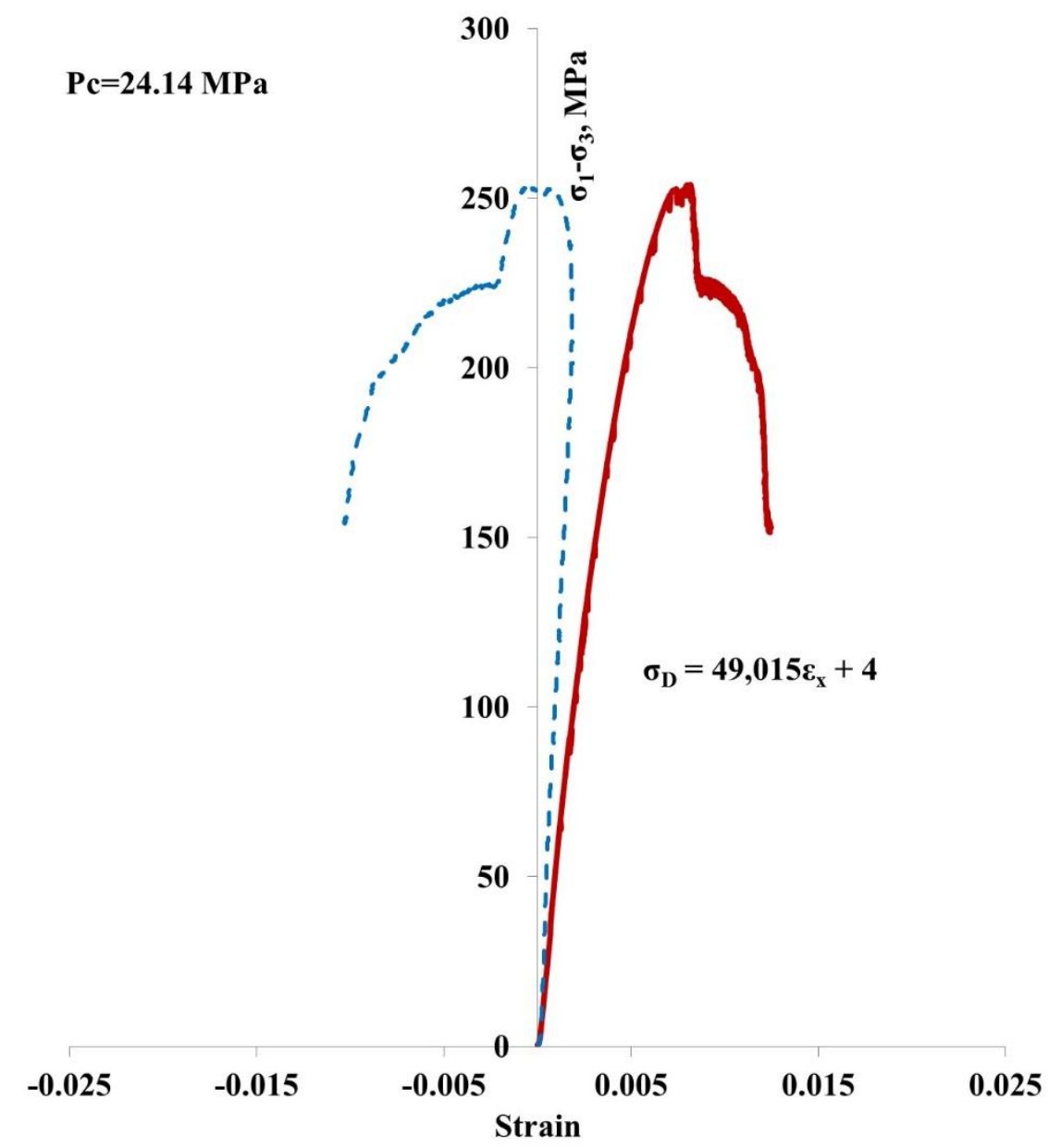

800

Figure 26. Stress-strain response of Oxy 72-3 4394.5-6V in a conventional triaxial test at a confining pressure of 3500 psi. 
805

806

807

808

809

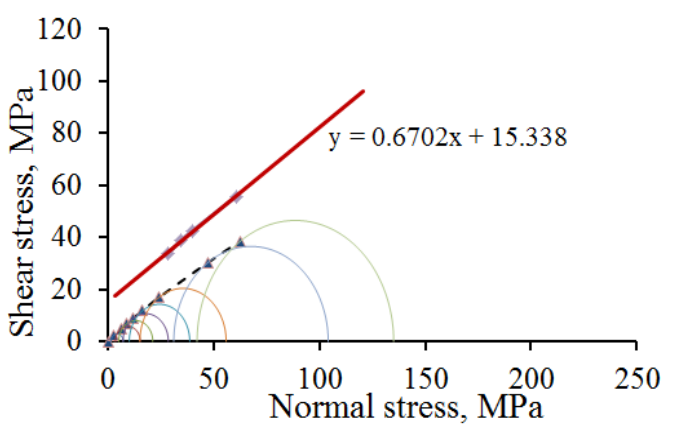

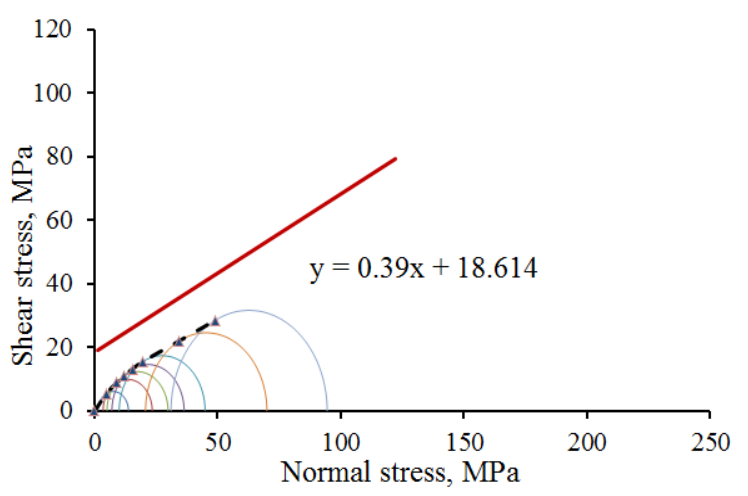

Figure 27. Intact rock compressive strength envelope (red solid line) and shear strength envelope (black dashed line), N1-4013-1H and N1-4348-2H samples.

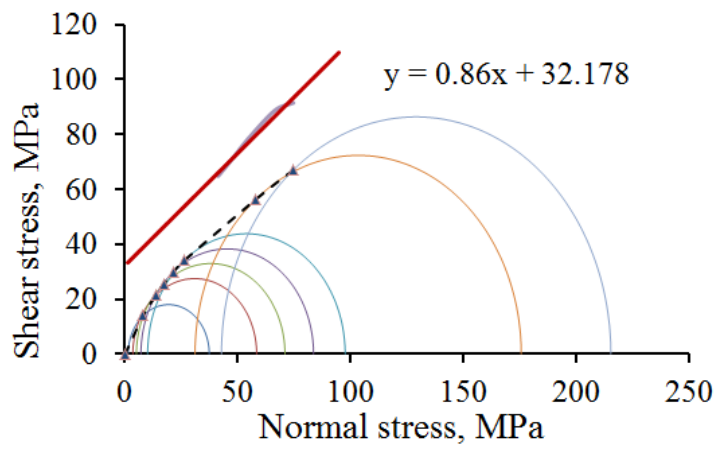

Figure 28. Intact rock compressive strength envelope (red solid line) and shear strength envelope (black dashed line), N2-4219.5-2H and Oxy-4395-5v samples.
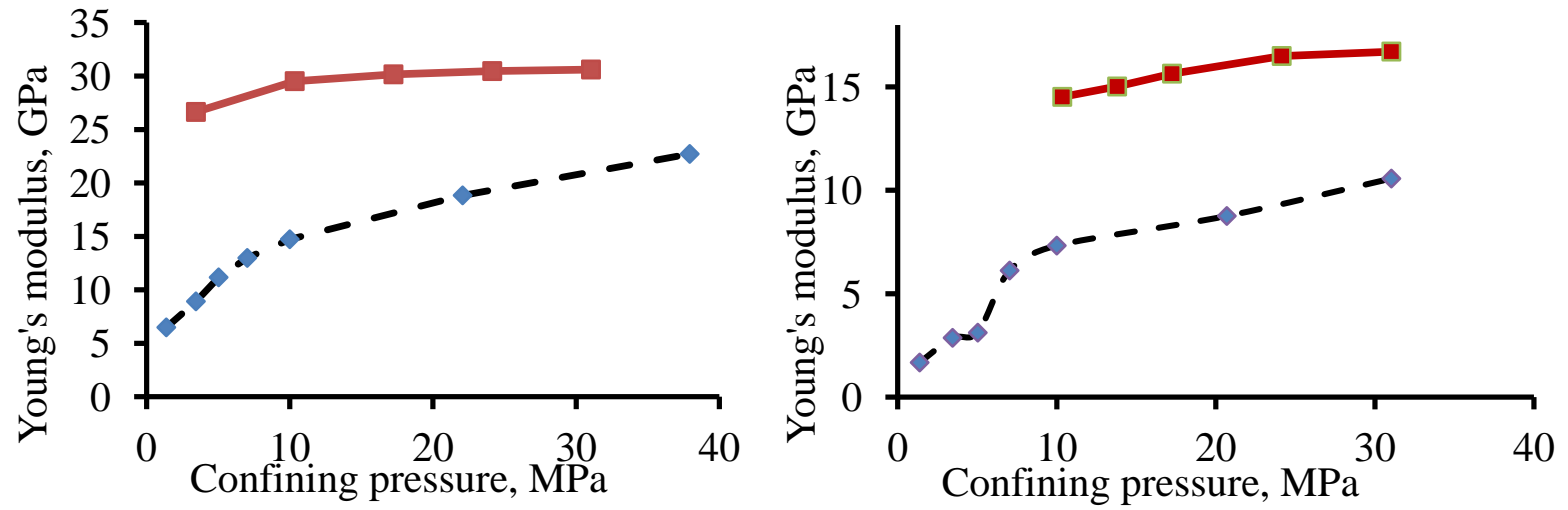

Figure 29. Intact rock Young's modulus degradation by the presence of a joint and its closure, red line is the modulus of intact rock, dashed line is the modulus of jointed rock, N1-4013-1H and N1-4348-2H sample. 


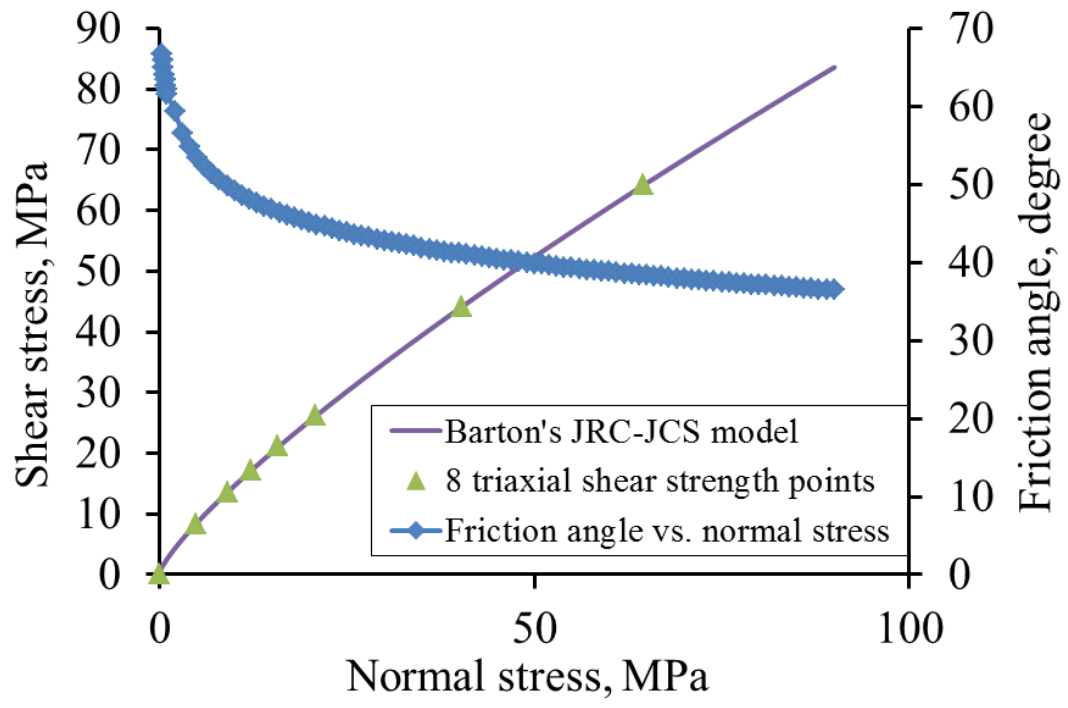

Figure 30. Eight joint shear strength and friction angle data points for N1-4013-1H, fitted with Barton's model.

822

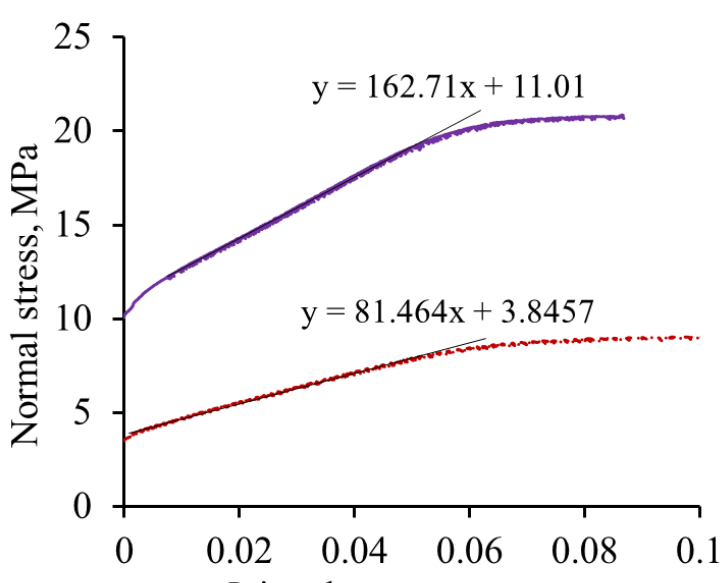

Joint closure, $\mathrm{mm}$

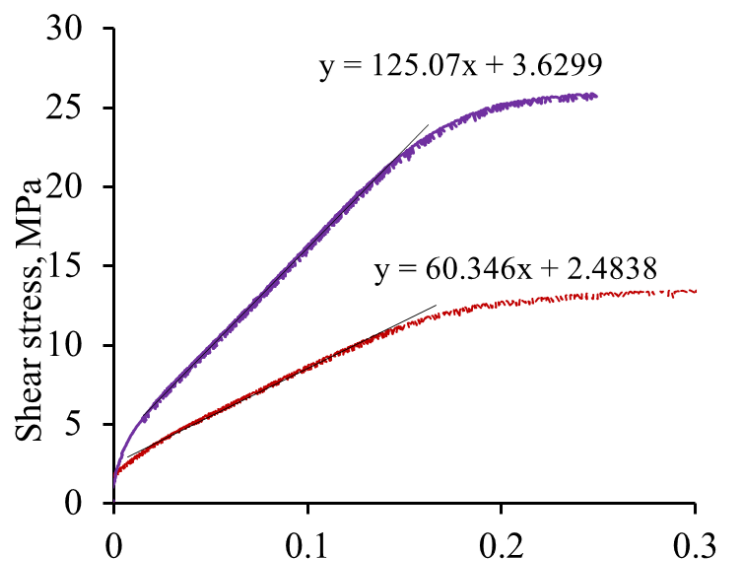

Average joint shear displacement, $\mathrm{mm}$

Figure 31. Normal and shear stiffness of N1-4013-1H at 3.45 MPa (red dashed line) and 10.34 MPa (blue line) confining pressure. 

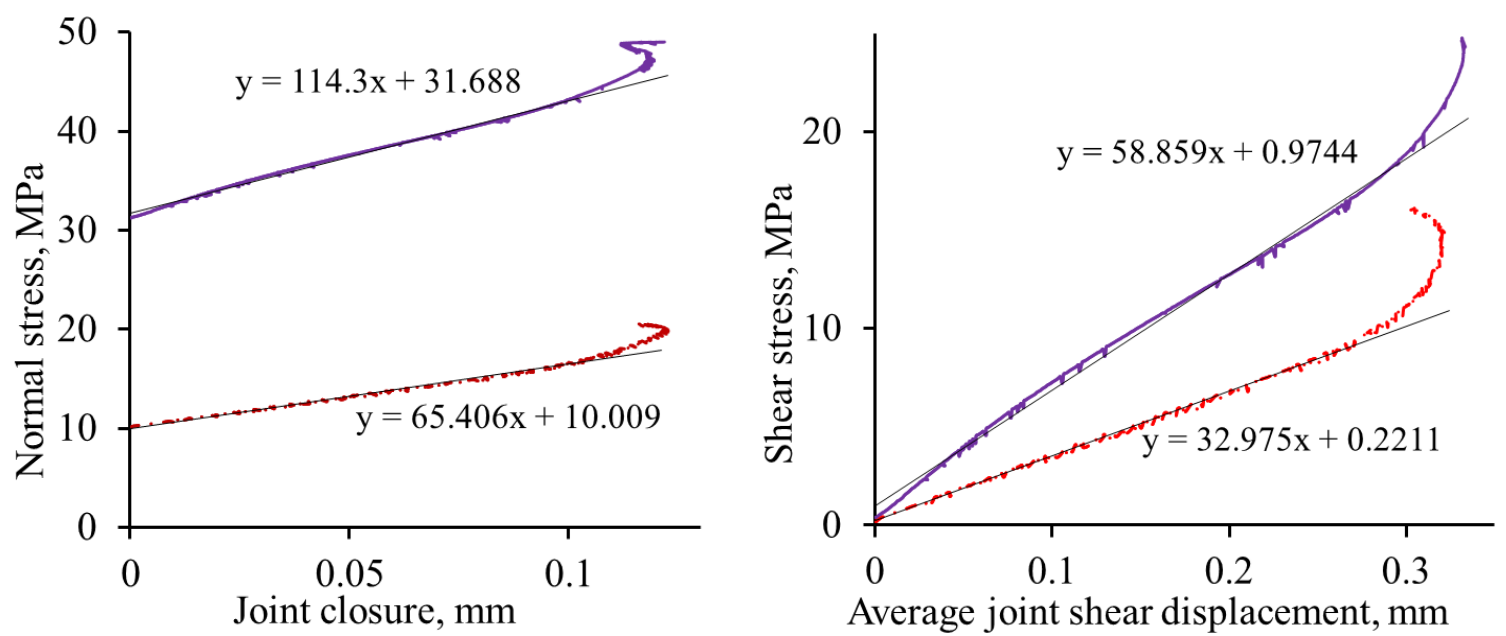

Figure 32. Normal and shear stiffness of N1-4348-2H at 10.34 MPa (red dashed, lower curve) and $31.03 \mathrm{MPa}$ (blue, upper curve) confining pressure.

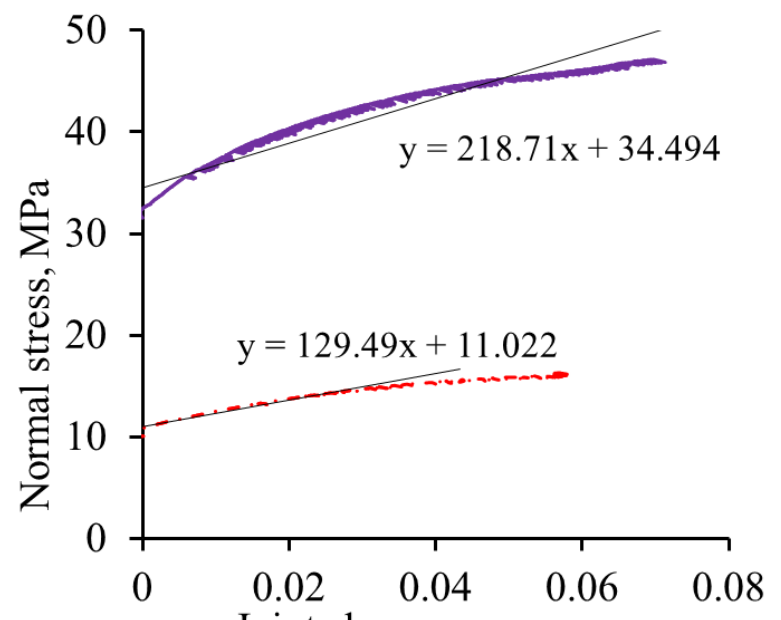

Joint closure, $\mathrm{mm}$

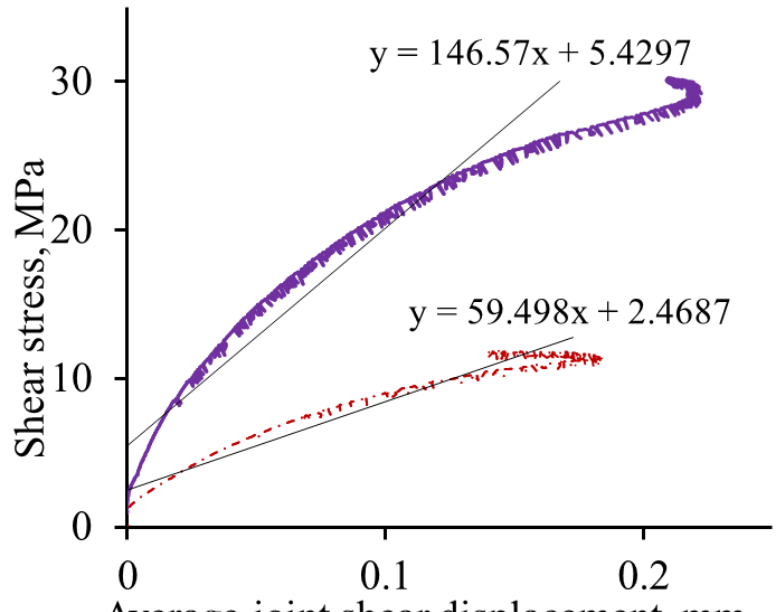

Average joint shear displacement, mm

Figure 33. Normal and shear stiffness of N2-4019.5-2H at 10.34 MPa (red dashed, lower curve) and 31.03 MPa (blue, upper curve) confining pressure. 
851

852

853

\section{1}
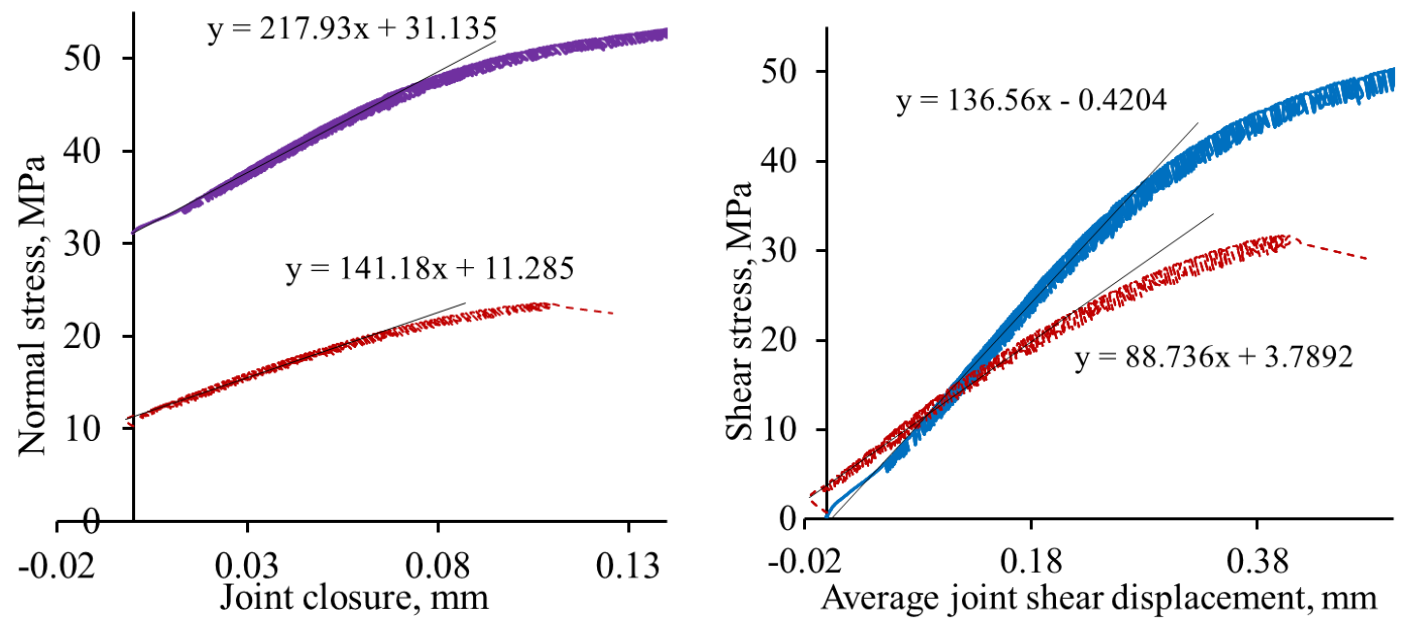

Figure 34. Normal and shear stiffness of Oxy-4395-5V at 10.34 MPa (red dashed, lower curve) and $31.03 \mathrm{MPa}$ (blue, upper curve) confining pressure.

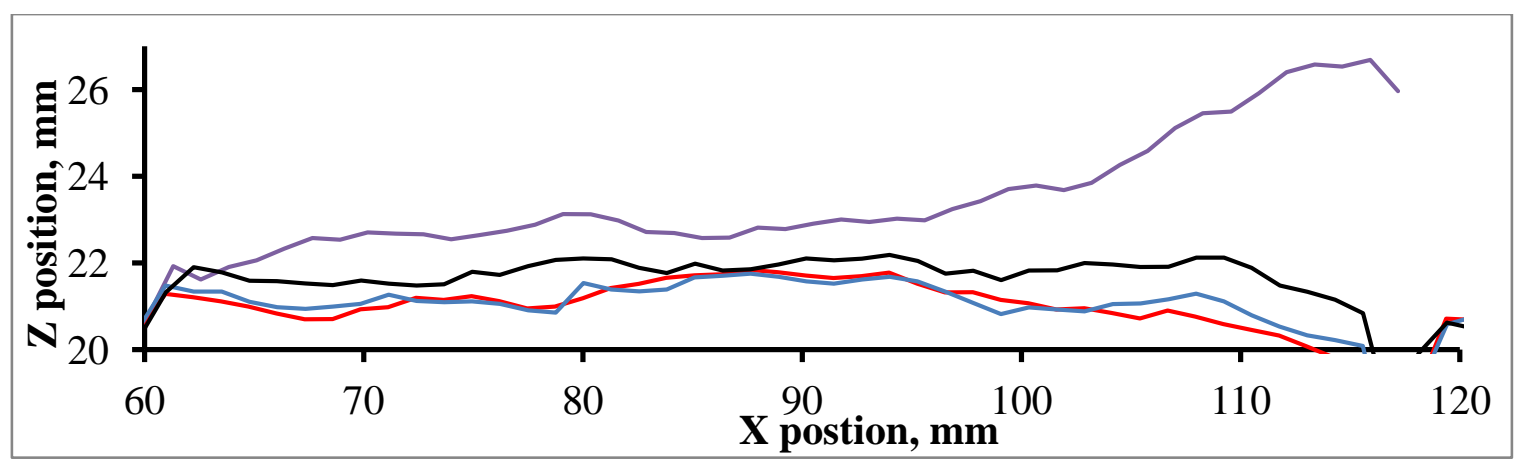

Figure 35a. Scanned surface roughness profiles of two fracture surfaces, N2-4220-2H. Sane lines are along each fracture surface and across them (one fracture, two surfaces). 


\begin{tabular}{|c|c|}
\hline & $J R C=0-2$ \\
\hline$\sim$ & $J R C=2-4$ \\
\hline & $J R C=4-6$ \\
\hline$\sim$ & $J R C=6-8$ \\
\hline & $J R C=8-10$ \\
\hline & $J R C=10-12$ \\
\hline & $J R C=12-14$ \\
\hline & $J R C=14-16$ \\
\hline & $J R C=16-18$ \\
\hline & $J R C=18-20$ \\
\hline L & \\
\hline $5 \mathrm{~cm}$ & \\
\hline
\end{tabular}

Figure 35b. Barton's standard surface roughness profile (after Barton, 1972). 